Prepared in cooperation with the Office of Federal Lands Highway, Central Federal Lands Highway Division

\title{
Compilation and Assessment of Resource Values and Hazards to Inform Transportation Planning and Associated Land-Use Planning
}
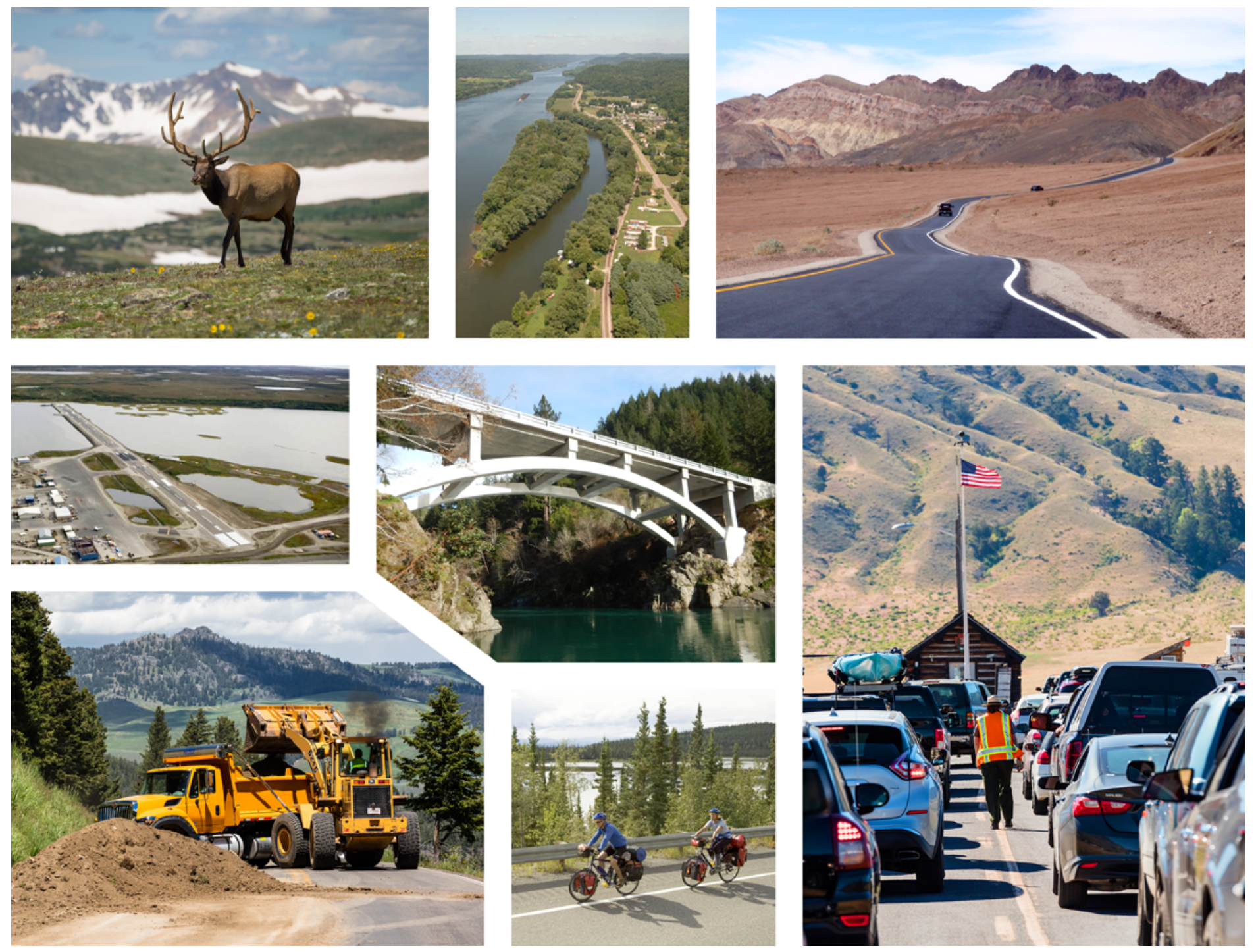

Scientific Investigations Report 2018-5039

U.S. Department of the Interior U.S. Geological Survey 
Cover.

Elk-Burst, Andrew Gosine, Creative Commons CCO

Ohio Rivers Island Refuge—Janet Butler, U.S. Fish \& Wildlife Service

Death Valley National Park, California—Elijah Henley, Federal Lands and Highways

Selawik National Wildlife Refuge, Alaska—Steve Hillebrand, U.S. Fish \& Wildlife Service

Smith River Bridge, California-Elijah Henley, Federal Lands and Highways

Yellowstone National Park-National Park Service

Yellowstone National Park-National Park Service

Tetlin National Wildlife Refuge, Alaska-Steve Hillebrand, U.S. Fish \& Wildlife Service 


\section{Compilation and Assessment of Resource Values and Hazards to Inform Transportation Planning and Associated Land-Use Planning}

By Daniel Manier and Michael O'Donnell

Prepared in cooperation with the Office of Federal Lands Highway,

Central Federal Lands Highway Division

Scientific Investigations Report 2018-5039 


\title{
U.S. Department of the Interior \\ RYAN K. ZINKE, Secretary
}

\author{
U.S. Geological Survey \\ James F. Reilly II, Director
}

U.S. Geological Survey, Reston, Virginia: 2018

For more information on the USGS - the Federal source for science about the Earth, its natural and living resources, natural hazards, and the environment-visit https://www.usgs.gov or call 1-888-ASK-USGS.

For an overview of USGS information products, including maps, imagery, and publications,

visit https://store.usgs.gov.

Any use of trade, firm, or product names is for descriptive purposes only and does not imply endorsement by the U.S. Government.

Although this information product, for the most part, is in the public domain, it also may contain copyrighted materials as noted in the text. Permission to reproduce copyrighted items must be secured from the copyright owner.

Suggested citation:

Manier, D.J., and O'Donnell, M., 2018, Compilation and assessment of resource values and hazards to inform transportation planning and associated land-use planning: U.S. Geological Survey Scientific Investigations Report 2018-5039, 53 p., https://doi.org/10.3133/sir20185039.

ISSN 2328-0328 (online) 


\section{Acknowledgments}

This work was completed in cooperation with Elijah Henley and staff at the Central Federal Lands Highway Division of the Office of Federal Lands Highway. This final report was completed under Reimbursable Agreement No. DTFH68-13-X-00102. We also received input and feedback from numerous partners of the Office of Federal Lands Highway through cooperative long-range planning efforts. Numerous staff from the U.S. Geological Survey Fort Collins Science Center contributed to portions of the data development and management of this project. In addition, several reviewers and USGS publishing staff spent considerable time helping to revise and refine this report and the associated data. We are grateful for their support and assistance. 


\section{Contents}

Acknowledgments .............................................................................................................ii

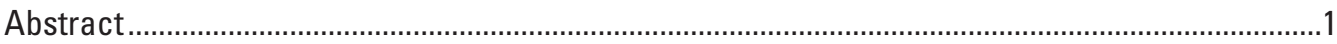

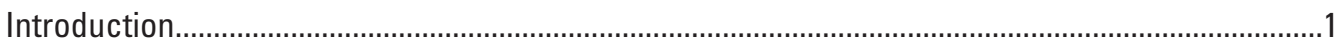

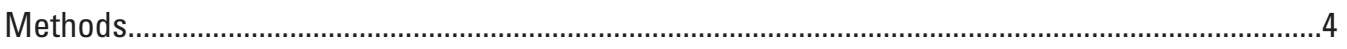

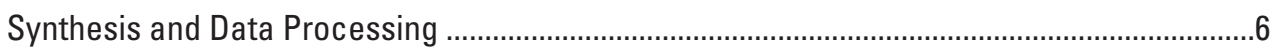

Data Documentation ..........................................................................................................10

Distribution of Threatened, Endangered, Sensitive, and Other Species of Concern ...............11

Terrestrial Resource Values....................................................................................................11

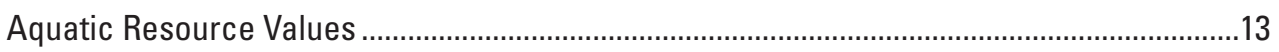

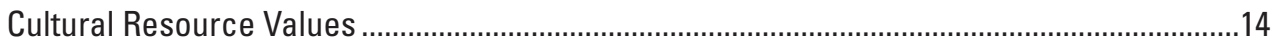

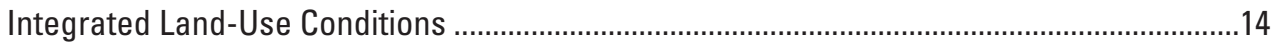

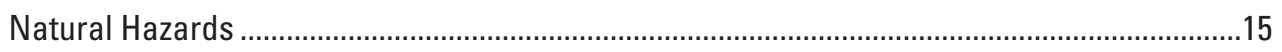

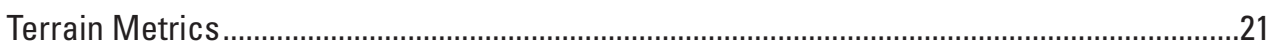

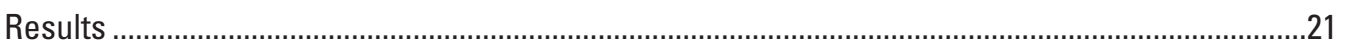

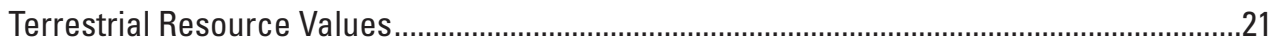

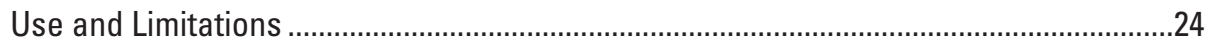

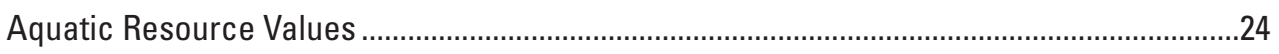

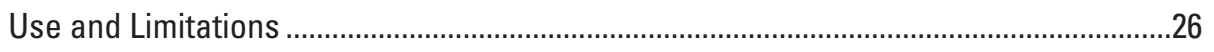

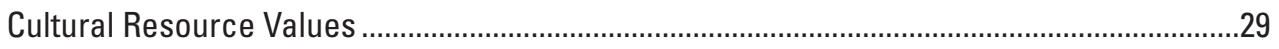

Use and Limitations ..................................................................................................

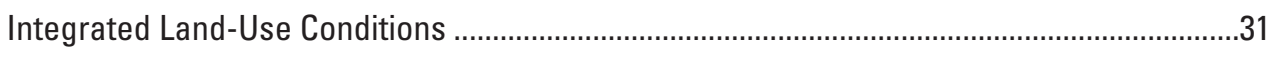

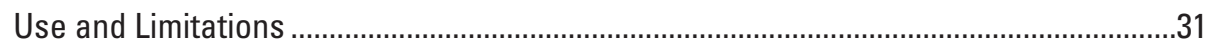

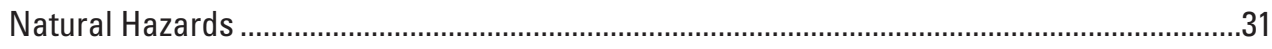

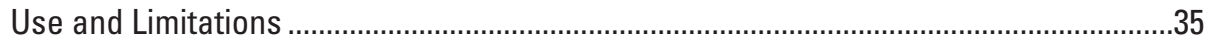

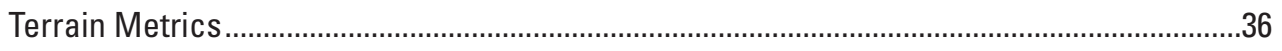

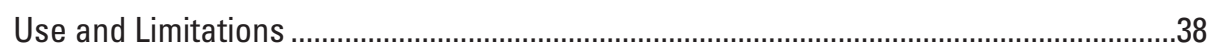

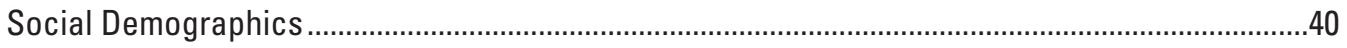

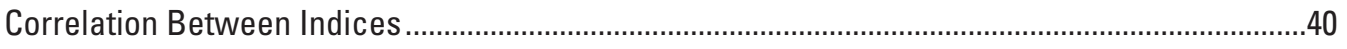

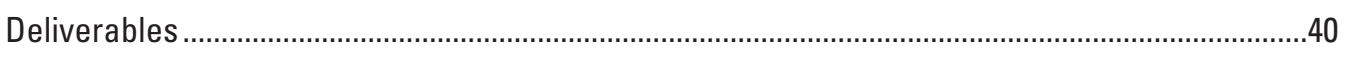

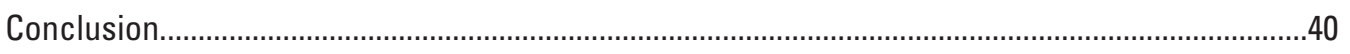

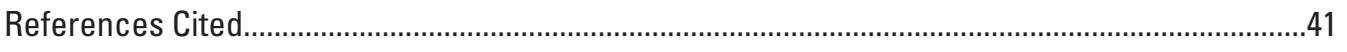

Appendix 1. Supporting Tables.............................................................................................. 


\section{Figures}

1. Conceptual diagram of the data development and processing workflow ..........................5

2. Graphical depiction of the components of this integrated assessment ............................6

3. Aggregated Terrestrial Resource Values Index using two alternative methods .............22

4. Terrestrial Resource Values Index, Metric 1-Species Diversity inputs........................23

5. Terrestrial Resource Values Metric 2a_Inputs of critical habitat for threatened

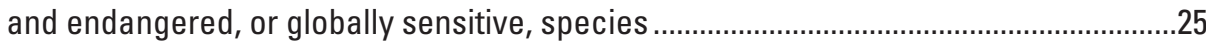

6. Terrestrial Resource Values Index inputs, Metric 2b-Conservation Areas and

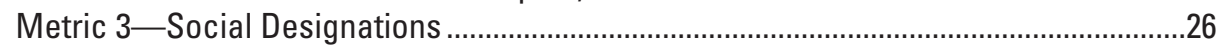

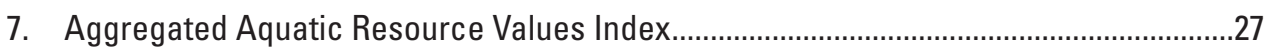

8. Aquatic Resource Values Index inputs, Metric 1-Species Diversity (fish), Metric 2a-Critical Habitat, and Metric 2b-Conservation Areas................................28

9. Aquatic Resource Values Index inputs, Metric 3-Social Designations and Metric 4-Landscape-Scale Water Quality.............................................................29

10. The Aggregated Cultural Resource Values Index and inputs .........................................30

11. Integrated Land-use Conditions, Development Impact (Metric 1) and

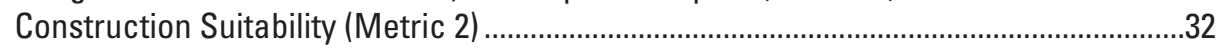

12. Integrated Land-use Condition inputs, Metric 2-Construction Suitability .....................33

13. Natural Hazards Metric inputs, Metric 1-Geophysical ..................................................35

14. Natural Hazards metrics for flood potential, Metric 2-National Flood Hazards ...........36

15. Natural Hazards metrics, Metric 2-Flood Frequency Potential ...................................37

16. Natural Hazards metrics, Metric 3-proximity to hazardous materials transportation hubs, Metric 4-Air Quality, and Metric 5-Water Quality .....................38

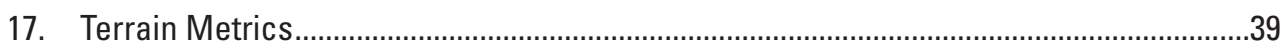

\section{Tables}

1. The root mean square error for various map scales ..........................................................

2. A reclassification of the A-weighted $L 50$ sound pressure level to conform to the integration of other land-use conditions

3. A description of the earthquake potential (minimum peak horizontal acceleration value) translated to U.S. Geological Survey codes used for displaying and combining data.

4. A description of the likelihood of karsts forming on the landscape and the crosswalk for combining data

5. A description of the incidence of landslides and the crosswalk for combining data.....17

6. A description of Federal Emergency Management Agency flood hazards and the crosswalk for combining data.

7. The Natural Resources Conservation Service delineation of flood frequency from the Gridded Soil Survey Geographic Database national soils data and the U.S. Geological Survey crosswalk for classifying data....

8. Ponding frequency and wetland potential delineations from the Natural Resources Conservation Service Gridded Soil Survey Geographic Database of national soils data and the crosswalk for U.S. Geological Survey classification of the data

9. Classification of proximity (distance) from each pixel to hazardous materials transportation hubs as documented by the U.S. Environmental Protection Agency......20 
10. Global, annual abundance of particulate matter smaller than or equal to 2.5 micrometers in diameter $\left(\mathrm{PM}_{2.5}\right)$ and the U.S. Geological Survey classification used for combining data

11. Distance in meters to U.S. Environmental Protection Agency Section 303(d) listed contaminated waters and a crosswalk for combining the data

1.1. Terrestrial Resource Values Index-Summary of source datasets used for terrestrial species and habitat indices

1.2. Aquatic Resource Values Index-Summary of source datasets used to inform aquatic species and habitat indices

1.3. Cultural Resource Values Index-Summary of source datasets used to inform the development of the Cultural Resource Values Index...

1.4. Land-Use Conditions-Summary of source datasets used for the integrated land-use condition metrics

1.5. Natural Hazards Metrics - Summary of data sources used to inform estimation of potential for natural hazards

1.6. Summary of equations and descriptions of aggregated indices and metrics compiled to support transportation planning

\section{Conversion Factors}

U.S. customary units to International System of Units

\begin{tabular}{lcc}
\hline Multiply & By & To obtain \\
\hline & Length & \\
\hline foot $(\mathrm{ft})$ & 0.3048 & meter $(\mathrm{m})$ \\
\hline
\end{tabular}

International System of Units to U.S. customary units

\begin{tabular}{lll}
\hline \multicolumn{1}{c}{ Multiply } & By & \multicolumn{1}{c}{ To obtain } \\
\hline & Length & \\
\hline meter $(\mathrm{m})$ & 3.281 & foot $(\mathrm{ft})$ \\
kilometer $(\mathrm{km})$ & 0.6214 & mile $(\mathrm{mi})$ \\
meter $(\mathrm{m})$ & 1.094 & yard $(\mathrm{yd})$ \\
\hline & Area & \\
\hline square meter $\left(\mathrm{m}^{2}\right)$ & 0.0002471 & acre \\
square meter $\left(\mathrm{m}^{2}\right)$ & 10.76 & square foot $\left(\mathrm{ft}^{2}\right)$ \\
\hline
\end{tabular}

\section{Datum}

Vertical coordinate information is referenced to the North American Vertical Datum of 1988 (NAVD 88) unless otherwise noted.

Horizontal coordinate information is referenced to the North American Datum of 1983 (NAD 83) unless otherwise noted.

Map projection is referenced to the CONUS Albers Equal Area Conic.

Altitude, as used in this report, refers to distance above the vertical datum. 


\section{Abbreviations}

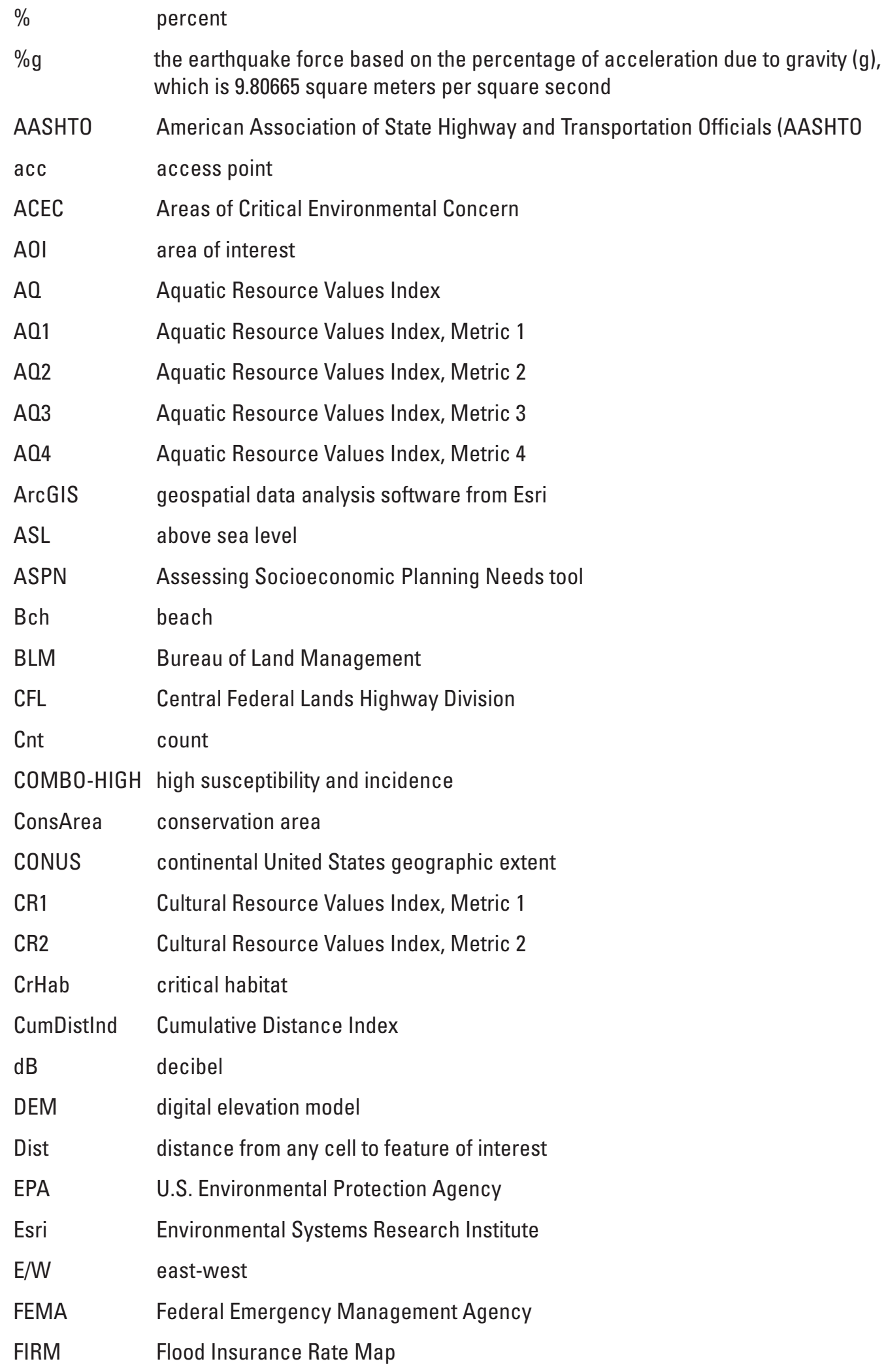


flowlines

FLH Office of Federal Lands Highway

FS U.S. Department of Agriculture Forest Service

FWS U.S. Fish \& Wildlife Service

GAP Gap Analysis Program

GDAL, Geospatial Data Abstract Library

GPS global positioning system

gSSURGO Gridded Soil Survey Geographic Database

gw groundwater

$\mathrm{HCl} \quad$ Habitat Condition Index

HUC hydrologic unit code

HUC8 hydrologic unit code for 8-digit sub-basins

HUC12 hydrologic unit code for 12-digit subwatershed units

HZ1 Hazards Potential Index, Metric 1

HZ2 Hazards Potential Index, Metric 2

HZ3 Hazards Potential Index, Metric 3

HZ4 Hazards Potential Index, Metric 4

HZ5 Hazards Potential Index, Metric 5

INC-HIGH high incidence

INC-LOW low incidence

INC-MOD moderate incidence

IUCN International Union for Conservation of Nature

LC1 Landscape Condition, Metric 1

LC2 Landscape Condition, Metric 2

MAUP Modifiable Areal Unit Problem

$\max \quad$ maximum

MCE Multi-Criteria Evaluation

MISR Multi-Angle Imaging SpectroRadiometer

MODIS Moderate Resolution Imaging Spectroradiometer

MS management system

NASA National Aeronautics and Space Administration

NCED National Conservation Easement Database

NED national elevation dataset

NEPA National Environmental Policy Act

NFHAP National Fish Habitat Partnership

NHDPlus National Hydrologic Dataset, PLUS version 


\begin{tabular}{|c|c|}
\hline NHD & National Hydrologic Dataset \\
\hline NPS & National Park Service \\
\hline NR & natural resource(s) \\
\hline NRCS & Natural Resources Conservation Service \\
\hline $\mathrm{N} / \mathrm{S}$ & north-south \\
\hline PADUS & Protected Areas Database of the United States \\
\hline PM & particulate matter \\
\hline $\mathrm{PM}_{2.5}$ & particulate matter smaller than or equal to 2.5 micrometers in diameter \\
\hline POC & point of contact \\
\hline Prop & proportion of area \\
\hline PWSL & potential wetland soil landscape \\
\hline RMSE & root mean square error \\
\hline SDM & species distribution model(s) \\
\hline SeaWiFS & Sea-Viewing Wide Field-of-View Sensor \\
\hline SUS-HIGH & high susceptibility \\
\hline SUS-MOD & moderate susceptibility \\
\hline T\&E & threatened and endangered \\
\hline TL & total length of a linear feature \\
\hline TR & Terrestrial Resource Values Index \\
\hline TR1 & Terrestrial Resource Values Index, Metric 1 \\
\hline TR2 & Terrestrial Resource Values Index, Metric 2 \\
\hline TR3 & Terrestrial Resource Values Index, Metric 3 \\
\hline URL & universal resource locator \\
\hline USGS & U.S. Geological Survey \\
\hline USGS ED & $\begin{array}{l}\text { Ecosystem Dynamics branch of U.S. Geological Survey Fort Collins Science } \\
\text { Center }\end{array}$ \\
\hline$w b$ & waterbody \\
\hline wet & wetland \\
\hline WSRblm & Bureau of Land Management-designated Wild and Scenic River \\
\hline $\begin{array}{l}\text { WSRfs } \\
\text { yrs }\end{array}$ & $\begin{array}{l}\text { U.S. Department of Agriculture Forest Service-designated Wild and Scenic River } \\
\text { years }\end{array}$ \\
\hline
\end{tabular}





\title{
Compilation and Assessment of Resource Values and Hazards to Inform Transportation Planning and Associated Land-Use Planning
}

\author{
By Daniel Manier and Michael O'Donnell
}

\begin{abstract}
Land-use planning has an important role in local, regional, State, and Federal land management, and planning efforts can benefit from consistent, spatially explicit information that can help guide priorities and decisions. The credibility and relevance of information used to inform planning activities depends on the availability of consistent information about the resources and values of interest or concern within the planning area. To support long-range transportation planning and other regional land-use planning efforts, the U.S. Geological Survey gathered, processed, interpreted, and compiled spatial datasets representing a wide range of information on terrestrial and aquatic ecosystem condition and importance, cultural (historical) features and places, and natural hazards. This report describes the spatial data compiled to represent natural landscape conditions (including social, cultural, and natural attributes) to estimate the potential importance of lands for wildlife, wild habitats, recreation, and conservation based on abundance of species, habitats, land and water conditions, and conservation designations. Abundance of resources, including the potential number of species, presence of important habitats and protected areas, and proximity to particular features or habitats, indicates the potential sensitivity of the natural landscape to land use, especially transportation networks. The source data, derived indices, and the methods for processing these data are described in this final report. The datasets referenced in the report are available from the U.S. Geological Survey (https://www.sciencebase.gov/catalog/ and https://doi.org/10.5066/F7MW2F8W) or the Central Federal Lands Highway Division of the Office of Federal Lands Highway (https://flh.fhwa.dot.gov).
\end{abstract}

\section{Introduction}

Land-use planning plays an important role in local, county, State, and Federal government and land management. Accurate information plays an important role in planning processes, and modern land-use planning typically incorporates a wide range of spatially explicit information to represent social values, such as economic importance, and natural values, such as ecosystem functions and services. Incorporating diverse and complex information into planning processes requires careful and informed combination and interpretation of data into an integrated assessment. Integrated assessment modeling is a process of incorporating knowledge from multiple disciplines into a single framework that informs planning and policy decisions (Rotmans and van Asselt, 1999; Jakeman and Letcher, 2003). The American Association of State Highway and Transportation Officials (AASHTO) has produced numerous reports to assist transportation planners in meeting the requirements of the National Environmental Policy Act (NEPA). These reports include guidelines on developing high-quality NEPA documents (AASHTO, 2014), explaining indirect effects of transportation projects (AASHTO, 2016), and planning NEPA projects (AASHTO, 2008). Information specific to tourism and recreational travel that considers transportation planning (Petraglia and Weisbrod, 2004) and methods for considering integrated ecological frameworks during transportation planning (Institute for Natural Resources and others, 2012) are also available.

This report compiles spatial data representing a variety of attributes related to natural landscape conditions (including social, cultural, and natural attributes) to estimate the potential importance of lands for wildlife and wild habitats based on the abundance of resources across multiple categories. The presence of natural resources, including threatened and endangered (T\&E) species, important habitats and protected areas, and proximity to particular features or habitats, was interpreted to indicate potential sensitivity of the natural landscape to land use, especially transportation networks. Typically, natural resource data represent particular features or attributes of interest for land and asset management, risk assessment, and scientific inquiry; thus, a comprehensive picture requires integrated information. Two important obstacles to integrating diverse spatial datasets exist: (1) spatial data can have many different formats, extents, accuracy (spatial and temporal resolution), and attributions; and (2) summarizing the information for many (tens to hundreds) different features (for example, habitats, species distributions, water quality) quickly becomes complicated and difficult to interpret. 
To inform transportation planning about environmental conditions and natural values, we began by identifying planning objectives, the information or data necessary to investigate those objectives, and the methods for combining the different categories of data needed to address the objectives. To facilitate this step, project partners who are active in regional planning efforts described their objectives for integration of the transportation planning process and natural resources information. The objectives for transportation planning on Federal lands addressed here are to

1. Protect resources by providing a transportation system that emphasizes stewardship of natural and cultural resources and ecological sustainability;

2. Ensure safety by providing safe and secure access for all users to, and within, public lands;

3. Provide access and enhance connectivity by providing a seamless multimodal transportation system that supports community connectivity and access to public lands;

4. Promote visitor experience by promoting ease and enjoyment of travel to and within Federal lands;

5. Ensure asset management by providing a sustainable transportation system that endures over time; and

6. Build partnerships by providing thoughtful Federal land management that uses collaboration to accomplish widely beneficial actions.

These objectives broadly represent the criteria for which we collected and integrated spatial and tabular data into integrated data products that can help inform land-use planning. Although the focus here is transportation planning, most of the data collected and integrated in this study may also benefit other land-use planning efforts as well as studies investigating natural resources applications, ecosystems, and species diversity.

Spatial information can delineate land conditions and uses, species habitats, hydrologic features, climate and atmospheric conditions, and social and cultural features. Spatial information describes elements in space and time, and tabular attributes provide documentation of events, analyses, and conditions within spatial units. The combination of these data can be used to represent a collection of interacting events or conditions. Data types exist as points, lines, polygons, and rasters (cells representing area) and they can jointly represent complex spatial data types, such as networks and linear referencing. The attributes (aspatial, tabular data) associated with spatial data can rely on a range of simple relationships with a single record associated to a single attribute (oneto-one) or more complex relationships linking information through multiple tables (many-to-many). Raster data are as complex as vector data (points, lines, and polygons) because they can store layer stacks (bands) that represent different types of information and time periods. Raster data are stored as different bit types that define the type of numeric values in the data. All data also may exist in different open source or proprietary data formats (for example, raster: GeoTiff, NetCDF; vector: geodatabases, shapefiles, Mongo; other: comma-separated values, maps). Combining disparate data requires compatibility of spatial representation and information content, attributes, to enable the combination of diverse information. Re-projection of source data created spatial compatibility; source attributes were rescaled, classified, or both, to support consistent combination of diverse information in metrics and indices.

All spatial data contain information about scale, accuracy, and a coordinate system (geographic, map projection), but an integrated assessment must consider multiple factors:

1. Combining diverse information requires foreknowledge, including the appropriateness of data for identifying relations and informing analyses.

2. Combining spatial data usually requires similar data types and the coordinate system and geographic extents must match.

3. Some data include omission and commission errors and identifying these errors is necessary when combining data (for example, handling one pixel with no data but the same pixel in another dataset has data).

4. Data often represent different scales and accuracies and combining these requires careful scrutiny and consideration when interpreting content and relative importance of data.

5. Spatial data often represent features that exist, or reflect information, at different times, so careful scrutiny is necessary when combing data of multiple temporal scales. For example, land cover and land-use types captured in a remotely sensed data product often reflect imagery from multiple timestamps to minimize cloud obfuscating, vector data delineating boundaries often change, and final classifications may include information captured from different sources or investigated at different times.

6. Aspatial information (attribute tables in vector data and pixel values in raster data) requires the same units (for example, meters versus feet) and values representing the same data type (for example, discrete values versus continuous range).

7. The Modifiable Areal Unit Problem (MAUP) is "a problem arising from the imposition of artificial units of spatial reporting on continuous geographical phenomena resulting in the generation of artificial spatial patterns" (Heywood and others, 1998, p. 416), so aggregating continuous data into different spatial units can affect the results and interpretation of analyses. Examples include grouping human demographics into counties, which exaggerates spatial patterns, or classifying the cover of vegetation versus using continuous estimation of cover. 
A transparent method for generating spatially explicit indices that combine both directly compatible and disparate information in a series of hierarchical steps was developed here. As a result, data users, such as land-use planners, can begin broad-area assessments using an index that aggregates scores to identify areas with potentially concentrated natural or social values. Users can also investigate a more detailed assessment of landscape features or species using a contributing metric (fewer aggregated inputs) or source data (for example, aquatic habitats) to clarify the type of potential natural values, determine the possibility of management conflicts or challenges, or identify specific features that may be distinct from a concentration of integrated values (high index scores). The overarching objective was to develop data for use in State and regional transportation planning, but this integrated assessment is also relevant for other landscape planning efforts that require synthesis and assessment of diverse landscape condition information.

Many challenges arise when examining spatial and aspatial data jointly. Typically, the greater the complexity in the approach, the more difficult the data are to use for resource planning. In addition, an oversimplification and aggregation of information leads to generalized information that is too broad for most planning decisions. Functioning ecosystems express complex environmental interactions and processes that are difficult to capture in models, and as a result, it is difficult to consider all relevant information. A hierarchical approach supports a structure for informing management needs at different scales; aggregated indices can support general patterns and questions and less aggregated indices provide information that can inform specific questions. Geospatial analyses and integrated assessments have proven to be cost-effective ways to link information for transportation planning and help inform management decisions mandated by legal authorities that are relevant to land use planning (for example, NEPA of 1969, Endangered Species Act of 1973, Safe Drinking Water Act of 1974, Federal Land Policy and Management Act of 1976, Clean Water Act of 1972, Clean Air Act of 1990, and Omnibus Public Land Management Act of 2009).

Wildlife, wild habitats, water quality, and other natural values may be affected wherever transportation infrastructure contacts natural systems. Awareness of these potential effects can allow planners and developers to incorporate mitigation practices and (or) avoidance into the planning process. We expect that integrating resource assessments with transportation planning would help minimize natural and social conflicts and improve the interface between modern societies, our natural and cultural heritage, and publicly owned resources that are important for quality of life and economics. Further, prior knowledge of the potential for infrastructure and wildlife conflicts and the distribution of potentially sensitive resources may inform and streamline environmental impact assessment procedures and the development of management alternatives.

The integrated assessment provided in this report will not provide all the detailed information that transportation planners require for planning in local areas. For example, species found in one area may respond differently to transportation features than the species found in another area. Several publications describe specific interactions between species and transportation networks, such as:

- Road effect zones (Shilling and Waetjen, 2012),

- Effects of roads on species abundance (Fahrig and Rytwinski, 2009),

- Effects of roads on wildlife (Gaines and others, 2003), and

- Habitat fragmentation due to roads (Jaarsma and Willems, 2002; Wilbert and others, 2008).

The development of integrated assessments has increased due to the need to consider many factors, such as the multitude of environmental factors, during transportation planning (see Jensen and Bourgeron, 2001). Specifically, transportation-planning approaches have considered ecological impacts (see National Research Council [U.S.] Committee on Ecological Impacts of Road Density, 2005; DittrichWesbuer and others, 2015; Schmale and others, 2015). For example, the Bureau of Land Management (BLM) regulates a variety of travel methods (for example, foot, horseback, mechanized vehicles, motorized vehicles) on roads and trails that access public lands. Within its resource management plans, BLM proposes travel management plans on a route-by-route basis that (1) designate areas of specific travel types and (2) define travel types and conditions. The travel management plans ensure that BLM meets legislative mandates to conserve and protect the multitude of resources (for example, wilderness, riparian, historical, cultural, archaeological, natural, and recreational areas) which they are responsible for managing. BLM is required by regulation (43 Code of Federal Regulations part 8340 - Off-Road Vehicles) to designate all public lands that it manages as open, limited, or closed to off-highway vehicles. These designations are necessary for the protection of resources located on the public lands, promotion of safety, and minimization of conflicts between multiuse practices.

The data (Manier and O'Donnell, 2018) described here were compiled (acquired and managed for spatial compatibility and content compliance) for contribution to interpretive data products, namely a series of indices that allow users to recognize broad distributions of resource values associated with particular resource types (for example, terrestrial habitats, aquatic species). To acquire these data, we contacted, either directly or indirectly through internet portals, a wide range of Federal and State agencies and departments. National-level data, when available, provide contemporary and consistent information across planning boundaries, and State-level data provide greater specificity for resources (especially sensitive species and conservation habitats) managed by the States.

A cooperative project between the Central Federal Lands Highway Division (CFL) of the Office of Federal Lands Highway (FLH) and the U.S. Geological Survey 
(USGS) Fort Collins Science Center facilitated development of the information discussed here, and includes plans for an internet-based tool for a comprehensive transportationplanning process that utilizes the data developed here. These data (Manier and O'Donnell, 2018) should allow land-use and transportation planners in State and Federal agencies to combine transportation network information (for example, roads, railroads, public right-of-ways) with existing social infrastructure (for example, population centers, industrial areas, recreation areas, conservation areas), natural resource values (for example, sensitive or protected species and habitats, important hydrologic resources), and natural hazards (for example, flood and sinkhole potential). As such, the cooperative agreement facilitated the provision of services to support FLH's nationwide initiatives on transportation planning and asset management. As a key component of this effort, staff undertook a series of steps, including planning and scoping, communicating with participants in ongoing interagency planning efforts, implementing spatial data analysis, and reporting. These steps will enable simultaneous consideration of transportation, social, and natural resource data. Key components of this effort are discussed below.

1. For seven States (California, Colorado, Maryland, Virginia [Washington, D.C. and surrounding metro areas], Georgia, Minnesota, and Oregon), geodatabases of readily available resource data (environmental, cultural, and historical) and socioeconomic data were developed that will be used in the FLH long-range transportation planning process. Products were generated using national-level data to provide CFL consistency and support regional planning efforts that extend beyond State and political boundaries. We recognized that local information might be more specific than national-level data and so would be important during State and local planning efforts. However, the wide diversity of information from different sources, and the variable spatial resolution of State and local data, made it difficult to use these data for transboundary analyses. Therefore, we excluded State-level data from the final national-level indices and metrics, but we encourage planners to acquire and use local data to supplement our national-level information. The USGS also provided socioeconomic data that are represented as gridded surfaces derived from census blocks from the USGS Assessing Socioeconomic Planning Needs program (https://my.usgs.gov/aspn/main/home), which were provided separately as another part of this project.

2. Collaborative work and data development done by the USGS Fort Collins Science Center and the CFL and its partners, which include the National Park Service (NPS), U.S. Fish \& Wildlife Service (FWS), U.S. Department of Agriculture Forest Service, BLM, and Army Corps of Engineers. The objectives for the collaboration included developing spatial models and other analytical tools to inform transportation planning and network evaluation by connecting transportation-system data, such as road surface conditions and usage volume, with indicators of resource sensitivity, hazard potential, and economic profiles for the area surrounding the transportation system.

3. A framework for creating transportation planning profiles developed using spatial information to inform planning projects currently underway at the CFL, which planners can replicate in other States and regions.

Specifically, this final project report focuses on the development and interpretation of data representing natural resource values and hazards. Data were compiled to represent previously identified natural and cultural values and potential hazards across the geographic extent of the continental United States (CONUS) and (or) within boundaries outlining State-based focal regions depending on the availability of data, the areal extent represented in the data, and the completeness and resolution of those data. These data were assembled as a series of environmental resource geodatabases including natural resource boundaries and distributions (hydrography, minerals, and land cover); ecologically defined areas, boundaries, and distributions (including, migration routes, species distributions, and protected areas for sensitive species and habitats); and culturally important boundaries (location of registered sites and properties). Importantly, although we acquired public historic cultural resource data, we have not provided any prehistoric data because of their sensitivity (protected status) as determined by State Historic Preservation Offices. Local planners may wish to contact State and local authorities for complete information regarding the location of sensitive, protected, and otherwise important historic and prehistoric sites.

\section{Methods}

To organize our data acquisition process to fit the intended application, we developed a conceptual framework to describe different categories of information and how these different types of information should be related to accurately, but simply, inform transportation and related land-use planning (fig. 1). In this framework, several primary categories were identified (social resources, cultural resources, natural resources, and natural hazards) to organize data describing resources or hazards with potentially important relationships associated with transportation networks. These relationships include direct influences, such as roadkill, flooding, and landslides; and indirect influences due to proximity, such as noise and air and water quality, and landscape patterns, such as habitat fragmentation (fig. 2).

This report documents the compilation and assessment of spatial datasets representing the distribution of natural and social values, and potential natural hazards, across the CONUS. A series of calculations were used to inform the integrated assessment and create a series of indices that combined similar indicators to build metrics from source data, such as 


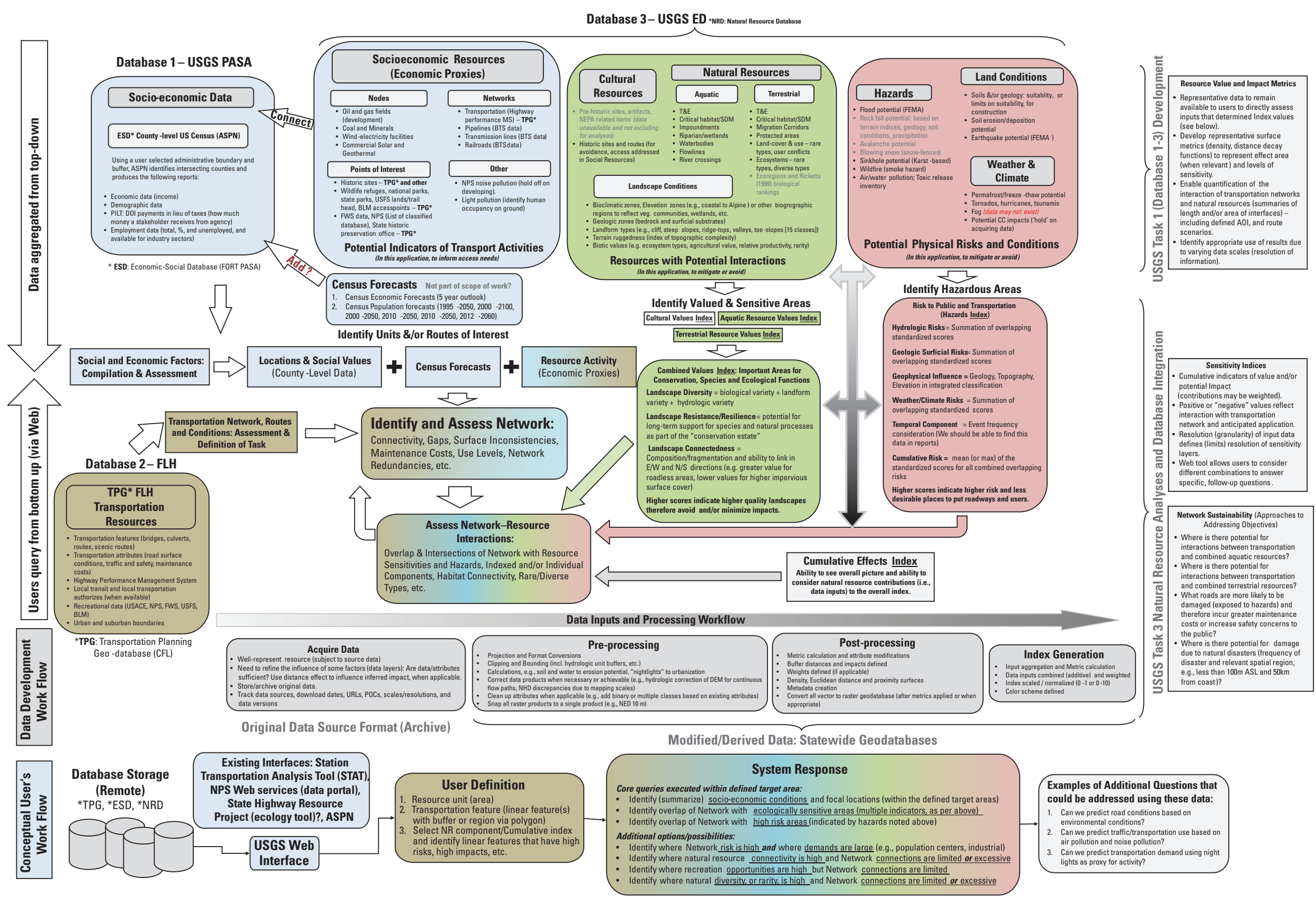

Figure 1. Conceptual diagram of the data development and processing workflow. [AOI, area of interest; ASL, above sea level; ASPN, Assessing Socioeconomic Planning Needs tool; BLM, Bureau of Land Management; BTS, Bureau of Transportation Statistics; CC, climate change; DEM, digital elevation model; E/W, east-west; FEMA, Federal Emergency Management Agency; FWS, U.S. Fish \& Wildlife Service; MS, management system; NED, national elevation dataset; NPS, National Park Service; NR, natural resource(s); N/S north-south; POC, point of contact; SDM, species distribution model(s); T\&E, threatened and endangered; FS, U.S. Department of Agriculture Forest Service; URL, universal resource locator; USGS ED, Ecosystem Dynamics branch of U.S. Geological Survey Fort Collins Science Center] 

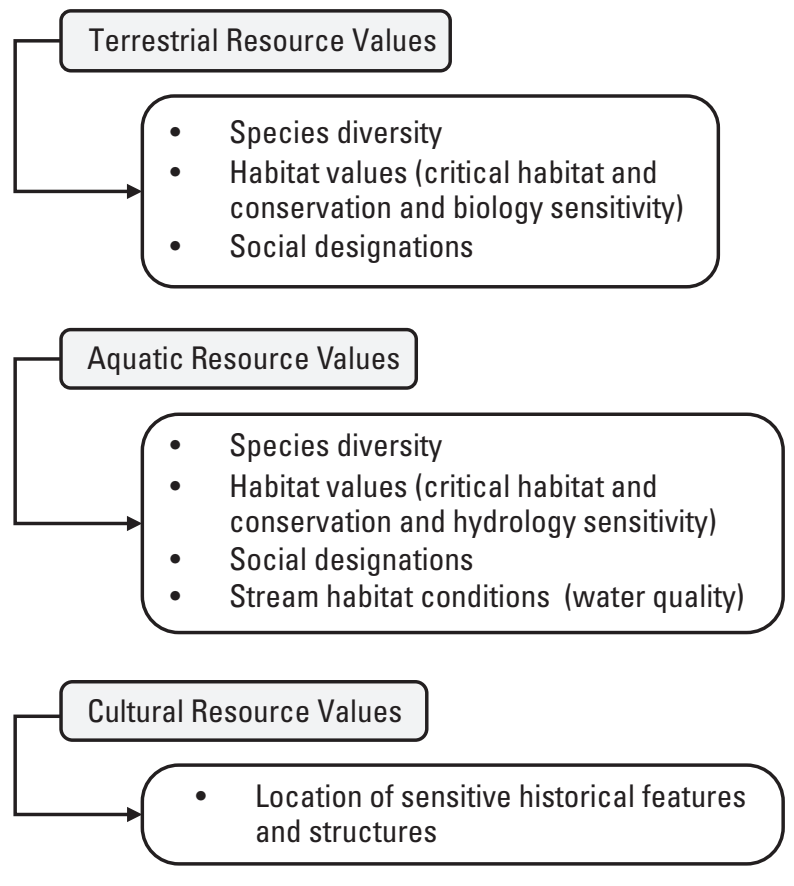
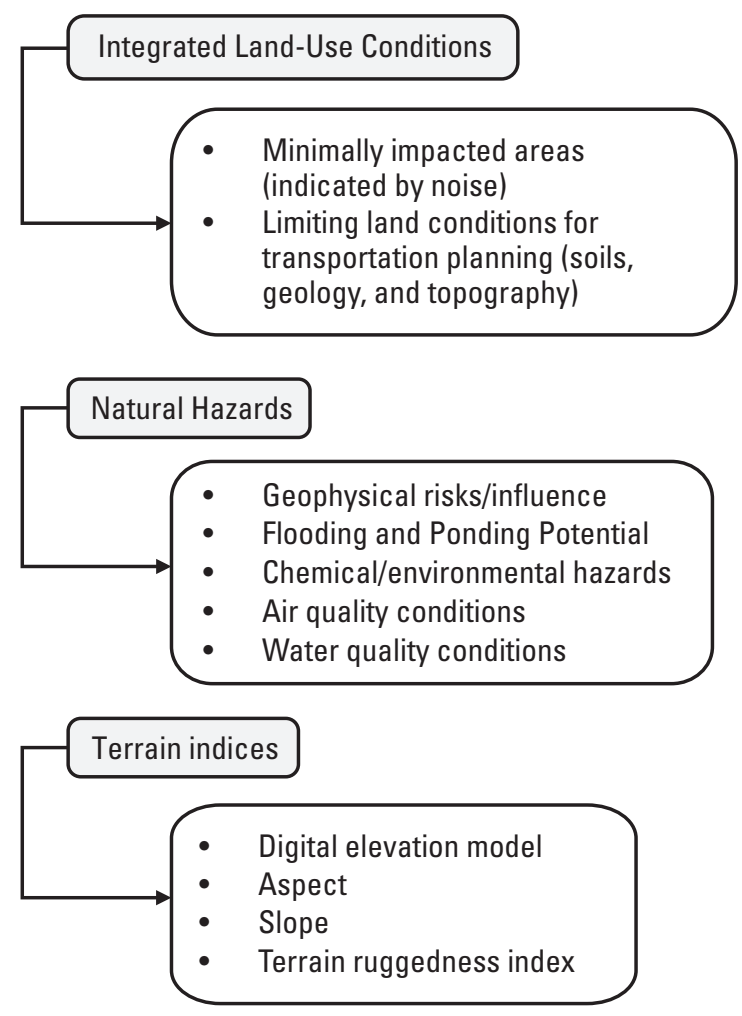

Figure 2. Graphical depiction of the components of this integrated assessment. Each nested category (those listed in the uncolored boxes) includes many datasets. Therefore, data for metrics and indices created for each item listed here were based on the combination of several source data inputs. The combined categories (those listed in the gray boxes) are generalized and intended for coarse-scale, regional planning, and metrics for the categories listed in the uncolored boxes may also prove informative for planning purposes.

land-use designations and species distributions, which were subsequently aggregated into an inclusive index. The metrics represent different, but related, types of information that can indicate the location of potentially greater, or lesser, ecosystem values. For example, proximity to any surface water, such as lakes, rivers, streams, and reservoirs, may be of interest when considering potential interactions with roads, and aquatic resources. The Aquatic Resource Values Index can be used to inform the planning process using inclusive consideration of aquatic features, whereas contributing metrics may be used to inform more specific questions or issues. Coincidence of, or proximity to, multiple features, such as species diversity, conservation areas, and recreational uses, is estimated to increase the potential importance of portions of the landscape compared to others. This may be particularly important when prioritizing funding and mitigation or management actions across broad landscapes with many options for allocation of efforts.

\section{Synthesis and Data Processing}

Although similar processing and analyses were used across all data categories (terrestrial, aquatic, cultural resources, land-use condition, natural hazards, and terrain), some notable differences were used to accommodate diverse data content, formats, and attributes in preparation for meaningful integration. To facilitate correct interpretation of the indices, specific information regarding unique calculation and processing steps with the results for each index or metric are described (also see the "Results" section of this report). To provide a clear understanding of the integrated assessment approach used for all data processing, the seven factors relevant to the approach, and the decisions made regarding how to address each, are described below.

1. Knowledge of environmental patterns and processes was used to determine and combine appropriate and compatible data to enable identification of relationships important for land-use planning.

- A conceptual framework to describe important thematic categories of information and relationships among the categories was developed, which can inform transportation and land-use planning (fig. 1). This framework was vetted with the CFL and State and local groups that are members of the Northwest Collaborative Long Range Transportation Plan team. 
2. Acquire and preprocess source information to ensure that spatial data intended for analyses have similar data types, coordinate systems, and geographic extents.

- All data were converted to a common CONUS map projection (CONUS Albers Equal Area Conic) and Datum (North American 1983; NAD 83), when necessary. All input datasets were converted into a 30 meter (m) x $30 \mathrm{~m}$ (hereafter, referred to as "30-m spatial resolution") raster data format, with identical rows and columns, data extents, and pixel origins, and all data were snapped to a common grid to ensure pixels aligned. All datasets were clipped to the CONUS boundary for final analyses and distribution. Thus, all source data and interim data are spatially compatible and patterns identified in indices (final products) may be connected to source data using locations in the respective datasets.

3. Some data will include omission and commission errors; therefore, identification and correction of errors are necessary prior to combining data. For example, to ensure proper aggregation when a location (pixel) has "no data" in one dataset, but important information in others, omissions and other "no data" values were assigned a lowestvalue class prior to aggregation.

- Omission of data was generally a result of the scale of the data. Therefore, the most accurate data representing the largest spatial scale and smallest spatial resolution were collected for all data. In some cases, other agencies compiled data for watersheds or some other unit of area but such data were included only when no other data were available and the scale of the data were sufficient for general planning purposes.

- To aggregate data using different sources of information, we required all spatial data within the CONUS, including water data, to have a cell value other than "no data." If there were interspaces between vector data (polygons), or unattributed raster cells, a value of "no importance" was assigned to align with the other data products. Linear- and point-vector data were converted to a continuous raster surface using the Euclidean distance from each point to the resource of interest, and then a threshold for maximum distance was applied; locations beyond the threshold distance were considered as not having substantial influence on the resource of interest. These approaches resulted in a cell value other than "no data" for every pixel in each dataset.

4. Data often represent different scales and accuracies; therefore, when combining these data, careful scrutiny and consideration were used to ensure proper interpretation, including the relative contribution of coarse data compared to higher-resolution data in metrics and indices. For example, the relative importance of coarse data may be down-weighted in algorithms to avoid saturation of index values that could hide distinctions provided by finer-resolution data.

- The scales for each dataset were investigated and data with the finest spatial scale (greatest inclusion of detail) were used, but detailed data products do not exist for some information. For example, species ranges are likely at a 1:1,000,000 scale and climate data are often at more than a 1-kilometer $(\mathrm{km})$ cell resolution, but air quality data exist at $10-\mathrm{km}$ resolution. These data remain important for incorporation, but some features of the landscape such as terrain, soil, and vegetation patterns cannot influence the local estimation of coarse-data measurements and models. Therefore, data users should consider information derived from coarse-data sources generally, across broad areas, with the understanding that local details and distinctions that may exist were not captured in the data or subsequent indices. To convey how scales relate to accuracy based on established standards, a table denoting commonly used map scales and spatial resolutions of raster data is provided (table 1). When low spatial resolution raster data (for example, $10 \mathrm{~km}$ ) was changed to a high resolution raster dataset (for example, $30 \mathrm{~m}$ ), the conversion did not involve down scaling (Hewitson and Crane, 1996; Trzaska and Schnarr, 2014; Wang and others, 2016) or increasing information, but rather ensured that all raster data had an identical spatial resolution, which was required to combine them. The spatial resolution and scale of each data source are provided when available (see tables 1.1 to 1.5 ).

5. Spatial data often represent features that reflect information at different times and careful scrutiny is necessary when combing data from different times. For example, land cover and use types captured in a remotely sensed data product often reflect imagery from multiple dates to minimize cloud obfuscating, and vector data delineating boundaries often change and may include information captured from different sources investigated at different times. Further, soil, vegetation, and aquatic inventories are often conducted independently and at different times, and large inventory projects are often staged over time leading to a range of dates within a single dataset.

- Changes in land uses can occur rapidly and there is no easy method for accounting for these constant changes. However, any user of spatial data should recognize that information captured in a map or dataset is a snapshot in time and the contents of the data, regardless of the publication date, may reflect a time long before the publication date and include multiple time intervals. For this study, indices were created to inform planning from multiple data sources and as long as the data represent relatively similar time lines 
Table 1. The root mean square error (RMSE) represented in meters is the error associated with the linear distance for each map scale. For example, data developed at a map scale of 1:24,000 will have potential error of \pm 20.3 meters. (Modified from Federal Geographic Data Committee, 1998 and American Society for Photogrammetry and Remote Sensing, Map Accuracy Standards Working Group, 2014)

\begin{tabular}{cc}
\hline Map scale & RMSE (meters) \\
\hline $1: 50$ & 0.0125 \\
$1: 100$ & 0.025 \\
$1: 200$ & 0.05 \\
$1: 500$ & 0.125 \\
$1: 1,000$ & 0.25 \\
$1: 2,000$ & 0.5 \\
$1: 4,000$ & 1 \\
$1: 5,000$ & 1.25 \\
$1: 10,000$ & 2.5 \\
$1: 20,000$ & 5 \\
$1: 24,000$ & 20.3 \\
$1: 50,000$ & 42.91 \\
$1: 100,000$ & 84.58 \\
$1: 250,000$ & 211.46 \\
$1: 500,000$ & 422.91 \\
$1: 1,000,000$ & 845.82 \\
\hline
\end{tabular}

and accuracies, these data are sufficient for regional planning purposes. However, including local data in planning is suggested, especially when local data provide important, contemporary information.

- There are many unknowns about data omission and commission errors, temporal resolution, spatial resolution (or scale), and quality control for many of the species data (ranges), and therefore the diversity indices developed for this study include uncertainties. The source data included information about the data collectors and the date on which they collected the information, but how those individuals collected the data and whether they collected the information on the ground, through modeling exercises, or through literature searches was unknown. To reduce our concerns with these potential ambiguities, our derived indices reflect relative species diversity using different designations (for example, ranges, critical habitats) and do not reflect absolute counts, specific locations, or more detailed information that have a greater potential for error. These source data are relatively accurate, but because there are large amounts of data, there are greater chances for human error. Details of species ranges may be limited by source information because not all species ranges are well mapped. Although combining these data into diversity indices is likely to capture important biological and ecological patterns across broad landscapes that are important for land-use planning, our diversity indices should be evaluated using locally specific information when potential impacts on species diversity or a particular species are identified.

6. Aggregating aspatial information (tabular attributes associated with both vector and raster data) requires compatibility of the units (for example, meters versus feet) and value formats (for example, discrete or classified values versus a continuous numeric range) used to represent environmental patterns. Therefore, measurements and estimates provided by source data may require processing before aggregation to ensure that inputs to the algorithm will generate the expected results when combined.

- All raster data used a common map projection with units of meters, so the horizontal position information is in meters, but the elevation data uses vertical units of feet. However, these indices were not combined with other data so the units did not need to be changed. Because most aspatial values and their units, with the exception of percentages, counts, and discrete classes were not used, we did not require many unit conversions.

- When the data existed in the same unit scale and contained all positive values, a row standardization (in other words, a linear rescaling) was appropriate (eq. 1; Abdi and Williams, 2010) and necessary for combining data.

$$
x_{l s}=\frac{\left(x_{i}-\min \right)}{\max -\min }
$$

where

$$
\begin{aligned}
& x_{l s} \text { is the linearly rescaled value, } \\
& x_{i} \text { is the target pixel value, } \\
& \min \text { is the global minimum value within the } \\
& \text { dataset, and } \\
& \text { max is the global maximum value within the } \\
& \text { dataset. }
\end{aligned}
$$

- One method to combine aspatial data with different types of continuous scales (different units such as percentage cover of vegetation and vegetation height) is to apply a z-score transformation (eq. 2; Abdi and Williams, 2010). This approach scales the mean to 0.0 with a standard deviation of $1.0 \mathrm{but}$ maintains the shape of the original distribution. This results in a symmetrical stretch (for example, -1.0 to 1.0). If the data are non-normal, a power transformation (for example, a box-cox statistic) is necessary. 


$$
z \text {-score }=\frac{\left(x_{i}-\mu\right)}{\vartheta}
$$

where

$$
\begin{aligned}
z \text {-score } & \text { is the transformed value, } \\
x_{i} & \text { is the target pixel value, } \\
\mu & \text { is the global mean of the raster, and } \\
\vartheta & \text { is the standard deviation of the raster. }
\end{aligned}
$$

- The distinction between standardization and normalization is important when working with data. Standardization, or linear scaling, does not change the unit but rather scales the same unit in multiple datasets to a common scale. The z-score transformation is a normalization approach that standardizes data by centering the values on the mean. In this case, the normalization results in a unitless scale. As a result, this approach was used to combine data that have different units of measurement.

- In many cases, unique data content and attribution were addressed by classifying a source attribute using classes scaled for integration with other datasets, for example 0-1.0 for continuous data or 3-4 aggregated classes for categorical data. In other cases, proximity was important to indicate potential influence so a Euclidean distance with a maximum threshold was used to classify areas in close proximity to potentially sensitive resources, such as aquatic habitats and cultural resources. Because simple summation was used to combine categorical data, processing steps did not standardize ranks using linear scaling, piecewise linear scaling, or z-scores.

- In some cases, datasets representing probabilities or percentages (as opposed to absolute values) were converted into class variables based on thresholds identified in the source data, a referenced document, or quantiles ( 25 percent increments), thereby creating values that extended beyond the $0-1$ range (for example, 4 discrete classes of 1, 2, 3, and 4). When class-variable ranges extended beyond 1 , those values were also scaled to the $0-1$ range using this same method. These steps, alone or in combination, facilitate integration of multiple datasets with different data ranges and (or) classification schemes by adjusting each source dataset to a common range based on the information contained therein.

7. The MAUP is "a problem arising from the imposition of artificial units of spatial reporting on continuous geographical phenomena resulting in the generation of artificial spatial patterns" (Heywood and others, 1998, p. 416). Aggregating data into units for analysis can result in artificial spatial patterns when continuous information is grouped into classes. Examples include grouping cancer occurrence into counties or classifying habitat values within watersheds based on abundance of small or rare features within larger areas. Often, these aggregations are useful for assessments and quantitative analyses, but as they may result in exaggerated spatial patterns, they require careful interpretation.

- Data were not aggregated into units that would result in a MAUP. Data were combined using multiple methods. These methods included: (1) developing Euclidean distances for independent data and selecting the smallest distance (pixel-by-pixel) of multiple Euclidean distance surfaces of related data themes; (2) examining overlapping raster surfaces for presence or absence and creating frequency counts, such as with species ranges; and (3) reclassifying data to match similar discrete classes, such as with most of the hazards data. The various methods used for combining the data for each index are described in the Methods and Results for each category. Therefore, data were not summarized using different units of area, which would lead to the MAUP.

Multi-Criteria Decision Methods and Multi-Criteria Evaluation (MCE) (other names include Multi-Objective Decision Analysis, Multi-Criteria Decision Analysis, and Spatial Multi-Criteria Decision Analysis) represent similar processes that provide structure for objectives, define the criteria to address those objectives, and then support different methods for prioritizing the criteria to produce alternative decisions (Carver, 1991, Malczewski, 2006a; Temiz and Tecim, 2009). In other words, when combining data to inform management decisions, the objectives were defined, the criteria that addressed the objectives were identified, and lastly, different methods to combine the criteria were compared, resulting in alternatives for representation of the combined information. Multi-Criteria Decision Analysis is a method used in a vast set of planning applications. For example, previous applications have included planning for forest firefighting (Temiz and Tecim, 2009), urban encroachment on forests (López-Marrero and others, 2011), habitat suitability modeling (Store and Kangas, 2001), transportation and landuse development (Sharifi and others, 2006), site selection for managed aquifer recharge systems (Rahman and others, 2012), land-use suitability analysis (Malczewski, 2006a and 2006b; Mustafa and others, 2011), and landslide susceptibility and hazard preparedness (Feizizadeh and others, 2014).

Typically, MCE methods facilitate development and selection of the best alternatives. However, long-range transportation plans include a spectrum of objectives, which sometimes conflict (for example, provide access to a protected area versus protecting an area by avoidance). Therefore, criteria (data) were aggregated into multiple categories by weighting the criteria within each category by accuracy, completeness, and importance to conservation. Because these data needed to be combined, they needed to be standardized. Although MultiCriteria Decision Analysis supports both vector data and raster data, generally the process involves converting all criteria 
(also known as factors or spatial data) to raster datasets, defining constraints where analyses will not apply, such as our use of distance thresholds, and evaluating different decision-making rule sets used to combine the data (Carver, 1991).

A value-focused, versus an alternative-focused, approach was used to identify resource values, and their relative importance, to best inform the objectives. The transportation planning objectives are two fold, so information needed to (1) represent the potential for interactions between specific routes or units (stations) and sensitive, protected, or otherwise important environmental resources and natural habitats; and (2) provide synthetic information to support creation of sustainable transportation systems that improve transportation experiences but also emphasize stewardship of natural and cultural resources. Thus, protection of natural values and accessibility to resources and natural areas were integrated here; therefore, some planning projects may require multiple perspectives and different considerations during the planning process. As a result, data were synthesized to reflect the presence of recreational opportunities, highlight sensitive areas and critical habitats, recognize patterns of species diversity, and include both conservation areas and areas with less natural value because of pollution, hazards, historical land uses, or other reasons. Because a large amount of data were considered in a large number of categories, with heterogeneity of data types and sources, the MCE process is challenging, and measuring the uncertainty inherent in such an evaluation is even more challenging.

The MCE process includes numerous examples of decision rules for combining data. These include Boolean logic (in other words, set theory), ordered weighted averaging, analytical hierarchy process, and weighted linear combination. Set theory is very limited in application to our data because most of our data exist on continuous scales. Because a clear set of objectives for each dataset did not exist for prioritizing resource values in the planning process, it was determined that ordered weighted averaging would add greater uncertainty to the data and process. In addition, analytical hierarchy processing was not considered because of the lack of information for ranking objectives and separating data into different categories by order of importance would allow greater flexibility in the planning process. Therefore, set theory, ordered weighted averaging, and analytical hierarchy process approaches were not applicable due to incompatibility with our data and (or) objectives.

The weighted-linear approach to combining data allowed a vast amount of data to be combined into similar categories, and addressed the relative importance of those inputs to the objectives and emphasis of existing policies (for example, weight added to critical habitat designations, protections for T\&E species, and wetland protections). Some of the data inputs informing our metrics and indices were attributed with qualifiers (such as none, low, moderate, and high for landslide potential), indicating that an MCE was already applied to those data, and in those cases, the existing qualification directly informed this assessment.
Data collected for each spatial extent (CONUS and pilot areas) were summarized using categories identified during index development (fig. 2). Categories of "terrestrial" and "aquatic" focus on species and habitat distributions found primarily on land, or in aquatic or wetland systems, respectively; however, these data were often explicitly connected to habitats or other land units during mapping. "Natural values" focused on those data representing species or habitat distributions, including species-focused conservation areas, whereas "social values" of natural resources included those areas with recreation, hunting, or other human activities connected to natural areas, but not explicitly to a species of interest. "Cultural values" included historic and archeological sites and other similar locations and structures, such as battlegrounds, burial grounds, and historic buildings. Because of data-access limitations, only registered, historic buildings and sites are included in this index. "Hazards" are features or characteristics of landscapes that may present risks or inconveniences for drivers/traffic, road construction, and (or) maintenance. Importantly, these locations are described over large areas (low resolution) so these data do not replace local knowledge, surveys, and other necessary engineering and safety information.

\section{Data Documentation}

Metadata associated with each dataset from the source was acquired with the data, when available. The source metadata were incorporated and standardized using a USGS metadata development tool (https://www.sciencebase.gov/catalog/ item/50ed7aa4e4b0438b00db080a), which added processing steps specific to this project and project objectives, identified any gaps or changes in information, and formatted the data for Federal Geographic Data Committee compliance. Errors in the metadata may exist due to variability of statements in the original metadata. The majority of national data from various government organizations lacked metadata despite Federal Geographic Data Committee standards, so documentation for these products and other products were compiled using USGS metadata development tools. All derived data developed for this project have accompanying metadata based on the Federal Geographic Data Committee standards, which include all sources and data contributions. None of the data presented here include proprietary or sensitive information. Some of the data sources, most notably NatureServe (2014) and the International Union for Conservation of Nature (2013; IUCN), do not permit redistribution of their data to the public. Therefore, these data, or any data that would allow users to reverse engineer the derived data to recreate the source data, are not included in the data released.

To process all data, tools in Environmental Systems Research Institute, Inc. (Esri) ArcGIS ${ }^{\circledR}$ 10.3.1 desktop (Esri, 2011a) and the Spatial Analyst ${ }^{\circledR}$ extension were used (Esri, 2011b). An 80-core server with 300 gigabytes of memory was used to process data for developing the terrestrial and aquatic species diversity metrics and indices. These resources were necessary to process the enormous quantity of data provided 
by NatureServe (2014) and the IUCN (2013), and to handle the complexity of the geographic information system operations executed across a very large area (that is, CONUS).

The result of this effort was the compilation and processing of more than 185 national and 183 State-specific datasets that represent the distribution of natural and cultural values. (Note: some source datasets contained multiple records resulting in a much larger number of compiled records). This report describes the data that we acquired and documented for each of the categories and that were used to calculate indices of the relative distribution of natural and cultural resource values. Because of the tremendous volume of information described herein, each "Methods" section of the report refers to a table in the appendix summarizing the data inputs (appendix tables 1.1 to 1.5). In addition, the appendix includes table 1.6, which provides a summary of calculations for the metrics and indices.

\section{Distribution of Threatened, Endangered, Sensitive, and Other Species of Concern}

Because absolute knowledge of the distribution of all species does not exist, developing a definitive map of biodiversity values, such as richness (number of species), for a continent, nation, or even a single State was not possible. As a representation of the potential distribution of species abundance (biodiversity), metrics representing potential species abundances based on the compilation of all species distributions mapped by NatureServe (2014) or the IUCN (2013) were developed. Importantly, species of conservation concern (T\&E, rare, sensitive, or similar) were preferentially represented in the IUCN data, but the NatureServe data were not limited to species of concern. Because these metrics represent the combination of the very large number of species on record in the IUCN and NatureServe data, these data should provide a reasonable representation of the distribution of vertebrate biodiversity across the United States. These data were used differently in index creation; NatureServe data were used to inform species diversity estimates (Metric 1) and IUCN data were used to identify potentially sensitive habitats (Metric 2) for the Terrestrial and Aquatic Resource Values Indices. Importantly, species range models provide a coarse resolution depiction of the range of each species; therefore, indices derived from these data suggest broad patterns in diversity and do not specify particular locations of species occurrence (Ricketts, 2001). As such, these indices provided a useful representation of the distribution of natural values associated with wildlife and biodiversity for regional planning purposes.

The data compiled here provide a summary of all species distributions mapped by NatureServe or the IUCN, and as such, species of conservation concern (T\&E, rare, sensitive, or similar) are more likely to be represented in these data; however, the vast number of species documented by NatureServe and the IUCN extend well beyond species of concern. The IUCN maintains a comprehensive inventory of plant and animal species and their global conservation status. NatureServe maintains data on species and ecosystems, including the
National Species Dataset, with data compiled from projects and programs across Canada and the United States. These data provided a reasonable, but not definitive representation of the distribution of total biodiversity across the United States, even though not all species are documented.

Because of the challenges associated with processing a very large number of species records, a simplistic separation of aquatic and terrestrial species was required for calculating the diversity (richness) metrics (Metric 1 for both terrestrial and aquatic species). Although some species are strictly limited to terrestrial or aquatic habitats, many species use both during some phase of their lives. In particular, bird distributions were not separated into terrestrial and aquatic species and bird diversity is represented in Metric 1 (Species Diversity) of the Terrestrial Resource Values Index. Aquatic diversity was based primarily on fish distributions. We believe these patterns represent the relative distribution of diversity related to aquatic and terrestrial habitats, despite our inability to make finer distinctions. We estimated species richness by calculating the number of species distributions overlapping each cell location (Ramirez-Villegas and others, 2014; Manhaes and others, 2016) using distribution models from NatureServe. Information that is more detailed, including local distributions of species, habitats, and protected areas, may be available from local sources (for example, State agencies). Our data provide a starting point for regional planning and analyses but should be supplemented with additional information prior to project implementation.

Thus, the species diversity represented in our metrics (Metric 1 in the Terrestrial and Aquatic Resource Values Indices) represent a compiled estimate of the abundance of species occurring at all locations across the CONUS, including mammals, birds, and reptiles (terrestrial), and fish (aquatic). However, because the metric is not based on an exhaustive list and information regarding the occurrence and distribution of species changes over time, this metric could be re-created (updated) when information about total biodiversity becomes available. Interpretation and application of the data herein should include explicit consideration of these limitations. That said, we believe these data, and Metric 1 in the Terrestrial and Aquatic Resource Values Indices, are good representations of the relative diversity among different locations on the U.S. landscape. As such, the species diversity data may inform planning and regional assessments that consider broad patterns of diversity, such as regional plans and landscape context for local plans.

\section{Terrestrial Resource Values}

An aggregated index of potential terrestrial resource values was created by combining cumulative evidence from multiple contributing factors, including patterns of species diversity, important habitats, conservation areas (for one or more species), and other natural and social values (for example, natural areas and parks). Data representing each of these components were compiled to calculate metrics based on compatible formats and 
complementary information content, and then these metrics were combined to create the Terrestrial Resource Values Index. The metrics for this index are Metric 1 - Species Diversity, Metric 2a-Critical Habitats, Metric $2 \mathrm{~b}$ - Conservation Areas, and Metric 3-Social Designations.

Species diversity data were developed using distribution maps, which were models created by NatureServe and the IUCN from observations and expert knowledge. Species richness, a component of diversity, was estimated across the CONUS by counting overlapping species distributions for each major taxonomic group (reptiles, birds, and mammals). The following steps were used to aggregate information contained in individual species distributions from many datasets: (1) all polygons (one for each species) were merged to create a single dataset with overlapping features; (2) numerous geometry errors were corrected; (3) nonoverlapping polygons were created using a union of the overlapping polygons; (4) centroid points for the nonoverlapping polygons were defined; and (5) a spatial join of the centroid points was used to connect the information attached to points to the overlapping polygons to allow a subsequent count of the overlapping polygons. Once compatible geometry was created and attributed, information was combined based on the spatial overlap of polygon regions in three steps: (1) the overlap count data were joined to the nonoverlapping polygons, and polygons with a count of zero were removed to reduce undesired attributes; (2) all products were clipped to the CONUS boundary; and (3) a raster dataset representing the count of species at each cell location (30-m spatial resolution) was calculated for the diversity index.

Species names, within and across datasets, were used to recognize redundancies within and between data, and we retained names in the aggregated data to ensure we did not "double count" species. (These data are sensitive or proprietary, or both, and therefore are not released by USGS; however, they are available from the sources, NatureServe and IUCN). Metrics based on counts of species (from spatialdistribution models) were achieved by summing the number of overlapping species predicted to occur at each location and then normalizing these counts into categories of importance between $0-100$. Areas with a higher potential number of species received higher scores.

Indices representing proximity to designated habitats were classified and inverted so that areas in close proximity to these habitats received higher scores (again, scaled from 0-100). For example, proximity to FWS-designated critical habitats were coded so distances less than $50 \mathrm{~m}$ were classified as "100," distances between $50 \mathrm{~m}$ and $1 \mathrm{~km}$ were coded "80," distances between $1 \mathrm{~km}$ and $1.5 \mathrm{~km}$ were coded "60," and so on until distances greater than $10 \mathrm{~km}$ were coded " 0 ." State-level data were acquired and were found, in many cases, to contain information that is more specific. However, inconsistencies in the methods and mapping scales used, and the species represented, in the State data made this data difficult to incorporate in a consistent manner. As a result, Metric 1Species Diversity for the Terrestrial Resource Values Index represents the coarse-scale distribution of species across the
CONUS and may be supplemented by additional data when planning applications require detailed information. Therefore, consideration of the spatial data inputs, such as the metrics and individual components used to create the indices, may be used to support interpretation of the index and enable evaluation of particular values and potential sensitivity.

Habitat values were divided into two principal components (separate metrics) during development: Critical Habitats (Metric 2a) and Conservation Areas (Metric 2b). The primary difference between the two is that a specified connection with a species (or suite of species) was used to define critical habitat, but a more general designation of natural areas by a State and (or) agency (without explicit connection to a species, but with general conservation benefits for wildlife and citizens) was used to define a conservation area. Similar to the diversity metrics, more information and additional designations may be available from local sources (for example, State wildlife and conservation agencies). Because most State habitat and natural area designations are well represented in national datasets, most Federal and State land designations were also included in these metrics.

Social designations (Metric 3) connected to natural areas and features, but without specific wildlife or habitat conservation designations, include greenways (semi-natural or natural easements and corridors), nature viewing areas, parks (Federal, State, and local), and recreational units, such as river access points, beach access points, trailheads, facilities, and trails. These areas exist to facilitate human interaction with nature, and therefore represent potential nodes in a transportation network. These locations add to the cumulative Terrestrial Resource Values Index based on the interpretation that human experience is an important driver for conservation of natural areas, and locations where people can access public lands have added importance for regional planning and conservation. Using a national distribution for each of the four metrics, they were combined in a $30-\mathrm{m}$ spatial resolution raster to create a continuous surface covering all parts of the CONUS.

A weighted summation approach, the established Spatial Multi-Criteria Decision Analysis approach (reviewed by Malczewski, 2006a), was used to calculate the Terrestrial Resource Values Index. By adjusting weights (model coefficients), the influence of species diversity, critical habitats, conservation areas, and social designations were balanced to provide an informative gradient in the final index. The formula identified for this aggregated index is (eq. 3 ):

$$
T R=0.375 \times T R 1+0.5 \times \max [T R 2 a, T R 2 b]+0.125 \times T R 3
$$

where

$\begin{aligned} T R & \text { is the Terrestrial Resource Values Index, } \\ T R 1 & \text { is Metric 1, } \\ T R 2 a & \text { is Metric 2a, } \\ T R 2 b & \text { is Metric 2b, and } \\ T R 3 & \text { is Metric 3. }\end{aligned}$

Metrics 1, 2a, and 2b were calculated using information related to terrestrial resource conditions (see appendix 
tables 1.1 and 1.6). Metric 3 was calculated based on the Euclidian distance from each pixel location to the nearest, terrestrially focused recreation area, such as a trail, park, or monument. Euclidian distances were classified into six classes: $0-1,000 \mathrm{~m}=100 ; 1,000-4,000 \mathrm{~m}=80 ; 4,000-8,000 \mathrm{~m}=60$; $8,000-12,000 \mathrm{~m}=40 ; 12,000-16,000 \mathrm{~m}=20$; and greater than $16,000 \mathrm{~m}=0$.

Coefficients for each metric were adjusted from equal ( 0.333 in this case) to increase the weighting (mathematical influence) of potential species diversity (TR1) and habitat designations (maximum value of TR2a and TR2b) and decrease the weighting of social designations (TR3). Metric 1 captures modeled ranges of known and mapped species (species diversity). Metric 2 a represents critical habitats of T\&E species, species of concern, and species on the IUCN List, a globally recognized list of species of conservation concern. Metric $2 \mathrm{~b}$ captures land holdings designated for conservation and habitat protection, recognized areas of critical environmental concern, and areas designated as protected for biodiversity. Lastly, Metric 3 captures social designations that provide recreational opportunities, such as trails, trailheads, and recreation facilities, as well as designated National Monuments, National Recreation Areas, National Wildlife Refuges, Wilderness Areas, and Wild and Scenic Rivers. The second aggregated Terrestrial Resource Values Index incorporated the same data as the weighted version and it provided an alternate way to view the aggregation. This method puts equal weights on all data inputs by normalizing the sum of the metric components between $0-100$. This is an attractive method because of its simplicity, but it does not provide the emphasis provided by the weighted algorithm.

\section{Aquatic Resource Values}

The Aquatic Resource Values Index includes the following metrics: Metric 1-Species Diversity, Metric 2a-Critical Habitats, Metric 2b-Conservation/Sensitivity, Metric 3Social Designations, and Metric 4-Landscape-Scale Water Quality. Species diversity (Metric 1) for aquatic resources was derived similarly to Metric 1 for terrestrial resources using data from NatureServe (2014) and the IUCN (2013) to provide consistent inputs representing the distribution of fish over large areas. A list of information contributing to each metric and index, and the sources of this information are provided in the appendix (tables 1.2 and 1.6). Because there is a large disparity in the number of species and the data formats included in State-level data, we did not use State-level data to calculate species diversity. Therefore, Metric 1 represents the coarsescale distribution of fish species across the CONUS, and more detailed information may be needed to inform some planning and projects, for example, project impact assessments or mitigation actions.

Similar to Species Diversity (Metric 1) for the Terrestrial Resource Values Index, information contained in individual species distributions (many datasets) were combined to create Metric 1 for the Aquatic Resource Values Index. The processing included five steps: (1) merging polygons for each species to create a single dataset; (2) correcting geometry errors; (3) creating non-overlapping polygons using a union of the original, overlapping polygons; (4) defining centroid points for each polygon; and (5) connecting the information connected to the central points (in original polygons) to the overlapping polygons using a spatial join. After compiling and correcting the spatial records, overlapping records were accounted for by (1) joining the overlap count data to the nonoverlapping polygons and removing polygons with a count of zero to reduce undesired attributes, (2) clipping all products to the CONUS boundary, and (3) creating a raster representing the count of species.

As with terrestrial habitats, aquatic habitat resources were divided into two components: (1) important habitat designations, which hinge upon connections between species, habitats, and protection; and (2) areas with general conservation designations or sensitivities. Critical Habitats (Metric 2a) includes rivers and streams identified by the FWS, and aquatic features within the U.S. Protected Areas Database. Because of the scientific and regulatory interpretation that all wetlands are important and worth protecting (for example, as stated in Executive Order 11990-Protection of Wetlands), Metric 2b (Conservation/Sensitivity) includes all wetlands in the FWS National Wetlands Inventory and USGS National Hydrologic Database. Further, because activities on nearby lands may disturb these sensitive habitats and potentially affect erosion, sedimentation, hydrology, contaminants, and predation, an algorithm was used to calculate the distance (Euclidean measure) from each pixel to the nearest wetland feature to represent the proximity of all locations within the CONUS to wetlands. Planners may use the distance calculation as an indicator of direct impact (overlap or intersection where distance is zero) and relative potential for influence of roads and trails in the area surrounding wetlands based on proximity.

Wild and Scenic River designations and recreational access points identify locations where interactions between people and the natural environment are prominent. Because of the importance of these locations for human interactions with natural resources, they were included in the cumulative index as socially important designations (Metric 3). The U.S. Environmental Protection Agency (EPA) has measured and modeled water quality across the nation, and EPA data on water quality impairments (chemical and physical) were used to create Metric 4-Landscape-Scale Water Quality. Collectively, these metrics represent the relative distribution of important aquatic and wetland resource values across the United States.

The distribution of important aquatic resources was calculated by summing values from multiple datasets representing the distribution of species (fish species count by watershed), aquatic habitats (for example, lakes, rivers, wetlands), habitat designations (for example, FWS-designated Critical Habitats), and conservation areas (for example, Wild and Scenic Rivers). Cell-by-cell calculations addressing each unit of the raster dataset individually, in sequence, by means of a weighted equation (eq. 4) and a normalized summation provided the mechanism 
to combine multiple metrics (Metrics 1-4). Counts created for Metric 1 were normalized into a range between $0-100$, with locations having a greater potential number of species receiving the higher scores. Metrics representing proximity to designated habitats (Metrics 2a, 2b, and 3) were classified and inverted so that areas in close proximity to these habitats received higher scores (scaled from 0-100). For example, proximity to FWSdesignated Critical Habitats were coded so distances less than $50 \mathrm{~m}$ were classified as "100," distances between $50 \mathrm{~m}$ and $1 \mathrm{~km}$ were coded " 80 ," distances between $1 \mathrm{~km}$ and $1.5 \mathrm{~km}$ were coded " 60 ," and so on until distances greater than $10 \mathrm{~km}$ were coded " 0 ." This systematic, nonspecific approach was not based upon interpretation for any one, or a defined group of, species.

Our weighted summation of the collective Aquatic Resource Values Index relies on the same Spatial MultiCriteria Decision Analysis approach described for the Terrestrial Resource Values Index. In this case, the weighted index was calculated as:

$$
\begin{gathered}
A Q=(0.544 \times \max [A Q 1, A Q 4])+ \\
(0.364 \times \max [A Q 2 a, A Q 2 b])+(0.092 \times A Q 3)
\end{gathered}
$$

where

$\begin{aligned} A Q & \text { is the Aquatic Resource Values Index, } \\ A Q 1 & \text { is Metric } 1, \\ A Q 2 a & \text { is Metric } 2 \mathrm{a}, \\ A Q 2 b & \text { is Metric } 2 \mathrm{~b}, \\ A Q 3 & \text { is Metric } 3, \text { and } \\ A Q 4 & \text { is Metric } 4 .\end{aligned}$

As previously stated, contributions from Metrics 1, 2a, $2 \mathrm{~b}, 3$, and 4 were calculated using specified aquatic resource inputs (see appendix tables 1.2 and 1.6). This index put the greatest emphasis on potential species diversity (AQ1) and aquatic habitat condition (AQ4), added emphasis on habitat designations (AQ2a and AQ2b), and reduced emphasis on proximity to social/political designations (AQ3). A weighted, aggregated Aquatic Resource Values Index and an unweighted (equally-weighted) version of the index were created and compared. Although the simplicity of the unweighted model is attractive, the weighted model provides better spatial resolution of differences in aquatic values.

\section{Cultural Resource Values}

Most archeological information is sensitive and is protected by State Historic Preservation Offices. Therefore, our data compilation included only registered historic sites. Because prehistoric sites and other protected sites were excluded due to restrictions, the data used were incomplete in representation of historic and prehistoric features. Nonetheless, considerable locational information for historic scenic and recreational trails, places, and buildings on the National Register of Historic Places is available for public use and was used here. Data sources included publicly available records that provide information on historic buildings, historic districts, historic objects, historic sites, and historic structures (NPS, 2015a). Metric 1 combined records for buildings, districts, objects, sites, and structures delineated by point data (appendix table 1.3) and calculated the minimum Euclidian distance from any cell location to these features. Metric 2 combined records for buildings, districts, objects, sites, structures, and trails delineated by polygon data (appendix table 1.3) and calculated the minimum Euclidian distance from any cell location to these features. These components were processed to generate proximity surfaces (Euclidian distance) by calculating the minimum distance on a cell-by-cell basis for all data inputs, and then classifying the resulting surface at $1-\mathrm{km}, 4-\mathrm{km}, 8-\mathrm{km}, 12-\mathrm{km}$, and 16-km radial intervals. Closer proximity to one or more historic resources indicates greater potential for influence by a transportation feature, and the Cultural Resource Values Index describes the combination of Metric 1 and Metric 2 (table 1.6). In some planning contexts, cultural features may be important destinations for travelers making consideration of the proximity between resources and transportation networks dependent on the planning context. The potential impact of accessibility and pollution on sensitive cultural resources may suggest a need for alternate routes or protection of resources from proximity to roads.

\section{Integrated Land-Use Conditions}

The Land-use Condition metrics were created to represent current land-use intensity and suitability for existing and future construction. Current land-use intensity was represented by a model of the distribution of anthropogenic noise across the CONUS. The suitability (both risk and potential) of dominant soil types for different types of infrastructure were compiled to demonstrate potential opportunities or risks. Our assessment included Metric 1-Development Impact, and Metric 2Construction Suitability (see appendix tables 1.4 and 1.6). Metric 1-Development Impact highlights areas with abundant human influences (high noise impact) and areas with less human influence (low noise impact); planning considerations may include recognition of these areas as both destinations (for example, for recreation) and areas to minimize infrastructure and impacts to protect natural systems. Metric 2-Construction Suitability represents a combination of attributes provided in the Gridded Soil Survey Geographic Database (gSSURGO) of national soils data developed by the Natural Resources Conservation Service (NRCS) (NRCS, 2013).

Influence, or lack thereof, of anthropogenic influences across the CONUS, was estimated to inform the Development Impact Metric. Data combined in this metric represented development patterns and the absence of human development (remoteness) to determine places on the landscape with minimal influence of anthropogenic infrastructure and activities. Human development as indicated by noise (Metric 1; table 2), was calculated using A-weighted L50 sound pressure level data, where the sound pressure level is exceeded half of the time (NPS, 2015c). A-weighting adjusts the models to reflect how humans perceive sound; the data are a measure 
Table 2. A reclassification of the A-weighted L50 sound pressure level to conform to the integration of other land-use conditions. The U.S. Geological Survey (USGS) reclassification was based on visual inspection to preserve the level of detail where most of the data were distributed. The USGS class refers to a low, anthropogenic noise environment measured using the decibel (dB) scale, which is a logarithmic scale.

\begin{tabular}{cc}
\hline $\begin{array}{c}\text { Range } \\
(\mathbf{d B})\end{array}$ & $\begin{array}{c}\text { USGS } \\
\text { class }\end{array}$ \\
\hline $0-1$ & 10 \\
$1-2$ & 20 \\
$2-3$ & 30 \\
$3-5$ & 40 \\
$3-5$ & 50 \\
$7-9$ & 60 \\
$9-11$ & 70 \\
$11-15$ & 80 \\
$15-20$ & 90 \\
$20-33$ & 100 \\
\hline
\end{tabular}

of conditions predicted for a typical daytime hour during the summer with calm weather conditions and recognizing that sounds are generally lower at night and during the winter. Decibels $(\mathrm{dB})$, the scale of this data product, use a logarithmic scale, for example, a 3-decibel increase in background sound levels decreases your listening area by 50 percent. These NPS models predict measured sound pressure levels based on field measurements modeled using a combination of geospatial features, including topography, climate, hydrology, and anthropogenic activity. The CONUS estimates were developed using machine-learning algorithms. This report presents the NPS Impact Model, which used the difference between existing (as influenced by current land-use patterns) and natural (ambient noise levels without anthropogenic influences) to estimate the noise contributed by human activities and suggest where human disturbances are likely greatest. The NPS data, which ranged from 0-33 decibels, was classified into 10 class bins (10-100) to facilitate integration with other indices (NPS, $2015 \mathrm{c}$ ). When protection of resources is a priority, control (for example, restriction or mitigation) of human activity may be an important option for management. Therefore, minimizing effects of transportation on natural communities may include avoiding new infrastructure, managing traffic in low-noise areas or near sensitive habitats, or reducing the noise footprint in other areas through resurfacing, rerouting, or other actions.

The NRCS data (gSSURGO) were used to represent soil conditions across the CONUS. NRCS interpretation of soil attributes included classification of how soils may affect construction based on substrate conditions (Metric 2). These data reflect conditions of the dominant soil type within each Soil Survey Geographic Database map unit based on the composition of each map unit, and inclusion of minor types and conditions may exist, but not be represented, within soil classification boundaries, so local soil surveys may be required during project planning and implementation. Additionally, many dominant soil types were not assigned a constructionsuitability classification; therefore, those areas were not well informed by this metric. This metric was calculated as the median potential hazard by using four contributing data attributes, defined as ranked categories, on a cell-by-cell basis.

The NRCS classifications specify soil conditions that affect construction of local roads and streets, paths and trails, structures with basements, which potentially affect all subsurface construction, and potential erosion hazard during construction. The NRCS potential erosion hazard (road/trail) attribute (muaggatt.forpehrtdcp in gSSURGO) indicates the relative potential for erosion of the soil unit during construction and maintenance of forest roads and trails. The urban-recreation paths and trails weighted average attribute (muaggatt.urbrecptwta) provided relative rating of the map unit for use as paths and trails, expressed as a weighted average of numerical ratings for individual soil components in the map unit. The ratings are on a scale of 0.0 to 1.0 , with higher values indicating more limitations. The urban-recreation paths and trails attribute (muaggatt.urbrecptdcd) gives the rating of the dominant condition of each map unit for paths and trails based on composition of each map unit component. The engineering local roads and streets attribute (muaggatt.englrsded) is the rating of the dominant condition of each map unit for local roads and streets. The engineering dwellings with basements dominant condition attribute (muaggatt.engdwbded) provided a rating of the suitability for dwellings with basements, and although not directly related to most transportation infrastructure, this interpretation provides an indication of subsurface stability and hydrologic suitability. These five soil classifications, which identify predominant construction conditions, were combined to create Metric 2-Construction Suitability.

\section{Natural Hazards}

Some natural features and events have the potential to affect road conditions, maintenance, and safety. This report addresses a subset of the potential threats and influences for which spatial data are available. Potential hazards that may be important for transportation planning include flooding potential and geophysical hazards (karst/sinkhole potential, earthquake potential, and landslide potential). Flooding potential was evaluated based on Federal Emergency Management Agency (FEMA) records and surface soil conditions conducive to flooding, ponding, and wetlands. Several other environmental quality variables were requested by CFL, including air and water quality, and metrics representing these factors are provided, but were not included in an aggregated index due to incompatibility of the information contained in different metrics. The Natural Hazards Metrics include Metric 1-Geophysical, Metric 2-Flooding, Metric 3-Chemical/Environmental, Metric 4-Air Quality, Metric 5-Water Quality (see appendix tables 1.5 and 1.6). 
Potential geophysical hazards (Metric 1) were represented using a combination of geologic information sources, including karsts (caves and related subsurface instabilities) (Tobin and Weary, 2004), landslide potential (Godt, 1997), and earthquake potential (Hopper and others, 2005). To simplify applications and facilitate combining the different datasets for the index, the quantitative values from the data source (USGS for all three datasets) were classified into three classes: Low, Moderate, and High. Karsts (underground caves, caverns, and related geomorphic features) present considerable hazard potential for roads, structures, and human activities; however, mapping of these features and their associated potential hazards was not spatially precise. Data representing the distribution of karsts highlight areas with increased potential for sinkhole formation due to coincidence of geologic and climatic conditions that promote karst formation, which were classified using geologic information within dry-climatic or humid-climatic regions, but do not specify local details of the geologic patterns. The landslide data (Godt, 1997) are outdated, but progress on an updated product may be found at https://landslides.usgs.gov/research/. Updated information could be used to revise this index and associated information in the future.

Regional data on the potential for earthquakes (part of Metric 1) (Peterson and others, 2014; USGS, 2014b) inform many public works and construction policies regarding earthquakes, including seismic-design regulations for buildings, bridges, highways, railroads, and other structures. The data were designed to help inform building and construction codes in areas where the earthquake potential requires prudent concern. These data could be updated as the science improves and new analyses of earthquakes improve modern predictions. The data classification (table 3) presented here translated the g-force $(1 \mathrm{~g}=9.80665$ square meters per square second) scale to integer classes for display and aggregation with other metrics.

Karst potential (part of Metric 1) reflects the presence of soil and geologic profiles that are conducive to the production of sinkholes. The metric is not absolute in determinism or spatial resolution but is designed to identify where sinkholes may exist or develop (Weary and Doctor, 2014). The classification scheme for these features (table 4) was based on regional risks due to geologic formations, however these data do not discriminate localized potential for hazard within geologic units.

Landslide potential data (part of Metric 1) from Spiker and Gori (2003) included mostly dated information, but USGS (https://landslides.usgs.gov/) research and landslide potential model development is ongoing, so revised information may be available. These data were evaluated as a component of the geophysical hazards because, at most locations, the slidepotential profile does not change quickly and this information could be extremely useful for transportation planning (for example, to support avoidance of risky topography). The potential for landslides was characterized using the classification described by Spiker and Gori (2003) (table 5).

Descriptive flood potential attributes from historical observations included annual flooding frequency, percentage of unit subject to ponding (four classes: Low, Moderate-low,
Table 3. A description of the earthquake potential (minimum peak horizontal acceleration value) translated to U.S. Geological Survey (USGS) codes used for displaying and combining data.

$[\% \mathrm{~g}$, the earthquake force based on the percentage of acceleration due to gravity $(\mathrm{g})$, which is 9.80665 square meters per square second (see also https://earthquake.usgs.gov/learn/glossary)]

\begin{tabular}{|c|c|c|c|}
\hline $\begin{array}{c}\text { Source } \\
\text { data value }\end{array}$ & $\begin{array}{c}\text { Earthquake force: } \\
\text { minimum peak } \\
\text { horizontal } \\
\text { acceleration }\end{array}$ & $\begin{array}{c}\text { Risk } \\
\text { interpretation }\end{array}$ & $\begin{array}{l}\text { USGS } \\
\text { scale }\end{array}$ \\
\hline 0 & $0-2 \% \mathrm{~g}$ & None & 1 \\
\hline 2 & $2-4 \% \mathrm{~g}$ & None & 1 \\
\hline 4 & $4-6 \% g$ & Low & 2 \\
\hline 6 & $6-8 \% \mathrm{~g}$ & Low & 2 \\
\hline 8 & $8-10 \% \mathrm{~g}$ & Low & 2 \\
\hline 10 & $10-12 \% \mathrm{~g}$ & Low & 2 \\
\hline 12 & $12-14 \% \mathrm{~g}$ & Low & 2 \\
\hline 14 & $14-16 \% \mathrm{~g}$ & Low & 2 \\
\hline 16 & $16-18 \% \mathrm{~g}$ & Low & 2 \\
\hline 18 & $18-20 \% \mathrm{~g}$ & Low & 2 \\
\hline 20 & $20-30 \% \mathrm{~g}$ & Moderate & 3 \\
\hline 30 & $30-40 \% \mathrm{~g}$ & Moderate & 3 \\
\hline 40 & $40-50 \% \mathrm{~g}$ & High & 4 \\
\hline 50 & $50-60 \% \mathrm{~g}$ & High & 4 \\
\hline 60 & $60-80 \% \mathrm{~g}$ & High & 4 \\
\hline 80 & $80-120 \% \mathrm{~g}$ & High & 4 \\
\hline 120 & $120-160 \% \mathrm{~g}$ & High & 4 \\
\hline 160 & $160-200 \% \mathrm{~g}$ & High & 4 \\
\hline 200 & $>200 \% \mathrm{~g}$ & High & 4 \\
\hline
\end{tabular}

Moderate-high, and High), percentage of the unit with a hydric (wetland soils) rating (same four classes), and FEMAdefined flood zones. This information was combined to create Metric 2. The FEMA zones were classified into four classes: Moderate to low risk, High risk, High risk coastal, and Undetermined risk. These data were combined to determine Metric 2: (1) flood frequency (Low, High, and Unknown risk) and (2) percentage of area with ponding or wetland potential (Low, High, and Unknown risk).

A classification scheme based on historical events and relations between topography, hydrology, and FEMAidentified national flood hazards (part of Metric 2) was used to identify the greatest risk among potential hazards. The eight levels described by FEMA (2015a and b) were converted into four classes for integration with other potential hazards (table 6).

Attributes of major soil units from gSSURGO (NRCS, 2013) summarized the potential occurrence of ponding, 
Table 4. A description of the likelihood of karsts forming on the landscape and the crosswalk for combining data. Interpretation adapted from Weary and Doctor (2014).

[USGS, U.S. Geological Survey]

\begin{tabular}{|c|c|c|c|}
\hline $\begin{array}{l}\text { Data } \\
\text { value }\end{array}$ & Description & $\begin{array}{c}\text { Risk } \\
\text { interpretation }\end{array}$ & $\begin{array}{l}\text { USGS } \\
\text { scale }\end{array}$ \\
\hline No data & Karsts do not exist & None & 1 \\
\hline 2 & Karsts not occurring in High risk States, and found in dry climates & Moderate & 3 \\
\hline 3 & Karsts not occurring in High risk States, but are found in humid climates & Moderate & 3 \\
\hline
\end{tabular}

Table 5. A description of the incidence of landslides and the crosswalk for combining data. (Adapted from Spiker and Gori, 2003.)

[COMBO-HIGH, high susceptibility and incidence; INC-HIGH, high incidence; INC-LOW, low incidence; INC-MOD, moderate incidence; SUS-HIGH, high susceptibility; SUS-MOD, moderate susceptibility; USGS, U.S. Geological Survey]

\begin{tabular}{clcc}
\hline $\begin{array}{c}\text { Source } \\
\text { data value }\end{array}$ & \multicolumn{1}{c}{ Description } & $\begin{array}{c}\text { Risk } \\
\text { interpretation }\end{array}$ & $\begin{array}{c}\text { USGS } \\
\text { scale }\end{array}$ \\
\hline No data & Landslides not identified & None & 1 \\
INC-LOW & Low incidence of landslides & Low & 2 \\
SUS-MOD & Moderate susceptibility to landslides & Moderate & 3 \\
INC-MOD & Moderate incidence of landslides & Moderate & 3 \\
SUS-HIGH & High susceptibility to landslides & High & 4 \\
INC-HIGH & High incidence of landslides & High & 4 \\
COMBO-HIGH & Both incidence and susceptibility are high & High & 4 \\
\hline
\end{tabular}

flooding, and wetlands. These data represent an amalgamation of past climatic events and local effects based on historical observations and soil conditions. Planners should not use these data to predict the timing or amount of future ponding or flooding. However, the data can be important for transportation planning because these soil conditions reflect the response of the substrate to weather and climate. Flood frequency potential (part of Metric 2) represents the annual probability of a flood event based on the dominant flood frequency class (muaggatt. flodfreqded attribute in gSSURGO); it was assigned to a component of the map unit with a composition greater than or equal to 15 percent of the map unit area. The data classified by NRCS as classes 1-7 (NRCS, 2013) were converted into four classes (1-4) for integration with other potential hazards (table 7).

Ponding frequency and wetland potential were combined to illustrate the presence of hydric soils and flooding potential that may affect construction, maintenance, and safety (part of Metric 2). Ponding frequency (muaggatt.pondfreqprs attribute in gSSURGO) is the percentage of the map unit that is subject to water ponding on the soil surface, expressed as one of four classes: Class 1: 0-14 percent, Class 2: 15-49 percent, Class 3: 50-74 percent, and Class 4: 75-100 percent. The potential wetland soil extrapolated across the landscape (pwsl1pomu attribute in gSSURGO) represents the percentage of each map unit (polygon) that meets the criteria for a potential wetland soil landscape (PWSL). According to NRCS guidance, the classification process included the following considerations:

- The percentage of the map unit that meets the PWSL criteria was identified. The hydric rating (soil component attribute "hydric rating") was used as the indicator of wet soils.

- Those soil components that met the criteria were tagged as PWSL and their percentage of the map unit (comppct_r attribute in gSSURGO) values were summed for each map unit. Soil components with hydric rating = "YES" are considered PWSL. Soil components with hydric rating $=$ "NO" are not PWSL.

- Soil components with hydric rating = "UNRANKED" were tested using other attributes, and are considered PWSL if any of the following conditions are met: drainagecl attribute $=$ "Poorly drained" or "Very poorly drained," or the localphase or otherph attribute fields contained descriptions including, "drained," "undrained," "channeled," "protected," "ponded," or "flooded." 
Table 6. A description of Federal Emergency Management Agency (FEMA) flood hazards and the crosswalk for combining data. (Zone definitions and interpretation from FEMA, 2015a and 2015b.)

[\%, percent; FIRM, Flood Insurance Rate Map; USGS, U.S. Geological Survey]

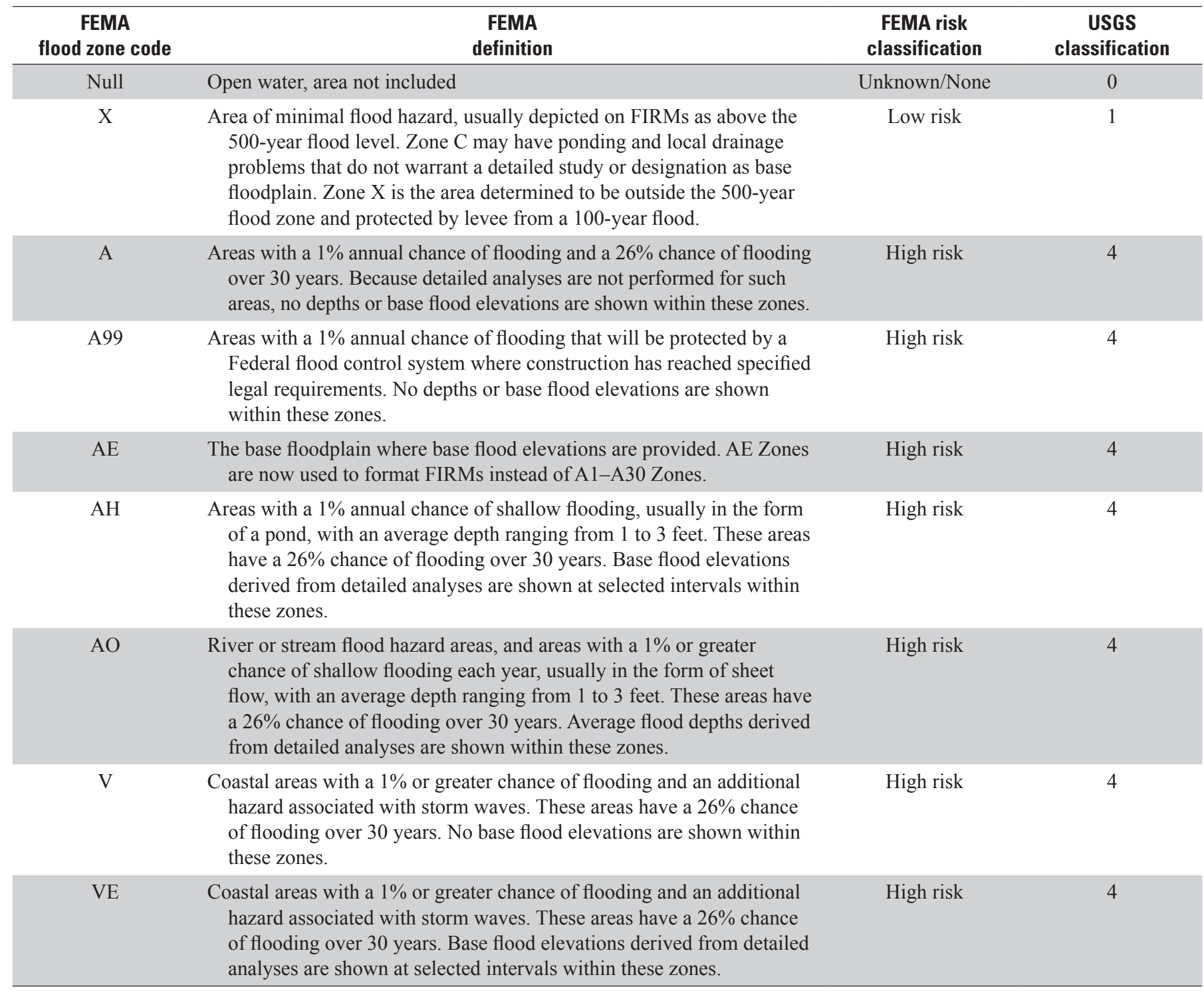

Table 7. The Natural Resources Conservation Service (NRCS) delineation of flood frequency from the Gridded Soil Survey Geographic Database (gSSURGO) of national soils data and the U.S. Geological Survey (USGS) crosswalk for classifying data. (NRCS data from NRCS, 2013.)

\begin{tabular}{cccc}
\hline $\begin{array}{c}\text { NRCS } \\
\text { code }\end{array}$ & $\begin{array}{c}\text { NRCS } \\
\text { classification }\end{array}$ & $\begin{array}{c}\text { USGS } \\
\text { risk interpretation }\end{array}$ & $\begin{array}{c}\text { USGS } \\
\text { classification }\end{array}$ \\
\hline Blank & 1 & None & 0 \\
None & 2 & None & 0 \\
Very rare & 3 & Low risk & 1 \\
Rare & 4 & Low risk & 1 \\
Occasional & 5 & Moderate risk & 2 \\
Frequent & 6 & High risk & 3 \\
Very frequent & 7 & High risk & 4 \\
\hline
\end{tabular}


- If these criteria do not determine the PWSL for a component and the hydric rating is "UNRANKED," the map unit was classified as PWSL if the map unit name contained any of the descriptions "drained," "undrained," "channeled," "protected," "ponded," or "flooded."

- Waterbodies were identified as "999" if the map unit names matched a list of terms that identified perennial, permanent, or intermittent water, or when map units have a sum of the attribute comppct_r for "Water" that is 80 percent or greater.

- NULL values are presented where data are incomplete or not available.

A classification scheme (table 8) was used to systematically describe hazard potential based on the greatest potential among all hydrologic hazards. Thus, ponding frequency and wetland potential (part of Metric 2) were integrated by selecting the highest rank (USGS classification) on a cell-by-cell basis and assigning this as the hazard risk value. Metric 2Flooding was developed using the aggregated hazards metric (Metric 2a), which was based on FEMA flood hazards and NRCS flood frequency potential, and the percentage area of ponding frequency and wetland potential (part of Metric 2). The maximum rank (risk of potential hazard) was determined on a cell-by-cell basis and assigned this maximum value to each cell location.

Another component of potential climatic hazards is storm damage associated with extreme weather. The probability of storm occurrence and potential for damage can be estimated using National Oceanic and Atmospheric Administration data on the frequency of hurricanes, tornadoes, hail, and ice storms. We intended to develop an integrated metric to capture storm events and hazards associated with hurricanes, tornadoes, ice storms, strong wind events, and lightening occurrences because these events can have a direct influence on transportation networks and planning. However, developing accurate probability surfaces and hazard potential for each available dataset proved to be too complicated for the current project. Information on air quality information was requested by CFL planning staff; therefore, annual information describing the amount and distribution of particulate pollutants from 19982012 (van Donkelaar and others, 2015) was summarized to provide a spatial representation of regions with "Low," "Moderate," or "High" potential for air-quality threats to people. These data were not used in aggregated metric calculations.

EPA data on chemical and environmental risks identified facilities that were hubs for transportation of hazardous materials according to 2015 records (EPA, 2015a) (Metric 3). Definitions were acquired from the EPA Facility Registry Service documentation at https://www.epa.gov/enviro/facilityregistry-service-frs (EPA, 2015a). EPA-registered facilities from the Facility Registry Service that were transportation hubs for hazardous chemicals (11,904 facilities) were mapped and Euclidean distance from each pixel to the nearest hub was calculated and classified to estimate the potential for influence on environmental quality and transportation network safety (table 9). In most cases, potential contamination is expected to be contained within 25 feet of facilities; however, transportation networks surrounding these hubs receive traffic from vehicles moving hazardous materials.

Air quality (Metric 4) reflects the recent (1998-2012) history of air pollution compiled and summarized from National Aeronautics and Space Administration remotely sensed models (van Donkelaar and others, 2015). Past occurrences do not necessarily project future occurrences of highlevel pollution due to potential changes in many contributing factors. However, these data may be used to understand better the distribution of areas with concentrated air pollutants due to human activities (including, but not limited to, automobile emissions on roads). Transportation planners may want to consider how transportation networks may be associated with current and future patterns of air pollution. The EPA aggregates information from monitoring stations across the United States to provide local measurements and spatial models of

Table 8. Ponding frequency and wetland potential delineations from the Natural Resources Conservation Service (NRCS) Gridded Soil Survey Geographic Database (gSSURGO) of national soils data and the crosswalk for U.S. Geological Survey (USGS) classification of the data. (NRCS data from NRCS, 2013)

$[\%$, percent $]$

\begin{tabular}{cccc}
\hline $\begin{array}{c}\text { NRCS percent } \\
\text { ponding area }\end{array}$ & $\begin{array}{c}\text { NRCS percent } \\
\text { wetland area }\end{array}$ & $\begin{array}{c}\text { NRCS } \\
\text { classification }\end{array}$ & $\begin{array}{c}\text { USGS } \\
\text { classification } \\
\text { for ponding and } \\
\text { wetland area }\end{array}$ \\
\hline No data or blank & No data-999 & 5 & 0 \\
$0-14 \%$ & $0-14 \%$ & 1 & 1 \\
$15-49 \%$ & $15-49 \%$ & 4 & 2 \\
$50-74 \%$ & $50-74 \%$ & 3 & 3 \\
$75-100 \%$ & $75-100 \%$ & 2 & 4 \\
\hline
\end{tabular}


Table 9. Classification of proximity (distance) from each pixel to hazardous materials transportation hubs as documented by the U.S. Environmental Protection Agency (EPA). (EPA data from EPA, 2015a.)

[USGS, U.S. Geological Survey]

\begin{tabular}{cc}
\hline $\begin{array}{c}\text { Distance to facility } \\
\text { (meters) }\end{array}$ & $\begin{array}{c}\text { USGS } \\
\text { classification }\end{array}$ \\
\hline $0-4,000$ & 4 \\
$4,000-12,000$ & 3 \\
$12,000-30,000$ & 2 \\
$>30,000$ & 1 \\
No data & No data \\
\hline
\end{tabular}

particulate matter (PM). The data here provide an indication of air pollution levels based on the years included in the records (1998-2012) (van Donkelaar and others, 2015). Thus, Metric 4 reflects the global, annual raster datasets of PM smaller than or equal to 2.5 micrometers in diameter $\left(\mathrm{PM}_{2.5}\right)$ from remotely sensed imagery. The source datasets include a series of 3-year running means that were used to calculate mean pollution values across all years of record (1998-2012) based on fine PM (solid particles and liquid droplets) estimates that were derived from a combination of Moderate Resolution Imaging Spectroradiometer, Multi-Angle Imaging SpectroRadiometer, and Sea-Viewing Wide Field-of-View Sensor Aerosol Optical Depth satellite retrievals by the National Aeronautics and Space Administration (van Donkelaar and others, 2015). Also known as particle pollution, PM, is a complex mixture of extremely small particles and liquid droplets. Particle pollution is composed of a number of components, including acids (such as nitrates and sulfates), organic chemicals, metals, and soil or dust particles. Particles that are smaller than 10 micrometers, which are referred to as " $\mathrm{PM}_{10}$," are harmful to humans because they accumulate in the respiratory system when inhaled, but smaller particles $\left(\mathrm{PM}_{2.5}\right)$ result in the greatest risk because they lodge more deeply in the lungs. As a reference, $\mathrm{PM}_{2.5}$ is one-thirtieth of the diameter of the average human hair. More information about PM is provided by the EPA at https://www.epa.gov/particle-pollutiondesignations, and information about the National Aeronautics and Space Administration surfaces, which is available at http://sedac.ciesin.columbia.edu/data/set/sdei-global-annualavg-pm2-5-2001-2010, can provide greater insights for interpretation. Information about interpreting the PM values was obtained from AirNow's Air Quality Index Basics web site at http://www.airnow.gov/index.cfm?action=aqibasics.aqi. The raster surfaces presented in this report were based on annual measurements, and they should be interpreted using a qualitative scale, with reference to the source data if greater specificity is required. To support this interpretation, a classification scheme was used to convert the abundance of small particles $\left(\mathrm{PM}_{2.5} ; 0-2.5\right.$ micrometers) to an index (table 10).

Water Quality (Metric 5) can inform understanding of historical and current water impairments, such as the presence
Table 10. Global, annual abundance of particulate matter smaller than or equal to 2.5 micrometers in diameter $\left(\mathrm{PM}_{2.5}\right)$ and the U.S. Geological Survey (USGS) classification used for combining data. (Data source: van Donkelaar and others, 2015.)

\begin{tabular}{ccc}
\hline Abundance of PM $_{\mathbf{2 . 5}}$ & Interpretation & $\begin{array}{c}\text { USGS } \\
\text { scale }\end{array}$ \\
\hline $0-12$ & Good & 1 \\
$12.1-35.4$ & Good & 1 \\
$35.5-55.4$ & Good & 1 \\
$55.5-150.4$ & Moderate & 2 \\
$150.5-250.4$ & Unhealthy & 3 \\
$250.5-1,000$ & Hazardous & 4 \\
\hline
\end{tabular}

of pollutants from various sources and in multiple combinations, according to the EPA. Contaminated waters listed under Section 303(d) of the Federal Clean Water Act may present opportunities for restoration and (or) mitigation, whereas more pristine waters represent opportunities for shoreline and rivercrossing protection to minimize new impacts to watercourses, lakes, and ponds. This information may be important for transportation planning because current roads and trails may contribute to current impairment status, and new or modified roads and trails may affect the condition of more pristine waters. The EPA tracks water quality through monitoring and provides this information to the public. Section 303(d) of the Federal Clean Water Act, and its implementing regulations (40 Code of Federal Regulations part 130) require each State to develop a list of waters that are not attaining water-quality standards and are not expected to meet State water-quality standards even after application of technology-based controls for point sources or other control requirements, such as best management practices, for nonpoint sources of pollution. Currently, States are required to submit their 303(d) lists to EPA every 2 years.

A combined metric (HZ5) was used to combine three different feature types, specifically point, line, and polygon features, and thereby represent the shortest distance from any given location to any 303(d)-designated waters on a cell-bycell basis. Smaller class values (table 10) represent potentially less sensitive areas because of their proximity to already polluted waters; conversely, effects of roads and trails on water quality might indicate that avoidance or mitigation may be needed to improve water quality, or to avoid impairment. These classes were identified so that they match the scale used for the other hazard indices. The linear-based metric for HZ5 represents the Euclidean distance to all 303(d) line features (rivers and streams). The point-based metric for HZ5 represents the Euclidean distance to all 303(d) point features. The polygon-based metric for HZ5 is the Euclidean distance to the boundary of all 303(d) polygon features. The combined index (HZ5 303d) is a reclassification of the combination of all three Euclidean distance surfaces using a schema that converts distances (less than $1,000 \mathrm{~m}$ to greater than $4,000 \mathrm{~m}$ ) to an index rank of 4-1, which was inverted so that shorter distances receive higher scores (table 11). 
Table 11. Distance in meters to U.S. Environmental Protection Agency (EPA) Section 303(d) listed contaminated waters and a crosswalk for combining the data. (EPA data from EPA, 2015b)

[USGS, U.S. Geological Survey]

\begin{tabular}{ccl}
\hline $\begin{array}{c}\text { Distance to } \\
\text { polluted water } \\
\text { feature (meters) }\end{array}$ & $\begin{array}{c}\text { USGS } \\
\text { ranking }\end{array}$ & \multicolumn{1}{c}{ Interpretation } \\
\hline $0-1,000$ & 4 & Greatest aquatic pollution potential \\
$1,000-2,000$ & 3 & Moderate aquatic pollution potential \\
$2,000-4,000$ & 2 & Low aquatic pollution potential \\
$>4,000$ & 1 & Least aquatic pollution potential \\
\hline
\end{tabular}

\section{Terrain Metrics}

We developed hydrologically corrected elevation data to inform planning, but these data are not directly included in the resource value and hazard indices. The data were included in a separate category because they are landscapelevel representations of factors that may affect transportation planning and potentially influence network construction and maintenance, but they did not fit with other metrics. The source digital elevation models (DEMs) were corrected for hydrologic accuracy by filling the sinks using the Optimized Pit Removal software developed by Texas A\&M University (Soille, 2004). We created the CONUS terrain products using USGS 30-meter DEMs (USGS, 2006), and then hydrologically corrected this elevation model before generating the derived topographic indices representing aspect, elevation, slope, and ruggedness (an indicator of topographic variability) (table 1.6).

Many derivatives of DEMs exist and each can provide different information that can serve multiple applications and planning. USGS used the Geospatial Data Abstract Library software (Geospatial Data Abstract Library, 2014) to derive one metric, the ruggedness of the terrain. The Geospatial Data Abstract Library uses methods described by Wilson and others (2007) for the indices developed for this project. The Terrain Ruggedness Metric measures the local variation of the terrain surrounding a central pixel. The absolute values of the differences between each neighboring pixel ( 3 by 3 kernel) and the central pixel were averaged to produce an output value for each pixel in the DEM. This index can have biological importance to many species and can provide information for transportation network planning, by enabling assessment of the potential complexity of construction and maintenance due to topography.

\section{Results}

\section{Terrestrial Resource Values}

The cumulative Terrestrial Resource Values Index (fig. 3) provides an intuitive, synthetic view useful for large landscape planning areas (for example, region or State) allowing users to quickly assess distribution of natural values relative to the larger landscape. Multiple variations for calculation of the cumulative index were considered by using equations that were either equally balanced (each metric contributing equally) or weighted (increasing or decreasing the influence of metrics). Using weighted equations is suggested because they provide consistent spatial resolution of regional differences, however an equally weighted alternative was provided for comparison (fig. 3). The perspective provided by the index and contributing metrics should help planners identify portions of a transportation network (or specific segments) that overlap with potentially sensitive resources. Details of the type of resources present may be identified by considering the metrics and source datasets used to calculate the cumulative index (table 1.1), which may provide more specific information for planning steps that require more detail. The contributing metrics and source data may be important for informing specific planning questions or concerns, whereas the cumulative index enables recognition of landscape patterns and regional context.

Although important information remains available to users (planners and managers) in the multitude of datasets informing our indices, the cumulative Terrestrial Resource Values Index provides an intuitive, synthetic view of a landscape-level planning area that allows users to assess the distribution of values relative to a larger landscape quickly, and within a planning area. Assessment of the principal causes of the index score for any particular area requires consideration of the source data and metrics used to calculate the aggregated index.

Species and diversity distributions were estimated based on source data that represent species ranges instead of specific habitat associations and specific occurrence locations. Importantly, while expert opinions were used to define species ranges, field observations also inform the range maps provided by the IUCN (2013) and NatureServe (2014). Because the range maps encompass broad regions that include heterogeneous habitats, each species may be expected to occur within the bounds of representative data units (for example, polygons) but not necessarily in all locations within any given range. Therefore, these data and our derived Metric 1 (Species Diversity) provide an indication of potential diversity and occurrence of sensitive, threatened, and other species of interest or concern (fig. 4). Local information and further evaluation based on locally identified habitats, wildlife behaviors (for example, specific habitat associations or response to roads), and projectspecific surveys will be required to discern potential influences of transportation networks and other human activities on particular species. Regional and local planning efforts will often benefit from, or require, more specific information about particular species distributions and related, local regulations. 


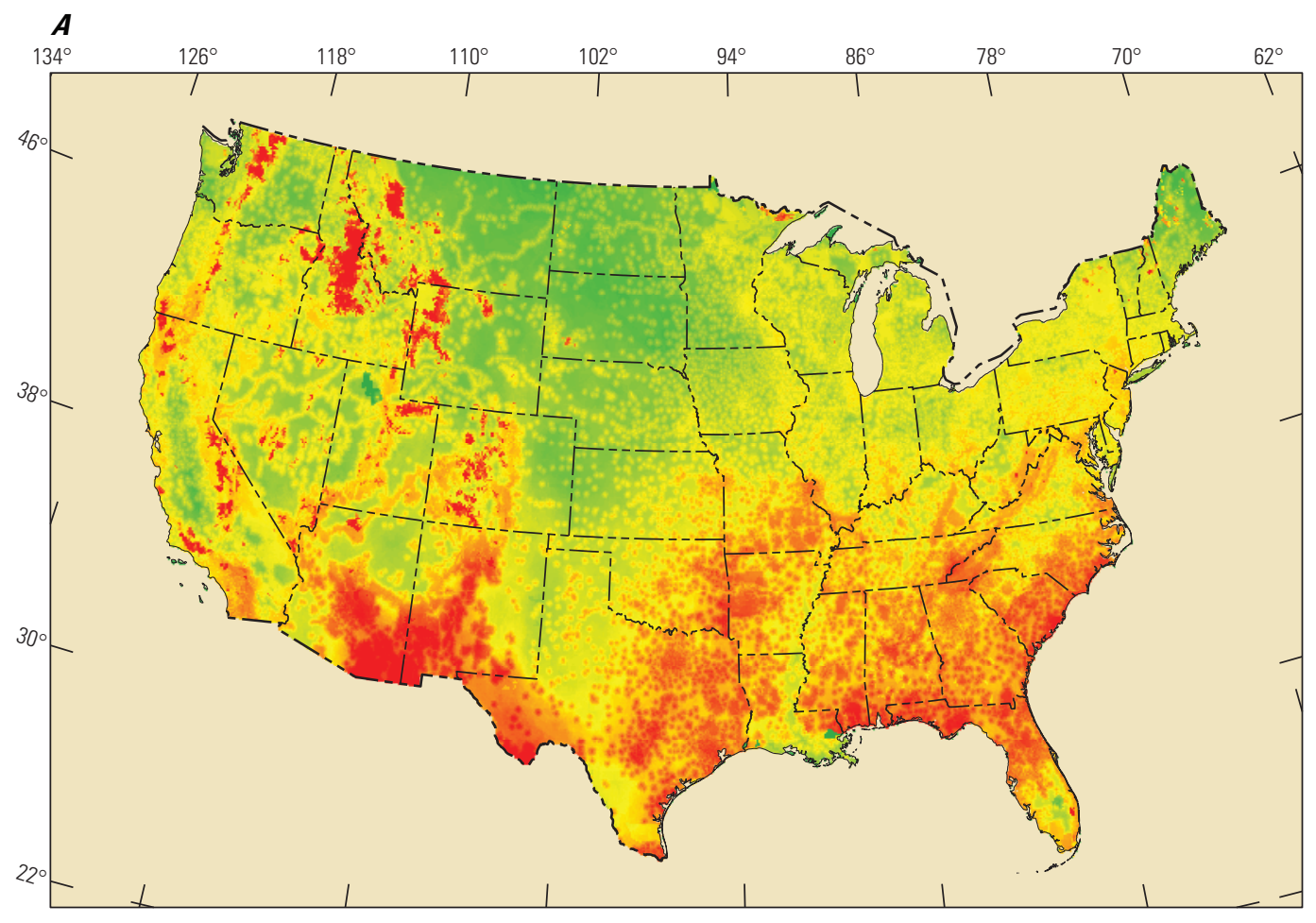

EXPLANATION

Index Score
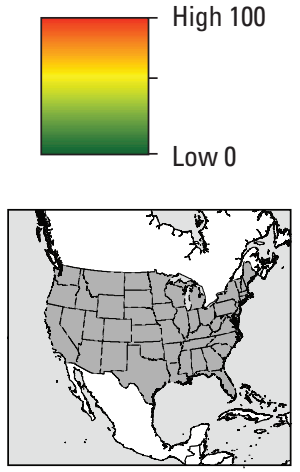

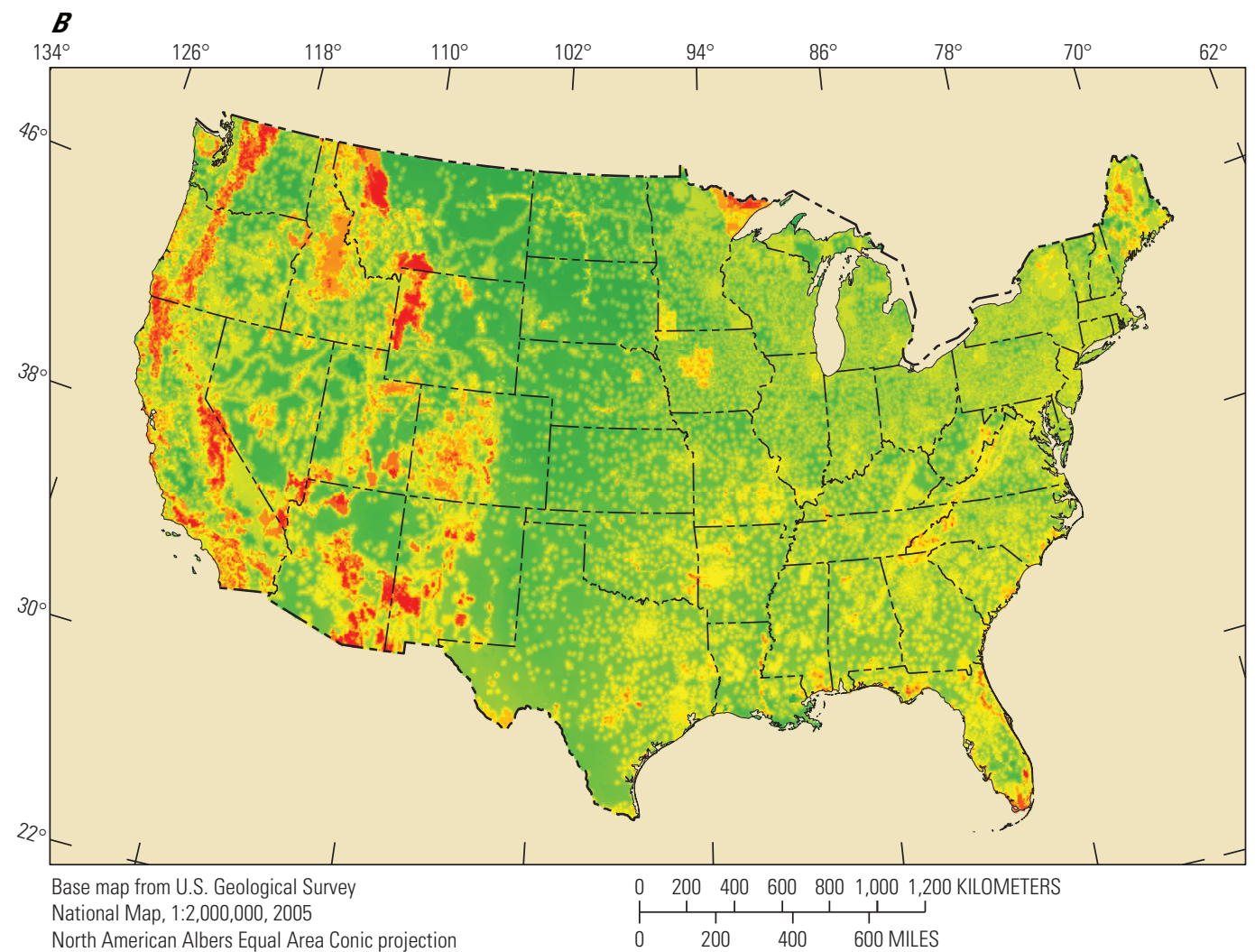

North American Albers Equal Area Conic projection

Standard parallels $20^{\circ} \mathrm{N}$. and $60^{\circ} \mathrm{N}$.

Central meridian $96^{\circ} \mathrm{W}$.

North American Datum of 1983

Figure 3. Aggregated Terrestrial Resource Values Index using two alternative methods. $A$, Terrestrial weighted (suggested). $B$, Terrestrial equally weighted and normalized (alternative). The two methods provide different approaches to combining the individual metrics that make up the aggregated version. Each metric includes information from numerous data sources (see table 1.1). The color ramps represent lower scores in green (less sensitive to development), moderate scores in yellow, and higher scores in red (more sensitive to development or greater recreational opportunity). 

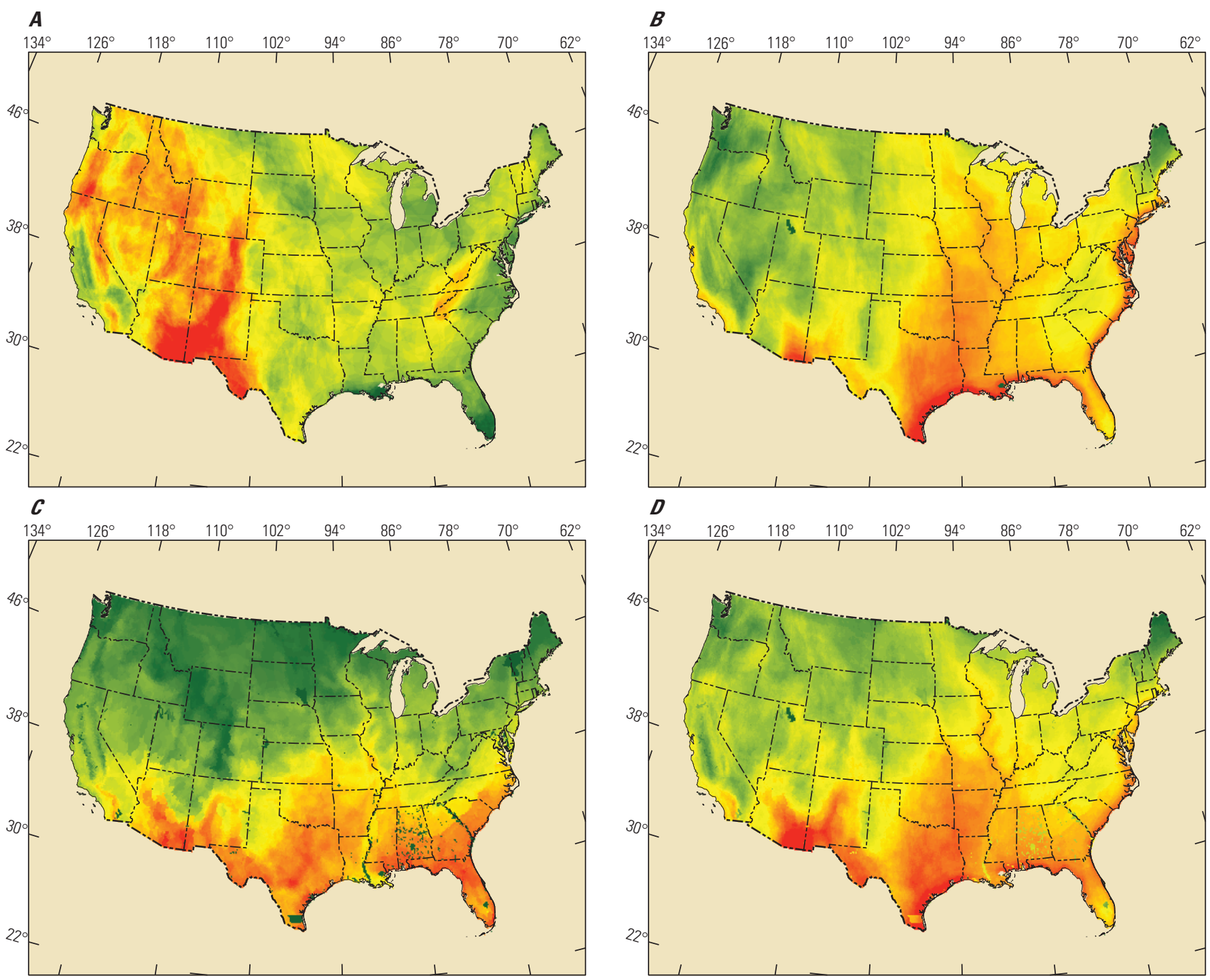

Base map from U.S. Geological Survey National Map, 1:2,000,000, 2005

North American Albers Equal Area Conic projection Standard parallels $20^{\circ} \mathrm{N}$. and $60^{\circ} \mathrm{N}$.
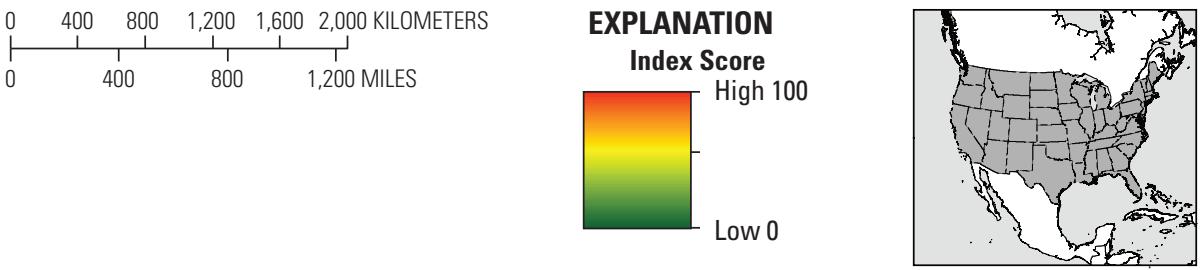

Figure 4. Terrestrial Resource Values Index, Metric 1 -Species Diversity inputs. A, Mammals. B, Birds. C, Reptiles. D, Mammals, birds, and reptiles combined. Each metric includes numerous data inputs (see table 1.1). The color ramps represent low count (less species diversity) in green, moderate in yellow, and higher counts (greater diversity) in red. 
The metrics used to calculate the Terrestrial Resource Values Index, Metric 2a-Critical Habitat (fig. 5), Metric 2b-Conservation Areas (fig. 6), and Metric 3Social Designations (fig. 6) are similar to the diversity metric (Metric 1-Species Diversity; fig. 4) because they represent the distribution of natural values based on biotic conditions. However, they are also distinct because they are land-unit based and also reflect social and (or) management values, including research areas, important habitats, wilderness, and conservation designations. Although locations identified by these indices may overlap in some areas, overlap between designated protections and an abundance of species is treated as additive in cumulative indices. Rather than "double counting," cumulative indices may be interpreted to represent the value added for species and conservation because of this overlap; thus, the combination of multiple lines of evidence is used to distinguish increased potential value and sensitivity to development. Specific decisions differentiating protected diversity from unprotected diversity (based on coincidence of diversity values and natural values) remain the purview of local planners and managers and may be project specific. For some planning applications, it may be useful to consider these metrics individually so that particular resources of interest or concern can be directly addressed during planning.

Designations of social values connected to natural areas and features (Metric 3) exist to facilitate human interaction with nature, and therefore may be important features within a transportation network. Areas with social values are not necessarily areas to be avoided due to conservation concerns, but rather may require special considerations for balancing use levels, impacts, and the anticipated user experience. Similar to Metrics 1 and 2, the social designations metric (Metric 3) was treated additively to calculate the Terrestrial Resource Values Index to allow overlapping designations to include an increase in the index score in areas with multiple lines of evidence for potential sensitivity and (or) need for additional planning focus. Similar to the habitat values, it may be useful to consider Metric 3 independently because features represented here may be important as transportation destinations in addition to their natural values (fig. 6).

Data and information sources for species and habitat distributions varies, and proper use and interpretation of our indices and their implications may require understanding of the attributes of the source data. For example, the specificity of information in datasets is indicated by the spatial resolution (horizontal accuracy) and creation methods and content (attribution), and matching this information to project or planning needs is necessary for appropriate interpretation of the data (see table 1.1 for resolution of source data). Within the Terrestrial Resource Values Index, it is important to consider the coarse resolution of the source models and use this information to recognize only broad patterns in species diversity. Subsequent consultation of local data for more specific species distribution and habitat designation information is suggested when species of conservation concern, Endangered Species Act-listed species, or other species of management interest may be affected. Consulting original documentation is suggested and a brief description of data representing species and habitat distributions is provided in table 1.1. Additional information may be obtained from the original sources, and their URLs are provided in table 1.1.

\section{Use and Limitations}

The data provided with this report are based on estimated, and modeled, distributions of species (for example, species ranges but not specific habitat associations) and as such, they do not provide precise locations of species or species habitats. Although these data cannot be used to infer specific locations where a species may be found, they are very useful for identifying regional patterns of relative abundance and recognizing the suite of species that may be present within a planning unit. Further, the diversity metrics we developed may be used to provide a general perspective on the relative distribution of species. Because inventories and spatial data are likely incomplete, and we do not represent absolute richness or diversity in this report, users must assume that these data contain a representative sample of total biological diversity. For specific applications, it may be important to take careful note of the scale of each data input and interpret aggregated indices based on resolution of the inputs (see "Scale/resolution" field in appendix tables 1.1 to $1.5)$ because coarse-scale data should not be used to make fine-scale inferences. Primary data from the IUCN (2013) and NatureServe (2014) may not be redistributed, but secondary products may be distributed. The specific requirements and (or) limitations on suitable use and distribution of these data are available from the data sources.

\section{Aquatic Resource Values}

Interpretation of the Aquatic Resource Values Index may consider any one, or a combination, of buffer distances for more specific interpretation related to a species or anticipated impact. The data produced by the index, and contributing metrics, demonstrate the relative distribution of species and habitat abundance that may be used as evidence of the pattern of aquatic values and sensitivity across the United States, and landscapes within the CONUS. The aggregation of the metrics is useful for general planning questions (fig. 7), and details provided by individual metrics (figs. 8 and 9) will likely be useful for specific situations, such as avoiding areas with critical habitats or high species diversity versus providing accessibility to destinations with social and recreational values. Spatial representation of source data may facilitate interpretation of the index and metrics for application related to specific values or concerns (for example, streams and rivers as opposed to the collection of aquatic values).

Metric 1-Species Diversity for the Aquatic Resource Values Index (fig. 8) represents the distribution of fish diversity across the CONUS. This metric also provides information 

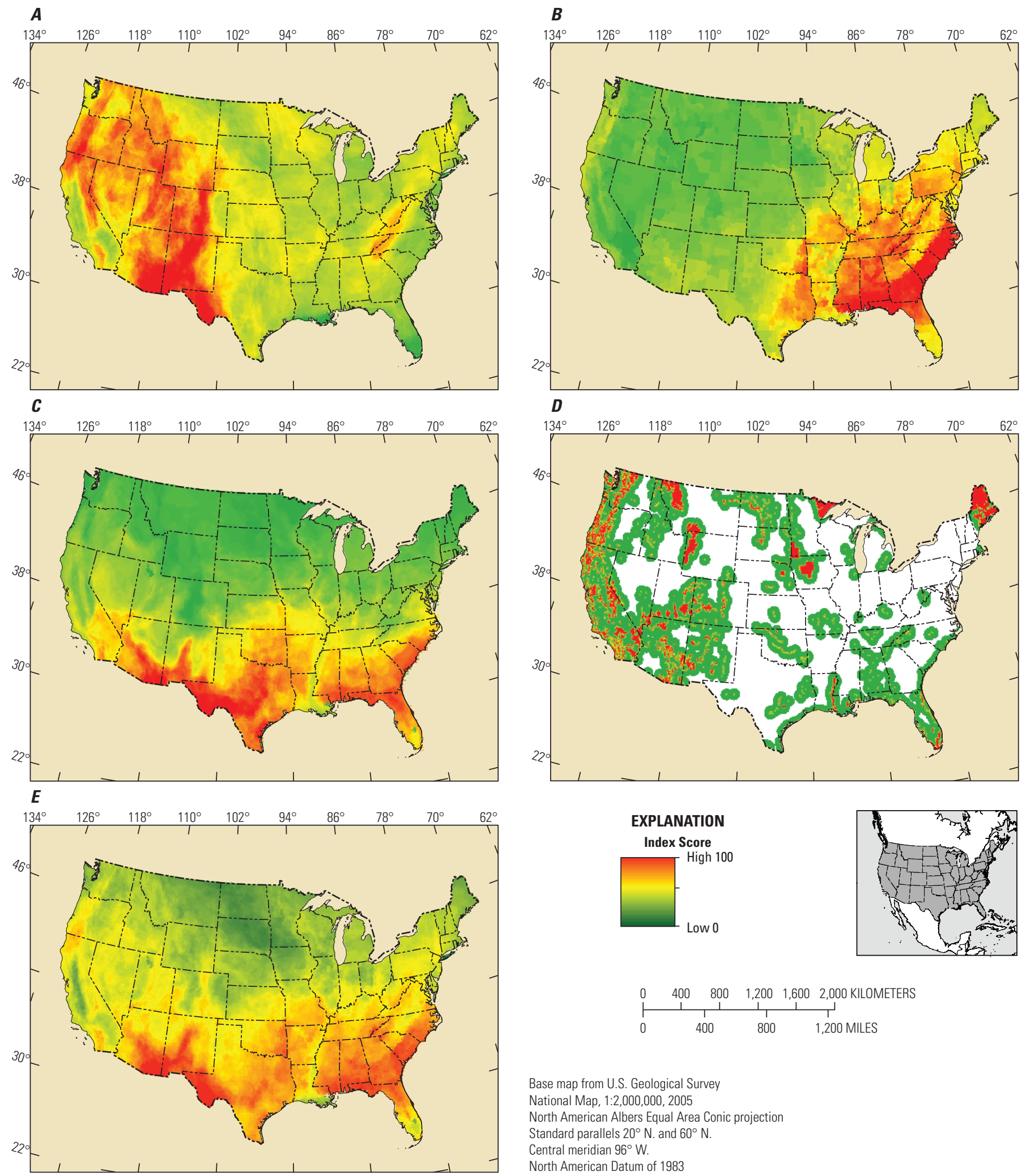

Base map from U.S. Geological Survey

National Map, 1:2,000,000, 2005

North American Albers Equal Area Conic projection

Standard parallels $20^{\circ} \mathrm{N}$. and $60^{\circ} \mathrm{N}$

Central meridian $96^{\circ} \mathrm{W}$

North American Datum of 1983

Figure 5. Terrestrial Resource Values Metric 2a - Inputs of critical habitat for threatened and endangered, or globally sensitive, species of $A$, mammals; $B$, amphibians; and $C$, reptiles. $D$, Distance to U.S. Fish \& Wildlife Service-designated critical habitats. E, Combined metric for habitat-Metric 2a. Each metric includes numerous data (see table 1.1). The color ramps represent lower count or larger distances (lesser importance) in green, intermediate count or distances in yellow, and higher count or smaller distances (greater importance) in red. 


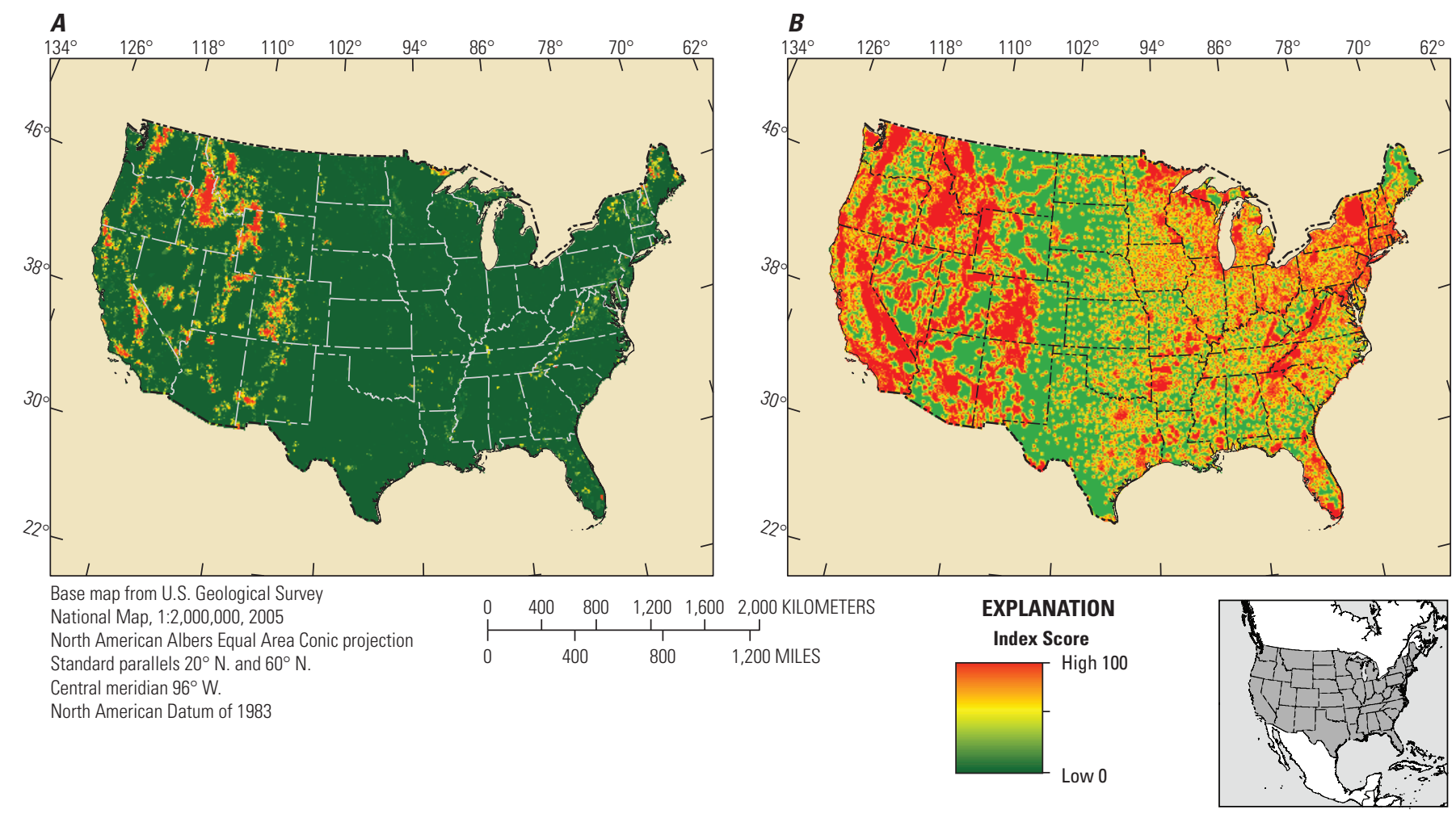

Figure 6. Terrestrial Resource Values Index inputs. A, Metric $2 b$-Conservation Areas. B, Metric 3 -Social Designations. Each metric includes numerous data (see table 1.1). The color ramps represent low count/larger distances (lesser importance) in green to higher count/smaller distances (greater importance) in red.

on the proximity of upland areas to nearby wetlands and water features because wetlands, ponds, rivers, reservoirs, and other water features are affected by surrounding land use and are important for most terrestrial species that occupy surrounding lands, including people.

Without specifying detailed impacts of upland developments and human land use on local wetlands, the natural values metrics (Metrics 2a and 2b; fig. 8) help identify where a transportation network may influence water quality, wetlands, and aquatic habitats based on proximity to aquatic features. Within this model, closer proximity to water and wetland features was assumed to incur greater potential for impacts due to altered hydrology, sedimentation, pollutants, noise, and human activities. The distance at which impacts may occur will vary depending on topography, land cover, land use, soils, and other local factors, so this index should be used as an indicator of relative potential for impacts.

Designations of social importance (Metric 3-Social Designations; fig. $9 A$ ) contributed to the evaluation of aquatic values, but may also be important as social nodes in a transportation network. The Landscape-Scale Water Quality Metric (Metric 4; fig. 9B) was based on EPA sampling and water-quality models and larger scores represent greater impairment of waters. From the perspective of transportation planning, it may be most important to recognize areas with few physical and chemical impairments because adding roads and other human infrastructure to these areas would be likely to change those conditions. However, it may also be useful to consider changing transportation networks in areas where altering the land-use footprint could improve water quality. Similar to the Terrestrial Resource Values Index and its associated metrics, the Aquatic Resource Values Index may be most useful when considered with one or more metrics in addition to the aggregated index, for example, to provide specific information about proximity to particular aquatic and wetland habitats.

\section{Use and Limitations}

The data included with this report were based on estimated, and modeled, distributions of species and as such, they do not provide precise locations of species or species habitats, so these results cannot be used to infer specific locations where a species may be found. Further, the distribution of aquatic and wetland species is restricted to areas with sufficient hydrologic conditions; however, data are typically associated with a designated reach (length of stream) or water body. Because of these limitations, the distribution of aquatic species is approximated by the data that represent distributions using coarse scales and cannot 


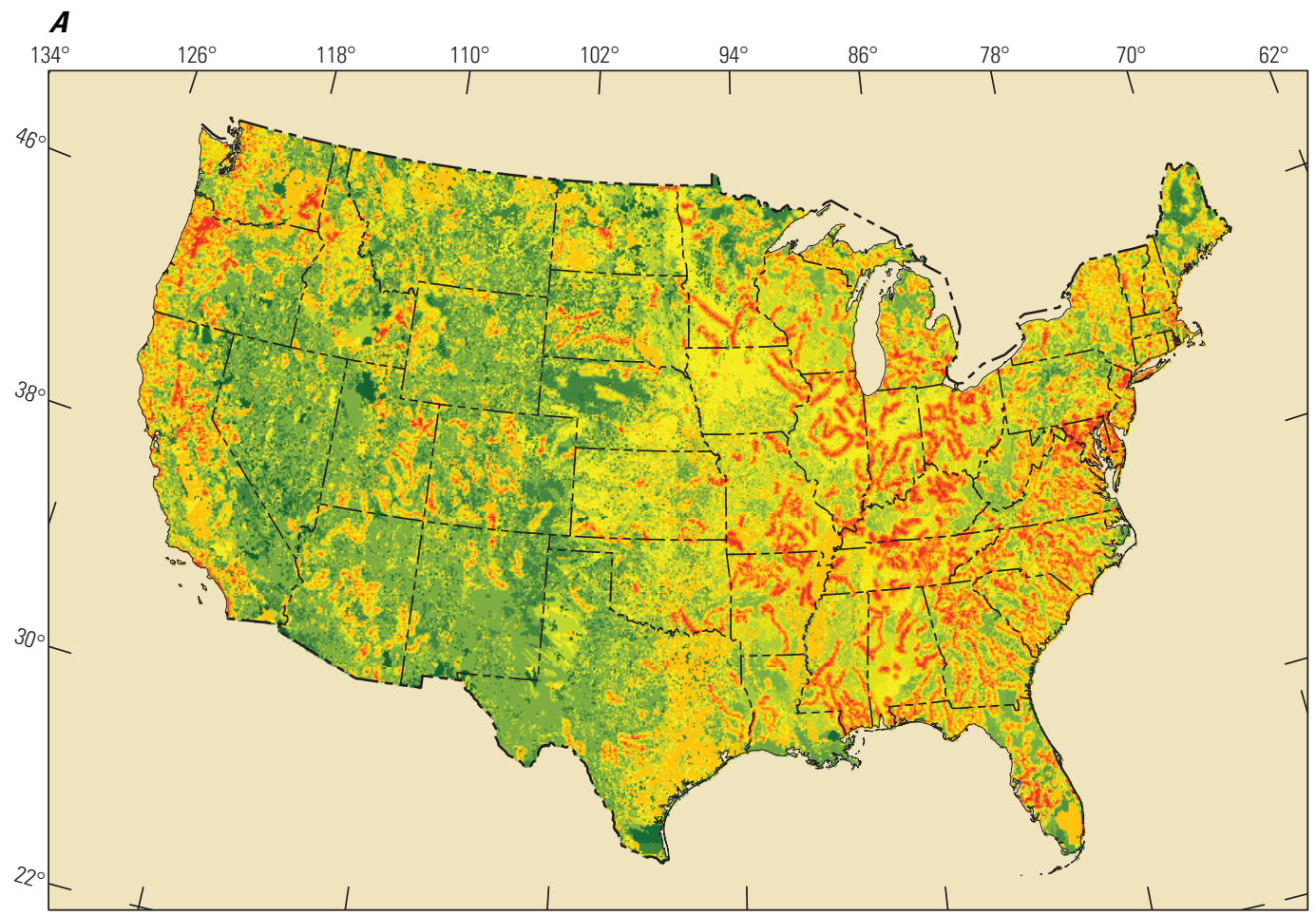

EXPLANATION

Index Score

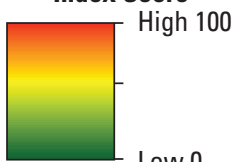

Low 0

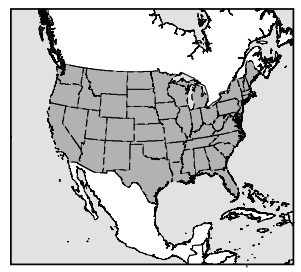

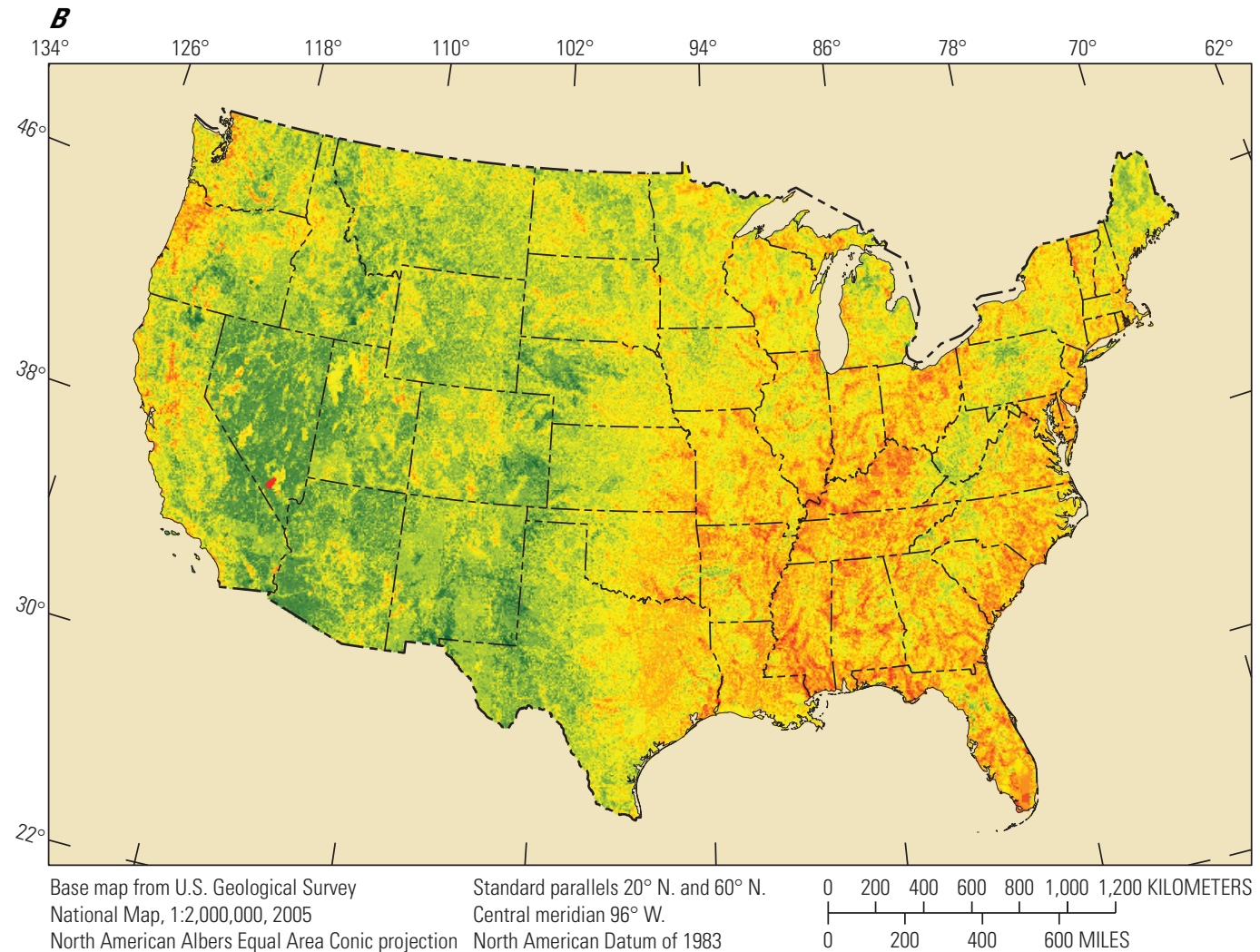

Figure 7. Aggregated Aquatic Resource Values Index. A, Aquatics weighted (suggested). B, Aquatics equally weighted and normalized (alternative). The two methods provide different approaches to weighting the individual metrics that make up the aggregated version. Both versions are provided for consideration, but the balance of information provided in the weighted index is suggested for most applications. Each metric includes information from numerous data sources (see table 1.2). The color ramps represent lower scores in green (less sensitive to development), moderate scores in yellow, and higher scores in red (more sensitive to development or greater recreational opportunity). 

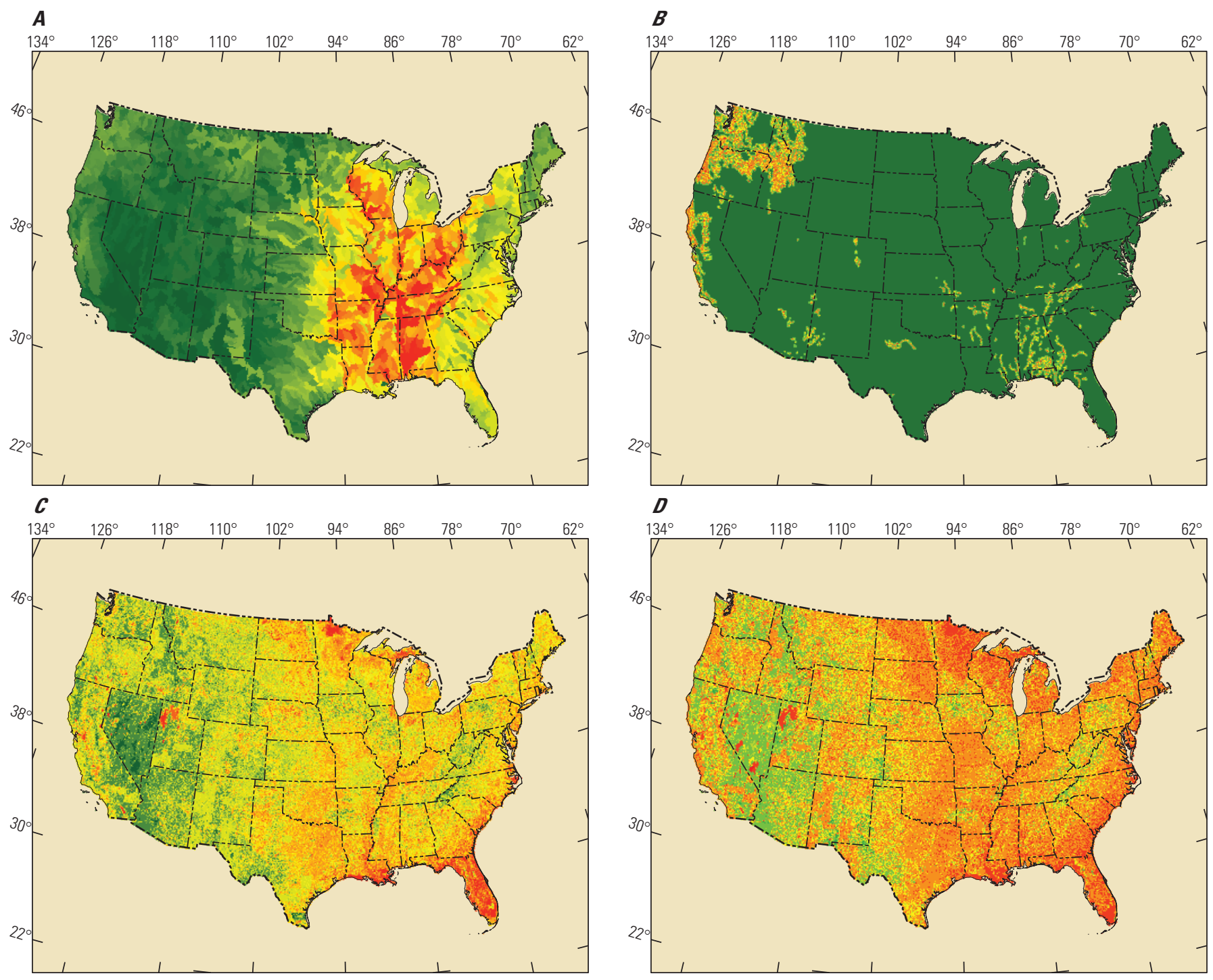

Base map from U.S. Geological Survey National Map, 1:2,000,000, 2005

North American Albers Equal Area Conic projection

Standard parallels $20^{\circ} \mathrm{N}$. and $60^{\circ} \mathrm{N}$.

Central meridian $96^{\circ} \mathrm{W}$.

North American Datum of 1983
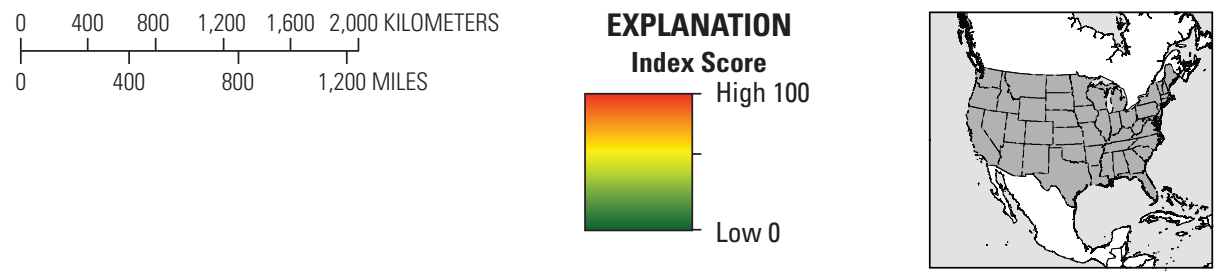

Figure 8. Aquatic Resource Values Index inputs. A, Metric 1 -Species Diversity (fish). B, Metric 2a-Critical Habitat. C, Metric 2bConservation Areas, sum and normalized combination of natural values, conservation, and hydrology sensitivity metrics. $D$, Metric $2 \mathrm{~b}-$ Conservation Areas, maximum value of natural values, conservation, and hydrology sensitivity metrics. Each metric includes numerous data (see appendix table 1.2). The color ramps represent low count/larger distances (less potential sensitivity to development) in green to higher count/smaller distances (greater potential sensitivity) in red. 


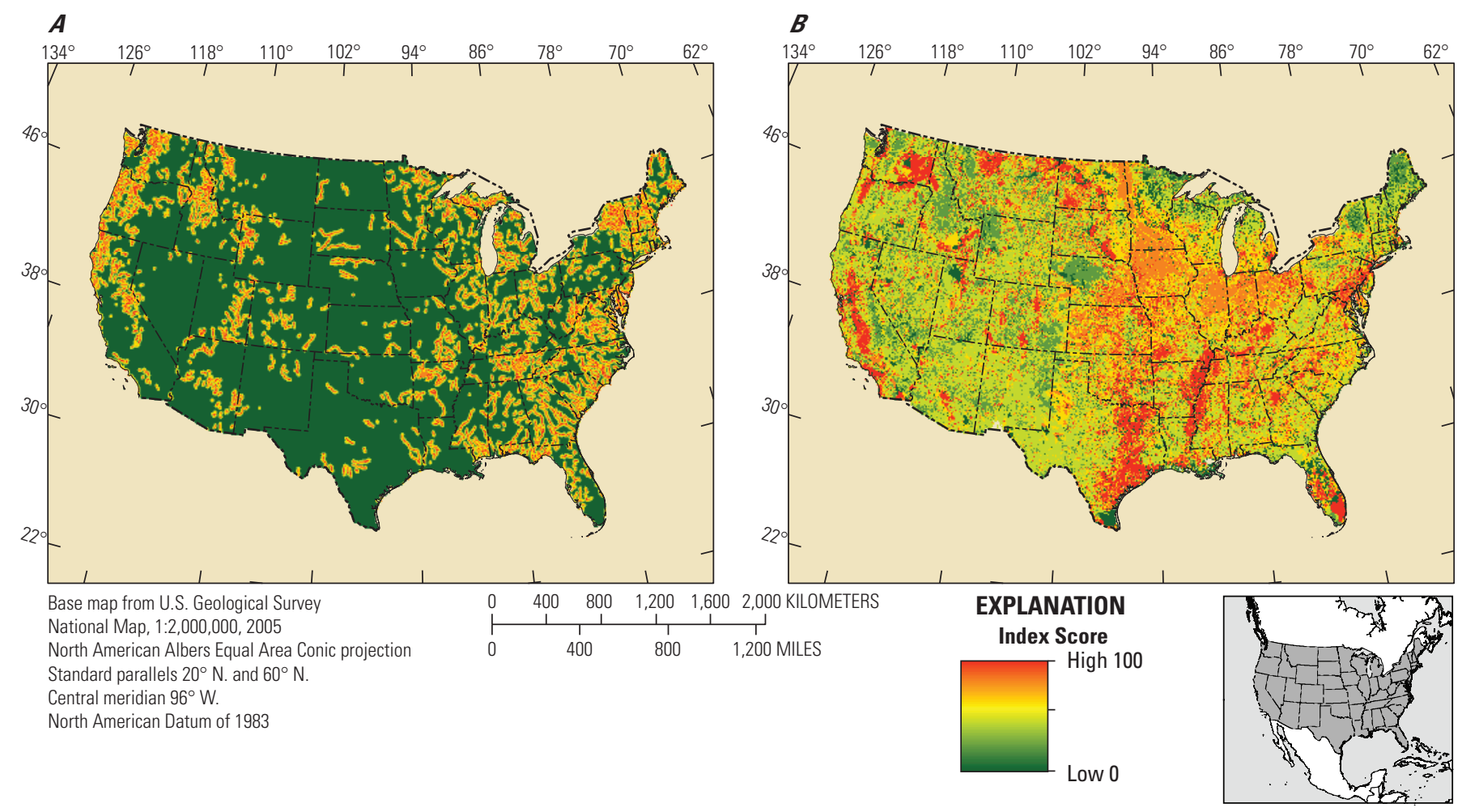

Figure 9. Aquatic Resource Values Index inputs. A, Metric 3-Social Designations (of natural values). B, Metric 4-LandscapeScale Water Quality (habitat condition). Each metric includes numerous data (see table 1.2). The color ramps represent low score/ larger distances (lesser importance) in green to higher score/smaller distances (greater importance) in red.

be used to infer the importance of locations at points within polygons or along linear features. As such, the diversity indices developed here may be used to provide a general perspective on the relative distribution of species and habitats. Because inventories and spatial data are likely incomplete, unconditional richness/diversity is not represented here, and users must assume that these data contain a representative sample of total biological diversity. Therefore, users should take careful note of the scale of each data input (see "Scale/resolution" field in appendix table 1.2) and interpret aggregated indices based on resolution of the inputs with the understanding that coarse-scale data are not suitable for fine-scale inferences.

Because data and information sources for species and habitat distributions vary, proper use and interpretation of our indices require understanding the source data. A brief summary of the species and habitat distribution data are provided in table 1.2, and users may consult the original documentation for details. Primary data from the IUCN (2013) and NatureServe (2014) may not be redistributed (they are available from the sources), but secondary products are provided. The specific requirements and (or) limitations on suitable use and distribution of these data are available from the data sources.

\section{Cultural Resource Values}

The Aggregated Cultural Resource Values Index (fig. 10) represents the relative proximity of each location on the landscape (30-m spatial resolution) to the nearest mapped cultural feature(s). Only features recorded in the National Register of Historic Places (NPS, 2015a) as historic places or routes (trails) (NPS, 2015b) are included in this dataset; because of the sensitive nature of prehistoric cultural data, prehistoric sites are not included. This information was compiled to evaluate the potential for impacts to historic features (for example, a road crossing wagon-trail ruts or passing close to a fragile structure) while also enabling recognition of the potential importance of these sites as transportation destinations (nodes). This information will be more complete and informative if combined with locally specific information. Proximity surfaces (Euclidian distance) and the index and metrics describe the minimum distance from any location to the nearest registered historic locations. Closer proximity $(1-\mathrm{km}, 4-\mathrm{km}, 8-\mathrm{km}, 12-\mathrm{km}$, and $16-\mathrm{km}$ radial intervals) to one or more historic resource suggests greater potential for influence by a transportation feature resulting in higher index values. These distances are not explicitly connected to impacts on historic and cultural resources, but provide room for planners to interpret and estimate potential influences. 


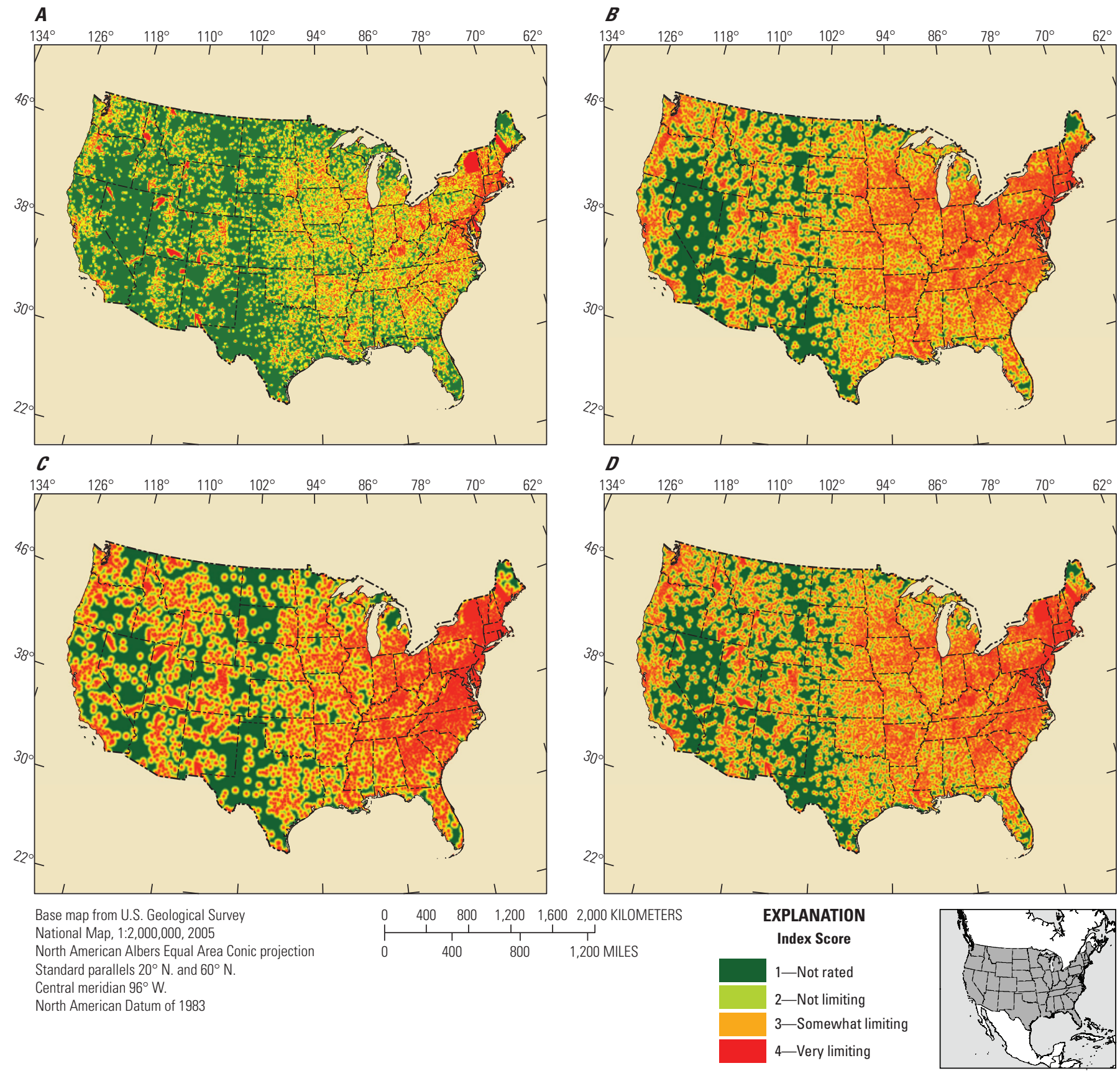

Figure 10. The Aggregated Cultural Resource Values Index and inputs. A, Aggregated Cultural Resource Values Index. B, Cultural Resource Values Index input Euclidian distance to point features. C, Cultural Resource Values Index input Euclidian distance to polygon features. $D$, Cultural Resource Values Index input minimum Euclidian distance to all features. (See table 1.3 for data sources.) The color ramp represents farther distances to locations with an historic site in green, intermediate distances in yellow, and smaller distances in red. Although many historic sites exist in these data, the scale of these maps may falsely suggest a continuous concentration of sites in some regions; however, closer inspection reveals considerable heterogeneity at local scales, which is not apparent in these figures. 
Data contributing to the Aggregated Cultural Resource Values Index were restricted to publicly available data from the National Register of Historic Places (NPS, 2015a; mapped at 1:24,000 using points and polygons; fig. 10). However, more detailed information may be available at a project level. Agencies that manage archeologic and historic sites, including State Historic Preservation Offices, State agencies, the NPS, and other entities may be consulted for more specific information and advice. A brief summary of all cultural resources data is provided in table 1.3, and we suggest that users consult the original documentation for details.

\section{Use and Limitations}

The data included with this report are based on estimated, and modeled, distributions of cultural sites and as such, they do not provide precise locations of many cultural and historical resources. These data cannot be used to infer specific locations where artifacts or ruins may be found. However, all features that are registered with the National Register of Historic Places (NPS, 2015a) were represented. Because cultural resources are sensitive and protected, their locations are not publicly available. USGS recognizes that these data are extremely important for NEPA planning and transportation projects, but because the data are managed by individual States and government agencies with public land holdings, it may not be possible to develop an accurate national dataset. As a result, the indices presented here may be used to provide a general perspective on the relative distribution of historic and other important anthropogenic features, but users must assume these data consist of a sample of the historic, heritage, and archeological inventory.

\section{Integrated Land-Use Conditions}

Land-use Condition metrics were developed to facilitate rapid assessment of current land-use patterns and the potential influence of surface conditions on current and future land use. Two metrics representing components of land-use condition that may affect planning, construction, and (or) maintenance of transportation networks were developed (fig. 11). These metrics compile very different types of information so they were developed and interpreted separately. The first addresses the distribution of developed and undeveloped lands (Metric 1-Development Impact); the second addresses substrate suitability and stability (Metric 2-Construction Suitability). These metrics provide insights into potentially influential patterns across the landscape that were not captured in other indices. Details regarding the cause of high or low index scores will require investigation of the contributing information, but these metrics may inform preliminary discussions and planning where a broad, synthetic view is required. The Development Impact Metric (fig. 11A) represents current land-use intensity and highlights areas with abundant human influences, which may be unaffected by new developments and also may be current nodes in transportation networks, and areas with less human influence where expanded development may have impacts on natural and social values. The second land-use condition metric, substrate limitations for construction (fig. 11B), describes patterns of soil-based limitations that may have an important influence on the costs of construction and maintenance and may require additional planning or increased maintenance effort. The final classification scheme used for each metric provides four categories: Not rated $=1$, Not limited $=2$, Somewhat limited $=3$, Very limited $=4$, and No Data $=$ NoData. Figure 12 describes several patterns in the distribution of suitability for construction based on potential substrate effects on subsurface construction; roads, paths, and trails; and erosion potential during construction. These data were combined to create Metric 2.

These metrics describe broad, regional patterns in current land-use patterns and soil conditions that affect land use. Patterns of topography (see the section "Terrain Metrics") and soil conditions may be useful together for comparing the relative complexity of network design, construction, and associated costs over large areas and networks.

\section{Use and Limitations}

The Land-use Condition Metrics do not include all sensitive or protected areas, or all soil conditions that potentially affect road and trail construction. For example, the anthropogenic noise data provide reliable information across the CONUS, but these data were transformed from continuous data to a discrete product with a few classes, thereby simplifying the complexity of the soundscape. Further, noise is not the only indicator of the influence of humans on natural habitats. All indices developed from the detailed NRCS data are based on the dominant soil type within each map unit defined by the NRCS Soil Survey Geographic Database data. Because of the potential for minor type inclusions and variability in soils, soils in local areas may not be the same as the dominant soil type. Landscape-level applications require multiple scales and sources of information, and it is suggested that these metrics be considered along with other information, such as the Terrestrial Resource Values Index, the Aquatic Resource Values Index, Terrain Metrics and locally specific data for landscape-level land-use and transportation planning efforts.

\section{Natural Hazards}

Some natural features and events have the potential to affect road conditions, maintenance, and safety. Potential threats and influences were represented in metrics derived from data representing geophysical conditions including karsts (subsurface features that increase the potential for sinkhole formation), landslides and earthquakes (based on geologic and topographic connections to previously observed events), and flooding potential (based on soil hydrology and weather). Information on other environmental hazards, such as wildfires, smoke, hurricanes, tornadoes, and ice storms, might be beneficial for transportation planners, but those data were either not available or not suitable for this application. This could be an important area for future research. 

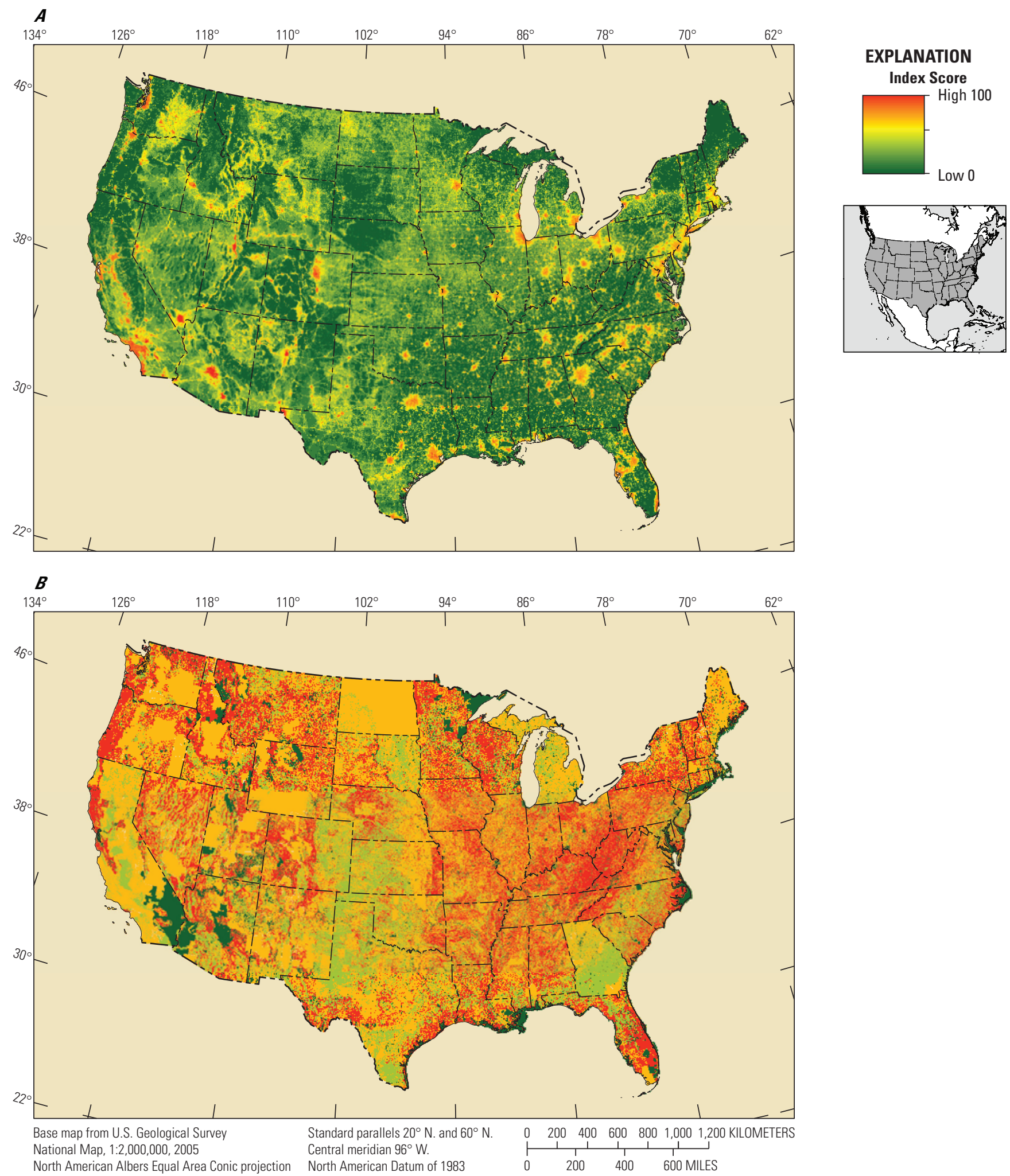

Figure 11. Integrated Land-use Conditions. A, Development Impact (Metric 1) represents lower scores in green (low current impacts and more sensitive to new development), moderate scores in yellow, and larger scores in red (less sensitive to new development because of current high impact). B, Construction Suitability (Metric 2) represents potential construction limitations or challenges due to soil conditions using dark green (not rated), light green (not limiting), orange (somewhat limiting), and red (very limiting). Metric 1 and Metric 2 represent contrasting information with respect to conservation and development, so they were not combined. Metric 2 incorporates numerous data attributes (see table 1.4). 

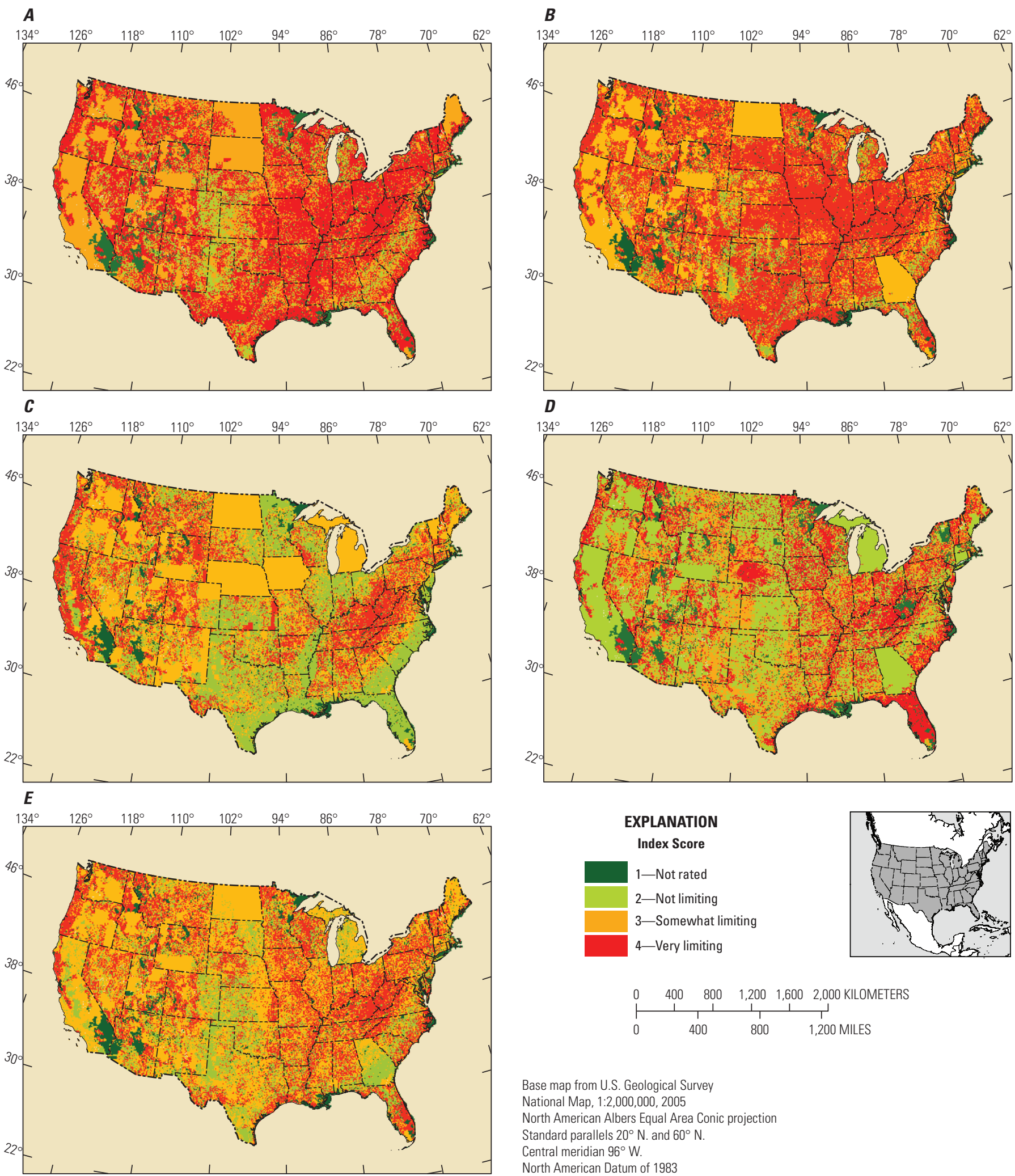

Base map from U.S. Geological Survey

National Map, 1:2,000,000, 2005

North American Albers Equal Area Conic projection

Standard parallels $20^{\circ} \mathrm{N}$. and $60^{\circ} \mathrm{N}$.

Central meridian $96^{\circ} \mathrm{W}$

North American Datum of 1983

Figure 12. Integrated Land-use Condition inputs, Metric 2-Construction Suitability. A, Substrate effects on dwellings with basements. $B$, Substrate effects on local roads and streets. $C$, Substrate effects on paths and trails. $D$, Substrate effects on potential erosion during construction. $E$, Median rank. The color classes represent dark green (not rated), light green (not limiting), orange (somewhat limiting), and red (very limiting). 
Because the different data inputs informing potential hazard included mostly discrete data with varying numbers of categories, it was necessary to use a minimal number of categories to normalize the data. The earthquake (fig. 13A) and karst (fig. 13B) data were updated recently, but the landslide data (fig. 13C) have not been revised recently. The landslide data were included here because limited information is likely better than no information, but caution should be used when applying this information. The aggregated geophysical hazard potential, Metric 1, represents the combination of earthquakes, karsts, and landslides (fig. 13D) by identifying the greatest risk from any of these sources. Flood hazard from FEMA (fig 14A) was combined with soil flooding potential from NRCS (fig 14B) to create the aggregated flooding hazard metric (fig. 14C). The weighted calculation best captured all the information informing the Aggregated Natural Hazards Metrics for planning purposes.

Karsts (underground caves, caverns, and related geomorphic features) may present considerable hazards for roads, structures, and human activities; however, mapping of these features and the hazards they may present has little discriminatory power (in other words, poor discrimination of local hazards at large spatial scales). Karsts identified on geologic maps fall into three categories: (1) carbonate karsts that arise from the combination of highly soluble rocks and well-developed porosity, such that water flows through rocks and dissolves bedrock (usually limestone or dolomite); (2) evaporite karsts that are also created by dissolution of rock by water, which produces highly mineralized waters (usually gypsum, anhydrite, and halite); and (3) pseudokarsts that resemble true karsts because cavities (caves) below the surface exist, but they are typically not caused by dissolution or erosion of rock. Importantly, regional climate, especially precipitation, has a strong influence on rates of dissolution and relations between subsurface water and geologic features and surface conditions. It is not possible to translate all of these factors into a definitive sinkhole potential map at this time; however, the presence of these geologic features is directly connected to geologic conditions leading to sinkholes. Therefore, data representing the distribution of karsts highlight areas with increased potential for sinkhole development due to the coincidence of geologic and climatic conditions that promote sinkhole formation. However, these maps cannot replace local knowledge, surveys, and regulatory mechanisms. Caution should be used when interpreting hazard distributions from source data and the synthetic indices to avoid underestimating potentials because of low index values, or overestimating potentials because of high index values. These data provide guidance and an indication of relative potential for influence of selected hazards; they do not provide definitive predictions of risks due to natural hazards.

Potential Natural Hazards also include information about potential flood hazards and soils with potential for ponding. By reflecting potential flooding, Metric 2 may inform regional, and sometimes local, problems for transportation. The FEMA flood hazards data (fig. 14A) include useful local information, but these data usually delineate only areas where there have been documented floods where people and businesses have encountered economic losses. NRCS data on flood frequency potential (fig. 14B) provide more complete coverage across the CONUS. This metric reflects ponding frequency determined by the limitations of the soil substrates to drain soils in a specific climate zone receiving a given amount of precipitation quickly. Because these data use discrete classes of flood hazards and ponding (flood potential) frequency, the resulting metrics and index used a synthetic ranking system common to all hazard potential data sources. Figure $14 C$ represents the combined flooding hazard using the maximum value from FEMA flood hazards and NRCS flood frequency potential for each location.

The Flood Frequency Potential metric (part of Metric 2) captures information about how often water collects (ponds) and whether an area has the potential for wetlands, which may also affect the sensitivity of the natural ecosystem and suitability of the substrate. This information is a direct reflection of soil substrate conditions and the substrate's ability to drain water relative to the average amount of precipitation the area receives. This information may provide a useful planning tool when considering construction due to potential complications for construction and maintenance due to water, as well as potential impact on wetland habitats that may require additional steps during NEPA evaluation and mitigation. Figure $15 \mathrm{~A}$ illustrates the percentage of area with ponding potential and figure $15 B$ illustrates the percentage of area with wetland potential. The combined ponding and wetland potential metric (fig. 15C) demonstrates the combined potential for surface water. As a final step, flooding potential was combined with ponding and wetland potential for an aggregated flooding potential metric (Metric 2; fig. 15D). Although the interpreted soils data are useful for planning purposes, local surveys and additional knowledge will be required to inform specific construction, management, and hazard concerns related to natural conditions.

Lastly, data representing several known environmental hazards, such as Metric 3-hazardous materials transportation hubs, Metric 4-Air Quality, and Metric 5-Water Quality, were compiled to address potential concerns of transportation planners related to environmental quality. These data were not included in an aggregated hazards index due to the disparity of information, and therefore, the lack of a clear application when combined. Figure $16 A$ (Metric 3) represents the chemi$\mathrm{cal} /$ environmental risks presented by transportation of hazardous materials. These data reflect locations of EPA-monitored transportation hubs for hazardous chemicals. Metric 4-Air Quality (fig. 16B) reflects the Global Annual $\mathrm{PM}_{2.5}$ based on a series of 3-year running means from 1998 to 2012. The areas with the greatest air pollution include metropolitan cities and larger cities where temperature inversions occur, such as along the coasts and areas adjacent to mountains. More accurate and local data at a station level exist and are publicly available, but compiling and modeling these data into a CONUS representation were beyond the scope of this project. 

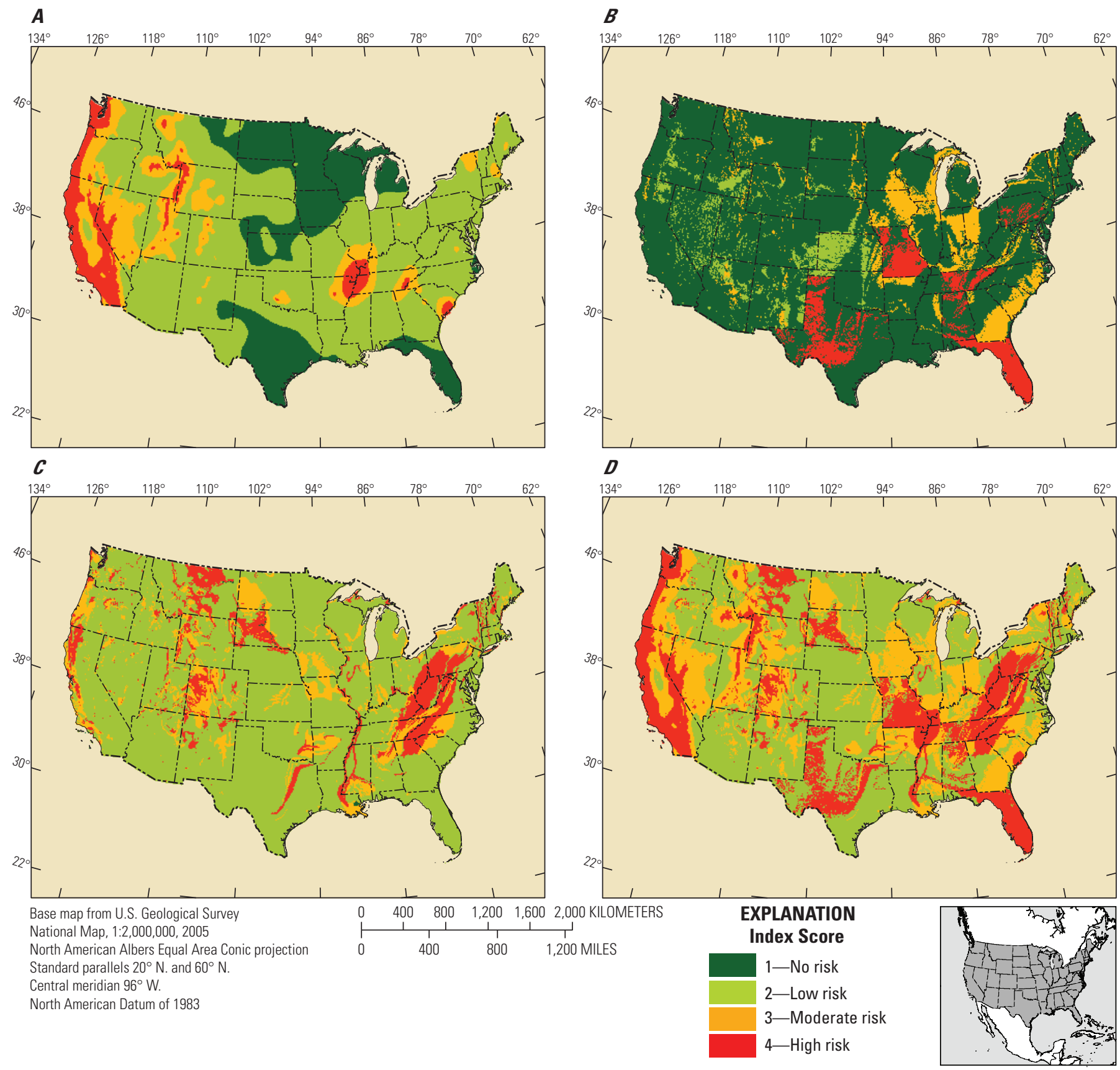

Figure 13. Natural Hazards Metric inputs, Metric 1 -Geophysical. $A$, Earthquake potential. $B$, Karst potential. $C$, Landslide potential. $D$, Metric 1-Combined earthquakes, karsts, and landslides. Each metric may include numerous data inputs (see table 1.5). The color classes represent dark green (no risk), light green (low risk), orange (moderate risk), and red (high risk). Three inputs (A, B, and C) were combined to create the aggregated metric (D).

Metric 5-Water Quality (fig. 16C) is an important indicator of potential health hazards to consider for urban planning and habitat effects, and the EPA uses water-quality information to make improvements to U.S. water quality by targeting monitoring and regulatory efforts. Water quality data can also inform transportation projects by helping to connect infrastructure and activities in watersheds to areas with poor water quality where mitigation or restoration may be needed, and limiting the number of concurrent, active transportation projects within a watershed to help avoid cumulative effects on both pristine and poor quality waters.

\section{Use and Limitations}

The data included with this report were based on estimated, and modeled, distributions of Earth's features, and as such, they do not provide precise locations of natural hazards. These data cannot be used to infer specific locations 

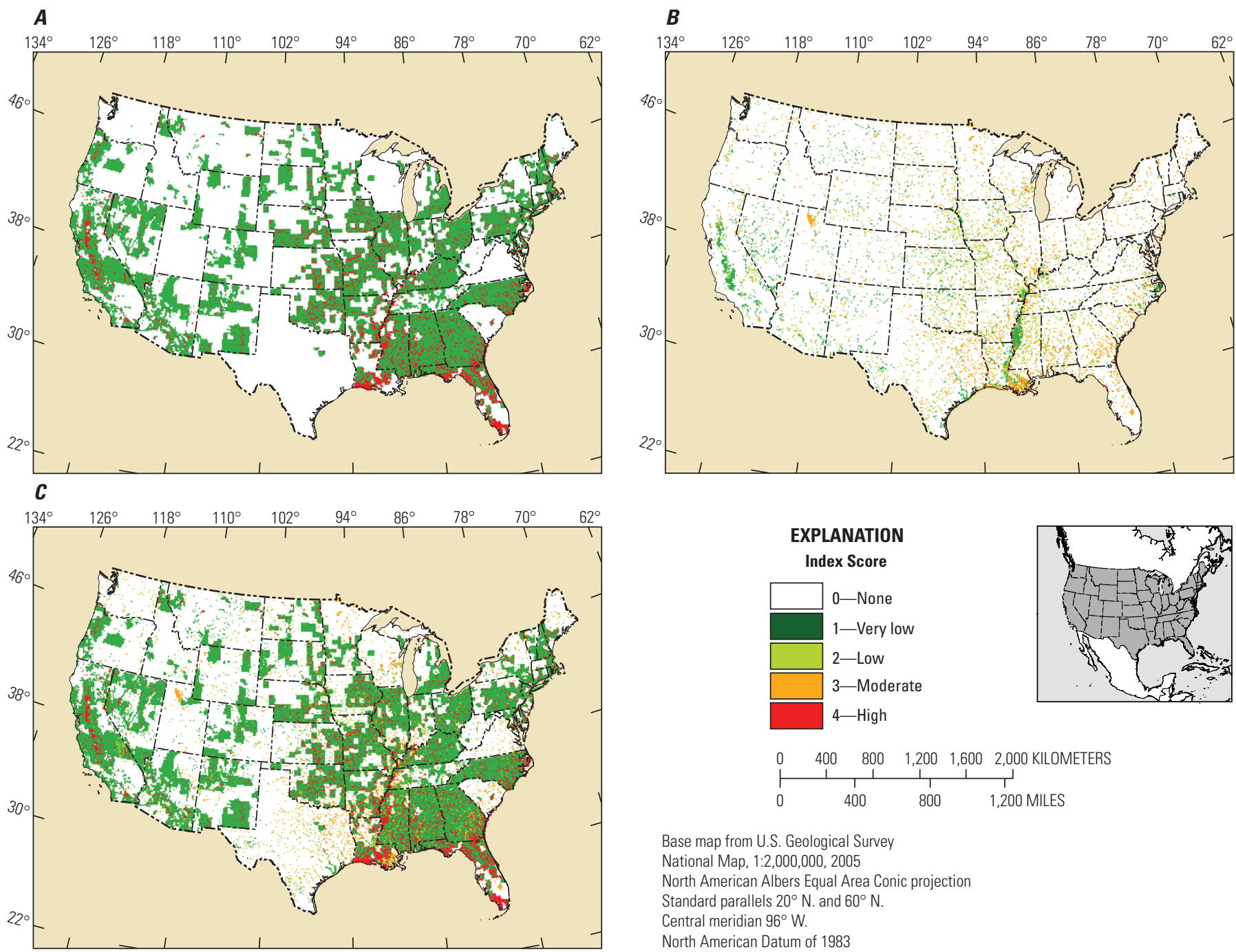

Figure 14. Natural Hazards metrics for flood potential, Metric 2-National Flood Hazards. A, Federal Emergency Management Agency (FEMA) flood hazards. $B$, Natural Resources Conservation Service (NRCS) flood-frequency potential. C, Combined FEMA flood hazards and NRCS flood-frequency potential. Each metric may include numerous data inputs (see table 1.5). The color classes represent maximum value for flooding risk: white (none), dark green (very low), light green (low), orange (moderate), and red (high). (Note: the class none includes areas with no data, so flooding risk may exist in some of these areas even though FEMA and NRCS do not have data.)

where earthquakes, storms, or flooding will occur. As such, the indices described here provide a general perspective on the relative distribution of important geologic and climatic events, but because inventories and spatial data are likely incomplete, users must recognize that these data consist of a sample of the history of these events along with expert interpretation (but not absolute knowledge). Extreme caution and (or) redundancy should be used when interpreting estimates of natural hazards when planning transportation routes, maintenance, and safety because distributions of hazard potentials, both individual and in compilation, are estimated and spatial precision is not defined. Potentially hazardous, and potentially low-hazard, areas should all receive appropriate local-level inventory and assessment.
Because data and information sources for natural hazard distributions vary (see "Scale/Resolution" field in table 1.5), proper use and interpretation of our indices and their implications may require understanding of the attributes of the source data. A brief summary of data representing potential transportation hazards and sources of information is provided in table 1.5 , and original documents may be consulted for further details.

\section{Terrain Metrics}

Hydrologically corrected elevation data were developed to inform habitat models, but the results were not directly 

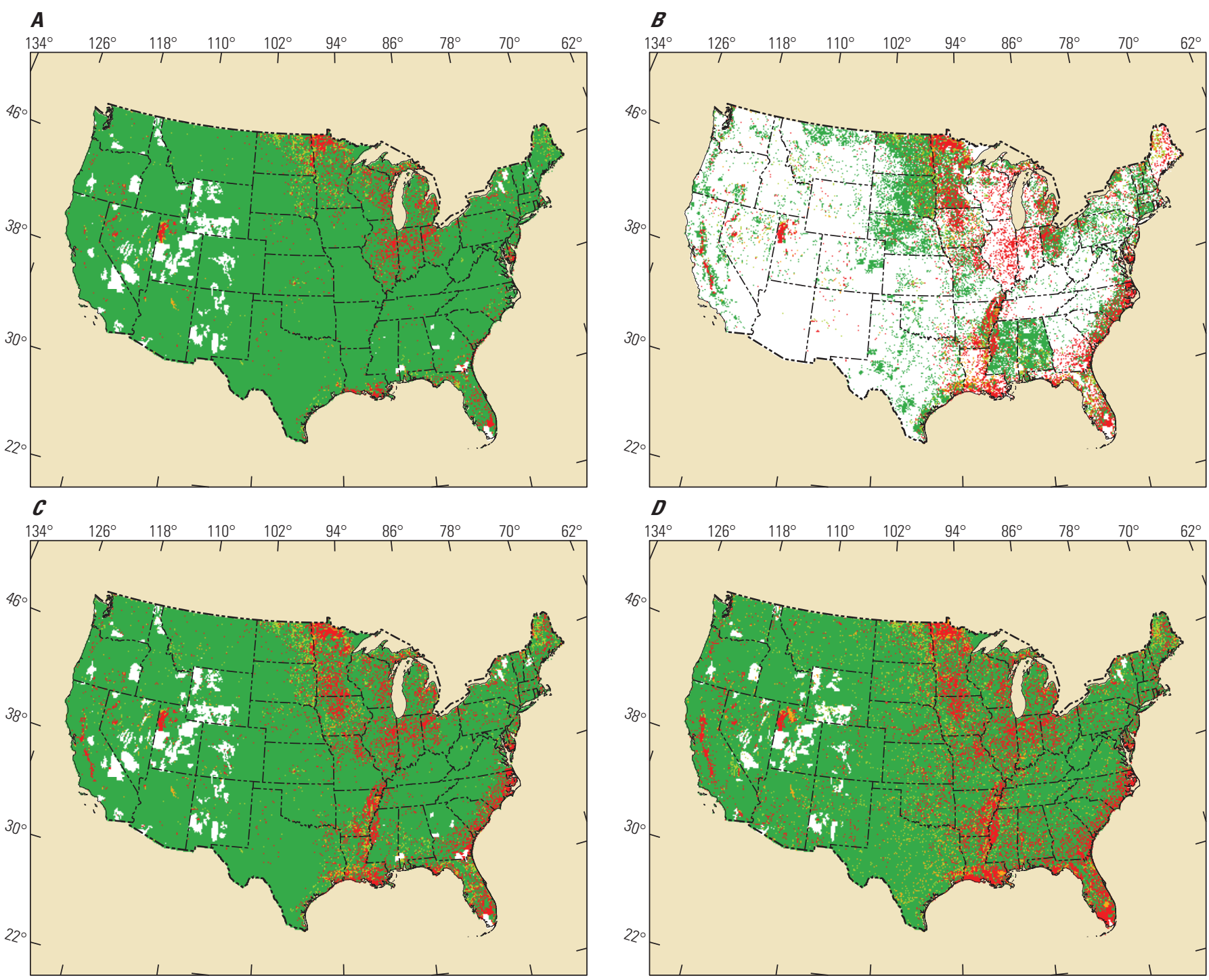

Base map from U.S. Geological Survey National Map, 1:2,000,000, 2005

North American Albers Equal Area Conic projection
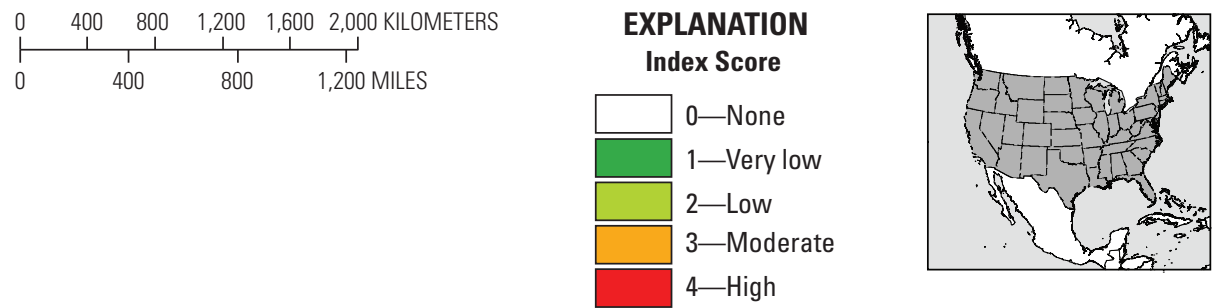

Central meridian $96^{\circ} \mathrm{W}$.

North American Datum of 1983

Figure 15. Natural Hazards metrics, Metric 2-Flood Frequency Potential. $A$, Percentage of area with frequent ponding.

$B$, Percentage of area with wetland potential. $C$, Combined percentage of area with ponding and wetland potential. $D$, Metric 2Flooding, ponding, and wetland (combined Metric). Each metric may include numerous data inputs (see table 1.5). The color classes represent maximum value for ponding, wetland or flooding occurrence (risk): white (none), dark green (very low), light green (low), orange (moderate), and red (high). (Note: the class none includes areas with no data, so flooding risk may exist in some of these areas even though FEMA and NRCS do not have data.) 

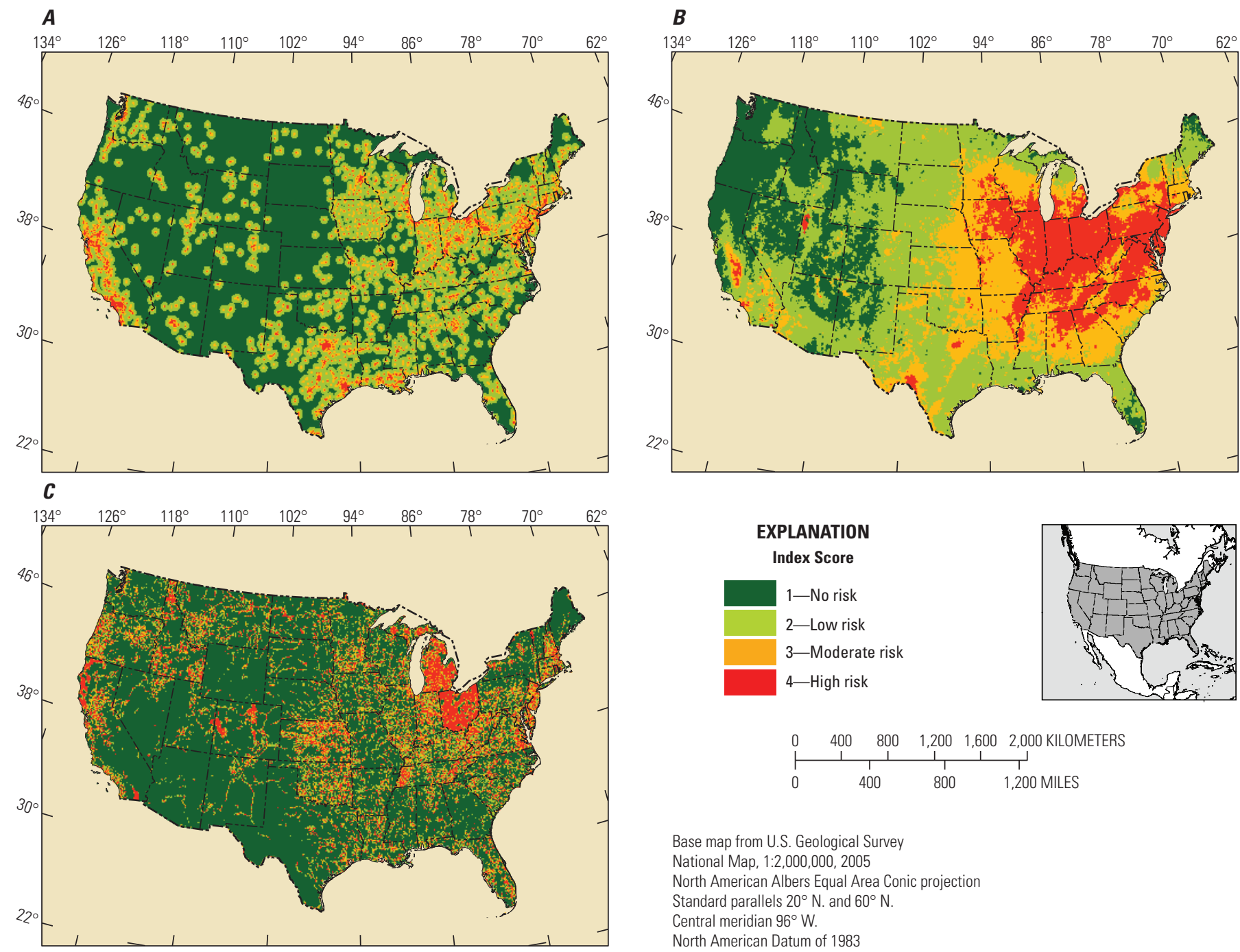

Base map from U.S. Geological Survey

National Map, 1:2,000,000, 2005

North American Albers Equal Area Conic projection

Standard parallels $20^{\circ} \mathrm{N}$. and $60^{\circ} \mathrm{N}$.

Central meridian $96^{\circ} \mathrm{W}$.

North American Datum of 1983

Figure 16. Natural Hazards metrics, A, Metric 3-proximity to hazardous materials transportation hubs. B, Metric 4-Air Quality. $C$, Metric 5-Water Quality. Each metric may include numerous data inputs (see table 1.5). The color classes represent dark green (no risk), light green (low risk), orange (moderate risk), and red (high risk).

included in the Terrestrial and Aquatic Resource Values Indices or the Natural Hazards Metrics. They are included separately because they are landscape-level representations of factors that may affect transportation planning and have a potential influence on network construction and maintenance. The DEM provides a consistent representation of elevations across the CONUS (fig. 17A). Interpretation of slope and aspect calculated from the DEM are expressed in degrees, and are otherwise self-explanatory (figs. $17 B$ and 17C). The Terrain Ruggedness Metric (fig.17D) describes the local variation of the surrounding terrain around a central pixel. This index may have biological importance and it provides information on potential effects of topography on construction and travel associated with the complexity of the land in the transportation corridor.

\section{Use and Limitations}

In areas with flatter topography, DEMs typically exhibit lower vertical accuracy. The overall vertical accuracy of the DEM used for this project, represented as the root mean square error, is approximately $2.44 \mathrm{~m}$. This accuracy varies spatially because more information is available for some areas. Therefore, the accuracy was better in some areas. The horizontal datum for any area in the contiguous lower 48 States is NAD 83 and the vertical datum for these areas is NAVD 88. Hydrologic corrections were made to improve the utility for applications, but the current data may not accurately represent all topographic sinks (low points) because these data were unavailable. Sinks are local depressions that appear in digital elevation products but are typically errors because, except in karst areas, they usually do not exist when compared to more accurate surveys, such as those with 10-m resolution (Mark, 1988; Wechsler, 2007). 


\section{A. Elevation}

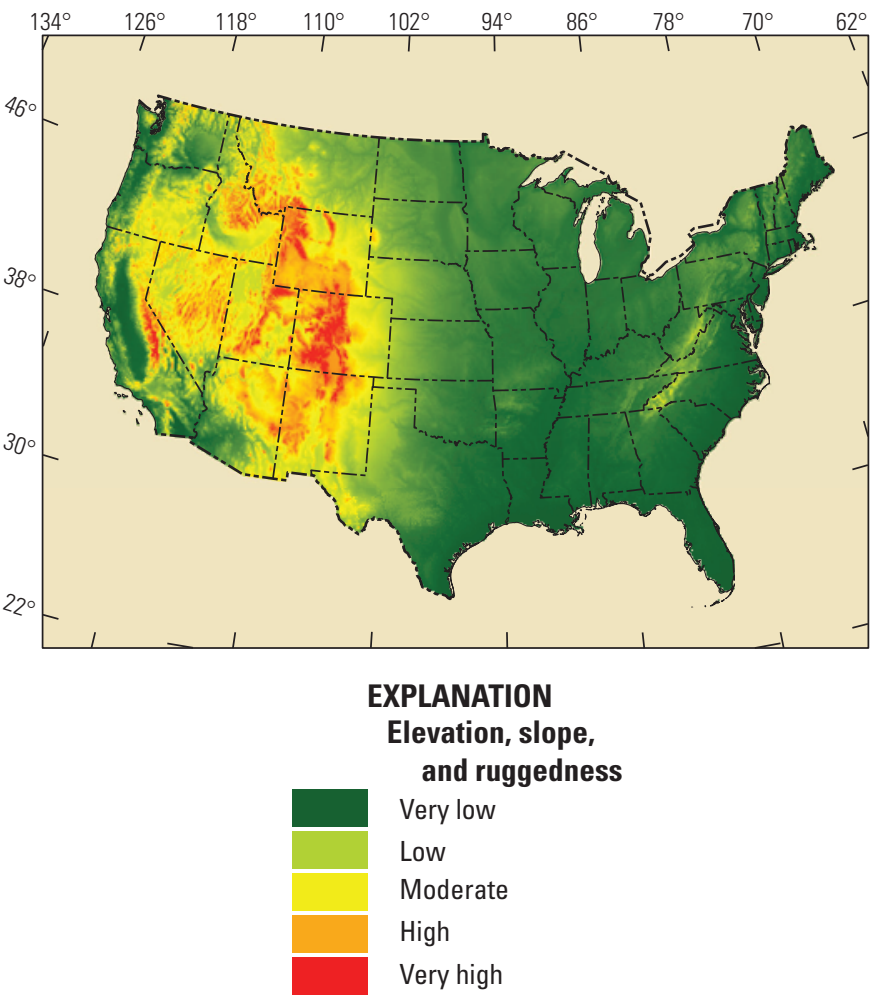

\section{B. Slope}

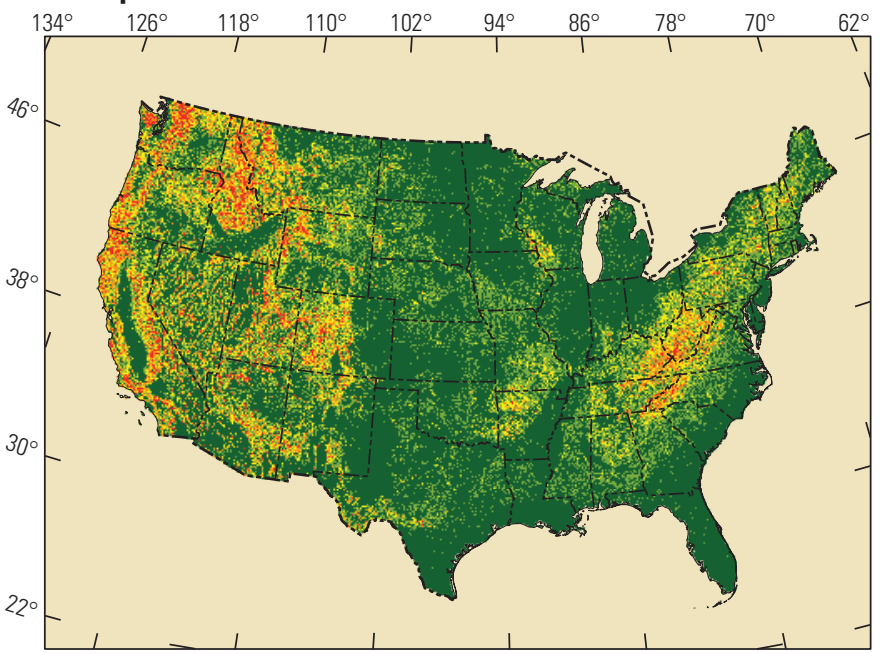

D. Ruggedness

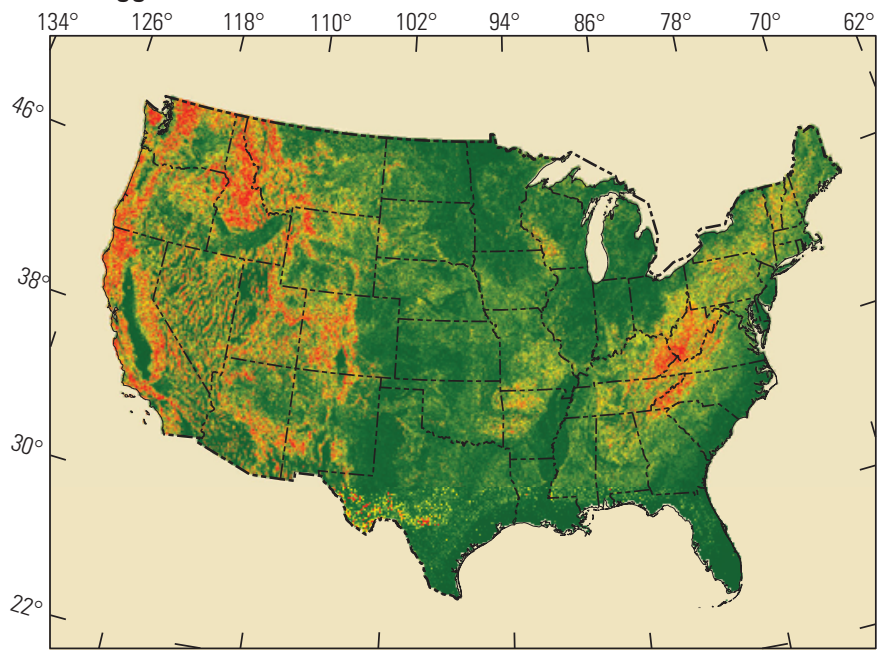

Aspect
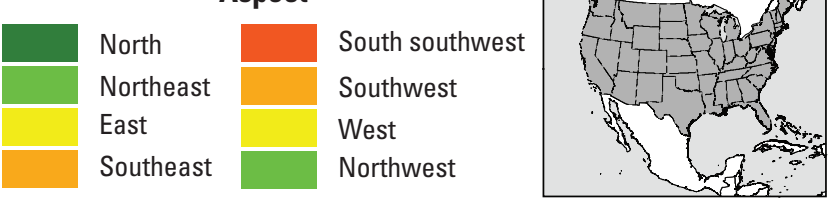

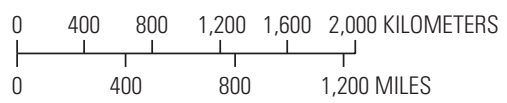

Base map from U.S. Geological Survey

National Map, 1:2,000,000, 2005

North American Albers Equal Area Conic projection

Standard parallels $20^{\circ} \mathrm{N}$. and $60^{\circ} \mathrm{N}$., central meridian $96^{\circ} \mathrm{W}$.

North American Datum of 1983

Figure 17. Terrain Metrics, $A$, Digital elevation model (meters above sea level); $B$, Slope (degrees); $C$, Aspect (classified degrees); and $D$, Terrain Ruggedness. Green represents lower elevation, slope, and roughness; yellow is moderate; and orange and red represent higher elevation, slope, and ruggedness. 


\section{Social Demographics}

The USGS sociodemographic assessment tool, Assessing Socioeconomic Planning Needs (https://my.usgs.gov/aspn) (Richardson, and others, 2014) was used to initiate development of the Economic and Sociodemographic Geodatabase (see fig. 1). That database, and associated tools have not been developed at this time. This report focuses on natural and cultural resource values, but integration with additional social and economic data was envisioned to complete the planning framework and a planned, web-based planning tool. To facilitate the creation of sociodemographic reports by project cooperators, new export procedures were created and 30 employees from FLH, BLM, and FWS were trained to use the Assessing Socioeconomic Planning Needs tool.

\section{Correlation Between Indices}

Because we compiled many spatial datasets representing species, habitats, and social designations, there is potential for undesired correlations among independent datasets. Spatial correlation between datasets implies that the same pattern(s) is represented repeatedly in the data, and this could distort analysis and interpretation of correlated data if those datasets are used in the same framework (a model, for example). Correlations among inputs to statistical models can produce unstable and incorrect results. Strong spatial correlation among supposedly independent indices would indicate that data users should not use those indices in conjunction, although independent assessment and interpretation remain valid. Although we were unable to produce statistical results for quantifying correlations due to extensive processing time and data storage requirements, we visually inspected these data and we observed low correlation among the metrics that were combined to generate the four primary indices (Terrestrial Resource Values, Aquatic Resource Values, Cultural Resource Values, and Hazards Potential). We took great care during the index development process to separate information and use different datasets to represent different types of information, thereby reducing the potential for correlation between the model inputs. Correlation between terrestrial indices and aquatic indices may exist because of natural patterns and land-use patterns (especially for conservation) even when the information being assessed is independent. For example, the coincidence of aquatic and terrestrial values in headwater watersheds could additively increase the index scores for mountain watersheds. Users who perform quantitative analyses using the metrics and indices may decide to assess the spatial correlation among the terrestrial and aquatic indices (primary indices and metrics).

\section{Deliverables}

The deliverables produced by this project include:

1. Environmental resource geodatabases of national and State data (Manier and O’Donnell, 2018).

2. A conceptual framework (fig. 1) to describe different categories of information and how these different types of information may inform transportation-planning and related land-use planning activities.

3. This final report summarizing the conclusion of this phase of the project.

4. Tables providing information on the sources of the data, including URLs (tables 1.1 to 1.5 ).

The majority of the source data were provided directly to the CFL in 2014, per the Work Plan. The USGS products (indices and metrics) are provided through ScienceBase (Manier and O’Donnell, 2018).

\section{Conclusion}

Abundant biotic resources and species diversity are likely associated with the relative distribution of important local ecological values including both natural (for example, ecosystem services, intact ecosystems) and social values (for example, recreation, hunting, heritage areas). This report summarizes the source data acquired and methods used for development of derived datasets that may be used by staff, partners, and constituents of the Central Federal Lands Highway Division of the Office of Federal Lands Highway for land-use planning. The project was initiated because of our partner's (Office of Federal Lands Highway) recognition that the diverse and relevant information available on natural and social values could be important for regional land-use planning. Thus, our goal was to compile data, conduct an organized synthesis of a diverse set of inputs, and provide the data and interpretation for land-use plans, especially long-range transportation plans. Thanks to a collaborative development process, and targeted acquisition and processing of data to represent key resource attributes for consideration in transportation planning, the data compiled and the indices calculated in this report should help expand the planning process to include recognition of a range of natural and social values, as well as natural hazards.

Specific application of this information remains the purview of planners and managers; however, areas with high natural and (or) social scores may be treated with increased sensitivity, including consideration of routing options and use of predevelopment surveys, to minimize impacts to species, habitats, and other important landscape features. Natural destinations, such as U.S. Fish \& Wildlife refuges, parks, rivers, lakes and coastlines, require suitable infrastructure to carry the transportation load but also sensitivity towards the resources and character of the area, and many areas with high 
diversity and an abundance of natural values may be important destinations (nodes) in a transportation network. Importantly, areas highlighted by indices and classified data should be recognized for potential influence of, or on, landscape patterns described in this report, and local information should be used to further assess potential influences and to determine the need for avoidance or mitigation. National maps of potential natural hazards should be used with caution because unrepresented patterns or processes will exist locally and some local hazards will not be identified here. However, the combination of the geologic, pediologic, hydrologic, and environmental information compiled here should help identify regions with greater potential hazards and thus trigger additional caution, surveys, and planning to avoid common hazards in those areas. Further value and utility is anticipated when these data are added to a web-based interface that will allow users (planners) to view and query the data. Development of this web-based interface was planned as the final step in the development and implementation of these data as a planning tool.

Because our representation of patterns in species diversity depends on coarse-resolution, large-area distribution maps, there may be considerable variability in locally realized species composition and diversity. Therefore, our data and indices may be used to recognize regional patterns, but should not be used to include or exclude any species from consideration in the planning process; local information is required for these decisions. However, coarse patterns of diversity, both within and across States for example, will be useful for recognizing overlap and disconnections between an extensive transportation network and biodiversity patterns; in this context, patterns of biodiversity are used to represent the distribution of abundance of biotic resources and biotic potential. These data represent national-level syntheses and therefore, coarse resolution. Therefore, using the indices and data developed here for initial planning efforts, and local data for more precise representation and project planning, is suggested.

\section{References Cited}

Abdi, Hervé, and Williams, L.J., 2010, Normalizing data, in Salkind, N., ed., Encyclopedia of research design: Thousand Oaks, Calif., Sage Publications, Inc., 4 p., accessed April 2015 at http://dx.doi.org.ezproxy2.library.colostate. edu/10.4135/9781412961288.n278.

American Association of State Highway and Transportation Officials [AASHTO], 2008, AASHTO practitioner's handbook 10-Using the transportation planning process to support the NEPA process: Center for Environmental Excellence by AASHTO, $16 \mathrm{p}$.

American Association of State Highway and Transportation Officials [AASHTO], 2014, AASHTO practitioner's handbook 15-Preparing high-quality NEPA documents for transportation projects: Center for Environmental Excellence by AASHTO, $28 \mathrm{p}$.
American Association of State Highway and Transportation Officials [AASHTO], 2016, AASHTO practitioner's handbook 12-Assessing indirect effects and cumulative impacts under NEPA: Center for Environmental Excellence by AASHTO, $24 \mathrm{p}$.

American Society for Photogrammetry and Remote Sensing, Map Accuracy Standards Working Group, 2014, ASPRS positional accuracy standards for digital geospatial data: Photogrammetric Engineering \& Remote Sensing, v. 81, no. 3, p. A1-A26. [Also available at http://www.asprs.org/ wp-content/uploads/2015/01/ASPRS_Positional_Accuracy_ Standards_Edition1_Version100_November2014.pdf.]

Appalachian Trail Conservancy, 2015, Appalachian Trail GIS data: Appalachian Trail Conservancy, accessed March 2015 at http://www.appalachiantrail.org/home/explore-the-trail/ gis-data.

Bureau of Land Management [BLM], 2015, Navigator: Bureau of Land Management, accessed March 2015 at https://navigator.blm.gov.

Carver, S.J., 1991, Integrating multi-criteria evaluation with geographical information systems: International Journal of Geographical Information Systems, v. 5, no. 3, p. 321-339.

Continental Divide Trail Coalition, 2015, CDT data: Continental Divide Trail Coalition, accessed April 2015 at http:// continentaldividetrail.org/cdt-data/.

Dittrich-Wesbuer, Andrea; Krön, Annette; and Mayr, Alexander, 2015, Site effects-Assessing the fiscal, social and ecological costs of planned developments: Regional Studies, Regional Science, v. 2, no. 1, p. 392-407.

Environmental Systems Research Institute, Inc. [Esri], 2011a, ArcGIS Desktop Esri 64-bit background geoprocessing Release 10.3.1: Redlands, Calif., Environmental Systems Research Institute.

Environmental Systems Research Institute, Inc. [Esri], 2011b, ArcGIS Desktop Spatial Analyst-Release 10.3.1: Redlands, Calif., Environmental Systems Research Institute.

Environmental Systems Research Institute, Inc. [Esri], 2013, Data \& Maps for ArcGIS-ArcGIS for Local Government, Park and Recreation Finder: Redlands, Calif., Environmental Systems Research Institute, version 2013, accessed June 2013 at https://services.arcgis.com/P3ePLMYs2RVChkJx/ arcgis/rest/services/USA_Parks/FeatureServer.

Executive Office of the President, 1977, Executive Order 11990 - Protection of wetlands: Federal Register, v. 42, p. 26961.

Fahrig, Lenore; and Rytwinski, Trina, 2009, Effects of roads on animal abundance-An empirical review and synthesis: Ecology and Society, v. 14, no. 1, article 21, accessed November 2014 at http://www.ecologyandsociety.org/vol14/ iss 1/art21/. 
Federal Emergency Management Agency [FEMA], 2015a, National flood hazard layer: Washington, D.C., Department of Homeland Security, Federal Emergency Management Agency, accessed December 2015 at https://www.fema.gov/ national-flood-hazard-layer-nfhl.

Federal Emergency Management Agency [FEMA], 2015b, Flood zones: Washington, D.C., Department of Homeland Security, Federal Emergency Management Agency, accessed December 2015 at https://www.fema.gov/flood-zones.

Federal Geographic Data Committee, 1998, Geospatial Positioning Accuracy Standards, Part 3-National Standard for Spatial Data Accuracy: Federal Geographic Data Committee, accessed October 2015 at http://www.fgdc.gov/standards/projects/FGDC-standards-projects/accuracy/part3/ chapter3.

Feizizadeh, Bakhtiar; Jankowski, Piotr; and Blaschke, Thomas, 2014, A GIS based spatially-explicit sensitivity and uncertainty analysis approach for multi-criteria decision analysis: Computers \& Geosciences, v. 64, p. 81-95.

Gaines, W.L., Singleton, P.H., and Ross, R.C., 2003, Assessing the cumulative effects of linear recreation routes on wildlife habitats on the Okanogan and Wenatchee National Forests: Portland, Oreg., U.S. Department of Agriculture Forest Service, Pacific Northwest Research Station, 79 p.

Geospatial Data Abstract Library, 2014, GDAL - Geospatial Data Abstraction Library, Version 1.11.3: Open Source Geospatial Foundation, accessed September 2014 at http:// www.gdal.org/.

Godt, J., 1997, Digital compilation of landslide overview map of the conterminous United States: U.S. Geological Survey Open-File Report 97-289, accessed October 2016 at https:// pubs.er.usgs.gov/publication/ofr97289.

Hewitson, B.C., and Crane, R.G., 1996, Climate downscalingTechniques and application: Climate Research, v. 7, p. 85-95.

Heywood, D.I., Cornelius, Sarah, and Carver, Steve, 1998, An introduction to geographical information systems: New York, Addison Wesley Longman, 279 p.

Hopper, M.G., Tarr, A., Dewey, J., McKeever, M., and Trevor, N., 2005, Significant United States earthquakes, 1568-2004: U.S. Geological Survey, National Earthquake Information Center accessed May 2014 at https://catalog.data.gov/dataset/significant-united-states-earthquakes-1568-2004-directdownload.

Institute for Natural Resources, NatureServe, Parametrix, Inc., and CH2M HILL, 2012, An ecological approach to integrating conservation and highway planning-Volume 2: Washington, D.C., Transportation Research Board, Strategic Highway Research Program Report S2-C06-RW-2, 163 p., accessed November 2014 at http://www.trb.org/Main/ Blurbs/166938.aspx.
International Union for Conservation of Nature [IUCN], 2013, Red List Spatial Data: Cambridge, United Kingdom, International Union for Conservation of Nature, accessed November 2013 at http://www.iucnredlist.org/technicaldocuments/spatial-data.

Jaarsma, C.F., and Willems, G.P.A., 2002, Reducing habitat fragmentation by minor rural roads through traffic calming: Landscape and Urban Planning, v. 58, no. 2-4, p. 125-135.

Jakeman, A.J., and Letcher, R.A., 2003, Integrated assessment and modelling - Features, principles and examples for catchment management: Environmental Modelling \& Software, v. 18 , no. 6, p. 491-501.

Jensen, M.E., and Bourgeron, P.S., eds., 2001, A guidebook for integrated ecological assessments: New York, SpringerVerlag, $536 \mathrm{p}$.

López-Marrero, Tania; González-Toro, Antonio; HeartsillScalley, Tamara; and Hermansen-Báez, L.A., 2011, Multicriteria evaluation and geographic information systems for land-use planning and decision making: Gainesville, Fla., U.S. Department of Agriculture Forest Service, Southern Research Station, 8 p.

Malczewski, Jacek, 2006a, GIS-based multicriteria decision analysis - A survey of the literature: International Journal of Geographical Information Science, v. 20, no. 7, p. 703-726.

Malczewski, Jacek, 2006b, Ordered weighted averaging with fuzzy quantifiers - GIS-based multicriteria evaluation for land-use suitability analysis: International Journal of Applied Earth Observation and Geoinformation, v. 8, no. 4, p. 270-277.

Manhães, A.P., Mazzochini, G.G., Oliveira-Filho, A.T., Ganade, Gislene, and Carvalho, A.R., 2016, Spatial associations of ecosystem services and biodiversity as a baseline for systematic conservation planning: Diversity and Distributions, v. 22, no. 9, p. 932-943.

Manier, Daniel, and O’Donnell, Michael, 2018, Data-Compilation and assessment of resource values and hazards to inform transportation planning and associated land-use planning: U.S. Geological Survey data release, https://doi. org/10.5066/F7MW2F8W.

Mark, D.M., 1988, Network models in geomorphology, in Anderson, M.G., ed., Modelling in Geomorphological Systems: Chichester, John Wiley, p. 73-97.

Mustafa, A.A., Singh, Man, Sahoo, R.N., Ahmed, Nayan, Khanna, Manoj, Sarangi, A., and Misha, A.K., 2011, Land suitability analysis for different crops-A multi criteria decision making approach using remote sensing and GIS: Researcher, v. 3, no. 12, p. 61-84.

National Fish Habitat Partnership, 2014, National Fish Habitat Partnership data system: U.S. Geological Survey, accessed June 2014 at https://ecosystems.usgs.gov/fishhabitat/. 
National Park Service [NPS], 2010, Nationwide Rivers Inventory: National Park Service, accessed April 2010 at http:// www.nps.gov/ncrc/programs/rtca/nri/.

National Park Service [NPS], 2015a, National Register of Historic Places Program - Research: National Park Service, accessed October 2015 at https://www.nps.gov/nr/research/.

National Park Service [NPS], 2015b, National Trails System: National Park Service, accessed April 2015 at https://www. nps.gov/nts/.

National Park Service [NPS], 2015c, Natural sounds: National Park Service, accessed August 2015 at https://www.nature. nps.gov/sound.

National Research Council (U.S.) Committee on Ecological Impacts of Road Density, 2005, Assessing and managing the ecological impacts of paved roads: Washington, D.C., The National Academies Press, 294 p.

National Wild and Scenic Rivers System, 2014, National wild \& scenic rivers system map: Burbank, WA, Bureau of Land Management, National Park Service, U.S. Fish and Wildlife Service and U.S.D.A. Forest Service, accessed April 2014 at https://www.rivers.gov/mapping-gis.php.

Natural Resources Conservation Service [NRCS], 2013, Gridded Soil Survey Geographic (gSSURGO-10) Database for the conterminous United States-10 meter: U.S. Department of Agriculture, Natural Resources Conservation Service, accessed February 2013 at https:/catalog.data.gov/dataset/ gridded-soil-survey-geographic-gssurgo-10-database-forthe-conterminous-united-states-10-m.

NatureServe, 2014, Data, maps and tools: Arlington, Va, NatureServe, accessed June 2014 at http://www.natureserve. org/conservation-tools/data-maps-tools.

Peterson, M.D., Moschetti, M.P., Powers, P.M., Mueller, C.S., Haller, K.M., Frankel, A.D., Zeng, Yuehua, Rezaeian, Sanaz, Harmsen, S.C., Boyd, O.S., Field, Ned, Chen, Rui, Rukstales, K.S., Luco, Nico, Wheeler, R.L., Williams, R.A., and Olsen A.H., 2014, Documentation for the 2014 update of the United States national seismic hazard maps: U.S. Geological Survey Open-File Report 2014-1091, 243 p., accessed February 2017 at https://doi.org/10.3133/ ofr20141091.

Petraglia, L.M., and Weisbrod, G.E., 2004, Integrating tourism and recreation travel with transportation planning and project delivery: Washington, D.C., Transportation Research Board, $61 \mathrm{p}$.

Rahman, M.A., Rusteberg, Bernd, Gogu, R.C., Lobo Ferreira, J.P., and Sauter, Martin, 2012, A new spatial multi-criteria decision support tool for site selection for implementation of managed aquifer recharge: Journal of Environmental Management, v. 99, p. 61-75.
Ramirez-Villegas, Julián, Cuesta, Francisco, Devenish, Christian, Peralvo, Manuel, Jarvis, Andy, and Arnillas, C.A., 2014, Using species distributions models for designing conservation strategies of Tropical Andean biodiversity under climate change: Journal for Nature Conservation, v. 22 , no. 5 , p. $391-404$.

Richardson, Leslie, Huber, Chris, Thomas, Cathy, Donovan, Liz, and Koontz, Lynne, 2014, Collaborative socioeconomic tool development to address management and planning needs: The George Wright Forum, v. 31, no. 2, p. 205-214, accessed December 2014 at https://pubs.er.usgs.gov/ publication/70174907.

Ricketts, T.H., 2001, Aligning conservation goals-Are patterns of species richness and endemism concordant at regional scales?: Animal Biodiversity and Conservation, v. 24, no.1, p. 91-99.

Rotmans, J., and van Asselt, M., 1999, Integrated assessment modelling, chap. 7 of Martens, P., Rotmans, J., Jansen, D., and Vrieze, K., eds., Climate change-An integrated perspective: Springer Netherlands, Dordrecht, p. 239-275.

Schmale, Julia, von Schneidemesser, Erika, and Dörrie, Axel, 2015, An integrated assessment method for sustainable transport system planning in a middle sized German city: Sustainability (Switzerland), v. 7, no. 2, p. 1329-1354.

Sharifi, M.A., Boerboom, L., Shamsudin, K.B., and Veeramuthu, L., 2006, Spatial multiple criteria decision analysis in integrated planning for public transport and land use development study in Klang Valley, Malaysia, in ISPRS Technical Commission II Symposium, Vienna, Austria, 2006, Proceedings: International Society for Photogrammetry and Remote Sensing, p. 85-91.

Shilling, F.M., and Waetjen, D.P., 2012, The road effect zone GIS model: Davis, Calif., University of California, Davis, Institute of Transportation Studies, Research Report UCDITS-RR-12-16, $14 \mathrm{p}$.

Soille, Pierre, 2004, Optimal removal of spurious pits in grid digital elevation models: Water Resources Research, v. 40, no. 12,9 p.

Spiker, E.C., and Gori, P.L., 2003, National landslide hazards mitigation strategy - A framework for loss reduction: U.S. Geological Survey Circular 1244, 56 p., accessed July 2015 at http://www.scopus.com/inward/record.url?eid=2-s2.08344266116\&partnerID $=40 \&$ md5 $=74$ ea5850f762fa 030514 8b489a0eb3fc.

Store, Ron, and Kangas, Jyrki, 2001, Integrating spatial multicriteria evaluation and expert knowledge for GIS-based habitat suitability modelling: Landscape and Urban Planning, v. 55, no. 2, p. 79-93.

Temiz, Nurcan, and Tecim, Vahap, 2009, The use of GIS and multi-criteria decision-making as a decision tool in forestry: OR Insight, v. 22, no. 2, p. 105-123. 
Tobin, B.D., and Weary, D.J., 2004, Digital engineering aspects of karst map - A GIS version of Davies, W.E., Simpson, J.H., Ohlmacher, G.C., Kirk, W.S., and Newton, E.G., 1984, Engineering aspects of karst, U.S. Geological Survey, National Atlas of the United States of America, Scale 1:7,500,000: U.S. Geological Survey Open-File Report 2004-1352, accessed February 2017 at https://pubs. usgs.gov/of/2004/1352/.

Trzaska, Sylwia, and Schnarr, Emilie, 2014, A review of downscaling methods for climate change projections: Washington, D.C., U.S. Agency for International Development, prepared by Tetra Tech ARD, $56 \mathrm{p}$.

U.S. Department of Agriculture Forest Service [USFS], 2001, Roadless areas: U.S. Department of Agriculture Forest Service, accessed May 2014 at http://www.fs.usda.gov/main/ roadless/2001roadlessrule/maps.

U.S. Department of Agriculture Forest Service [USFS], 2015, Recreational, heritage and volunteer resources: U.S. Department of Agriculture Forest Service, accessed April 2015 at http://www.fs.fed.us/recreation/.

U.S. Endowment for Forestry and Communities, 2015, National Conservation Easement Database [NCED]: U.S. Endowment for Forestry and Communities, accessed February 2015 at https://www.conservationeasement.us.

U.S. Environmental Protection Agency [EPA], 2014, EnviroAtlas data: U.S. Environmental Protection Agency, accessed August 2014 at https://www.epa.gov/enviroatlas.

U.S. Environmental Protection Agency [EPA], 2015a, Facility Registry Service - Geospatial Data Download Service: U.S. Environmental Protection Agency, accessed July 2015 at https://www.epa.gov/enviro/facility-registry-service-frs.

U.S. Environmental Protection Agency [EPA], 2015b, Impaired waters and TMDLs - Resources, tools and databases: U.S. Environmental Protection Agency, accessed March 2015 at https://www.epa.gov/tmdl/impaired-watersand-tmdls-resources-tools-and-databases.

U.S. Environmental Protection Agency [EPA], 2015c, NHDPlus Indexed Dataset-Beaches: U.S. Environmental Protection Agency, accessed November 2015 at https://www.epa.gov/ waterdata/waters-geospatial-data-downloads\#Beaches.

U.S. Fish \& Wildlife Service [FWS], 2014, U.S. FWS threatened \& endangered species active critical habitat report: U.S. Fish \& Wildlife Service, accessed July 2014 at https:// ecos.fws.gov/ecp/report/table/critical-habitat.html.

U.S. Fish \& Wildlife Service [FWS], 2015, Recreational opportunities, U.S. Fish \& Wildlife Service, accessed April 2015 at https://catalog.data.gov/dataset/trail-line-and-pointfeatures-u-s-fish-and-wildlife-service.

U.S. Geological Survey [USGS], 2006, Digital elevation models (DEMs): U.S. Geological Survey Long Term Archive, accessed November 2006 at https://lta.cr.usgs.gov/DEMs. (Note: these data are no longer provided. Revised elevation data products are available from https://nationalmap.gov/ elevation.html.)

U.S. Geological Survey [USGS], 2013, National Gap Analysis Program - Core science analytics and synthesis: U.S. Geological Survey, accessed August 2013 at https://gapanalysis. usgs.gov/padus/data/.

U.S. Geological Survey [USGS], 2014a, National hydrography dataset: U.S. Geological Survey, accessed February 2014 at https://nhd.usgs.gov/.

U.S. Geological Survey [USGS], 2014b, United StatesLower 48, 2014 long-term model: U.S. Geological Survey National Seismic Hazard Mapping Project, accessed July 2015 at https://earthquake.usgs.gov/hazards/hazmaps/ conterminous/index.php\#2014.

U.S. Geological Survey [USGS], 2015, Protected Areas Data: U.S. Geological Survey National Gap Analysis Program, accessed February 2015 at http://gapanalysis.usgs.gov/ padus/data/.

van Donkelaar, A., Martin, R.V., Brauer, M., and Boys, B.L., 2015, Global annual $\mathrm{PM}_{2.5}$ grids from MODIS, MISR and SeaWiFS Aerosol Optical Depth (AOD), 1998-2012: Palisades, N.Y., National Aeronautics and Space Administration Socioeconomic Data and Applications Center (SEDAC), accessed July 2015 at http://sedac.ciesin.columbia.edu/data/ set/sdei-global-annual-avg-pm2-5-modis-misr-seawifsaod-1998-2012.

Wang, T., Hamann, A., Spittlehouse, D., and Carroll, C., 2016, Locally downscaled and spatially customizable climate data for historical and future periods for North America: PLoS ONE, v. 11 , no. 6,17 p.

Weary, D.J., and Doctor, D.H., 2014, Karst in the United States-A digital map compilation and database: U.S. Geological Survey Open-File Report 2014-1156, 23 p., accessed February 2017 at https://doi.org/10.3133/ ofr20141156.

Wechsler, S.P., 2007, Uncertainties associated with digital elevation models for hydrologic applications-A review: Hydrology and Earth System Sciences Discussions, v. 11, p. 1481-1500.

Wilbert, Mark, Thomson, Janice, and Culver, N.W., 2008, Analysis of habitat fragmentation from oil and gas development and its impact on wildlife-A framework for public land management planning: Washington, D.C., The Wilderness Society, 33 p.

Wilson, M.F.J., O’Connell, Brian, Brown, Colin, Guinan, J.C., and Grehan, A.J., 2007, Multiscale terrain analysis of multibeam bathymetry data for habitat mapping on the continental slope: Marine Geodesy, v. 30, p. 3-35. 


\section{Appendix 1. Supporting Tables}

Because of the tremendous volume of information described herein, each "Methods" subsection of the report refers to a table in the appendix summarizing the data inputs (tables 1.1 to 1.5 ). In addition, table 1.6 provides a summary of the calculations used for selected metrics. 
Table 1.1. Terrestrial Resource Values Index-Summary of source datasets used for terrestrial species and habitat indices.

[EPA, U.S. Environmental Protection Agency; Esri, Environmental Systems Research Institute; GAP, Gap Analysis Program; GPS, global positioning system (spatial accuracy of GPS are typically 3-5 m, but accuracy may vary with location); HUC12, hydrologic unit code for 12-digit subwatershed units; m, meter; T\&E, threatened and endangered; TR 1, Terrestrial Resource Values Metric 1; TR 2, Terrestrial Resource Values Metric 2; TR 3, Terrestrial Resource Values Metric 3; USGS, U.S. Geological Survey]

\begin{tabular}{|c|c|c|c|c|c|}
\hline Data source & Index & $\begin{array}{c}\text { Content } \\
\text { (source version or year) }\end{array}$ & $\begin{array}{c}\text { Scale/resolution } \\
\text { (horizontal accuracy) }\end{array}$ & Contents & URL \\
\hline NatureServe & TR1 & $\begin{array}{l}\text { Bird and mammal species distributions } \\
\quad \text { (June 2014) }\end{array}$ & $1: 1,000,000(846 \mathrm{~m})$ & $\begin{array}{l}\text { Birds are global; mammals are western hemisphere; sum of spe- } \\
\text { cies per location (NatureServe, 2014) }\end{array}$ & $\begin{array}{l}\text { http://www.natureserve.org/conservation-tools/ } \\
\text { data-maps-tools/ }\end{array}$ \\
\hline EPA, EnviroAtlas & TR1 & Reptiles (June 2014) & HUC12 $(30 \mathrm{~m})$ & Habitats for reptiles; sum of species per location & https://enviroatlas.epa.gov/enviroatlas/ \\
\hline $\begin{array}{l}\text { International Union for Conserva- } \\
\text { tion of Nature }\end{array}$ & TR2 & Red list of threatened species (version 4) & $\begin{array}{l}\text { Polygon [scale/resolution is not } \\
\text { specified by the producers] }\end{array}$ & $\begin{array}{l}\text { Global datasets for T\&E species - amphibians, mammals; sum } \\
\text { of species per location (IUCN, 2013) }\end{array}$ & $\begin{array}{l}\text { http://www.iucnredlist.org/technical-docu- } \\
\text { ments/spatial-data }\end{array}$ \\
\hline Bureau of Land Management & TR2 & $\begin{array}{l}\text { Area of critical environmental concern } \\
\text { (2015) }\end{array}$ & $\begin{array}{l}\text { Polygon [scale/resolution is not } \\
\text { specified by the producers] }\end{array}$ & $\begin{array}{l}\text { Location of lands managed to prevent damage to historical, } \\
\text { cultural, or scenic values (BLM, 2015) }\end{array}$ & https://navigator.blm.gov \\
\hline $\begin{array}{l}\text { U.S. Endowment for Forestry and } \\
\text { Communities }\end{array}$ & TR2 & $\begin{array}{l}\text { National Conservation Easement Data- } \\
\text { base (2015) }\end{array}$ & $\begin{array}{l}\text { Polygon [scale/resolution is not } \\
\text { specified by the producers] }\end{array}$ & $\begin{array}{l}\text { Conservation easements by land trusts and public agencies; } \\
\text { includes approximately } 40 \text { million records; some easements } \\
\text { not represented at the time of data acquisition (U.S. Endow- } \\
\text { ment for Forestry and Communities, 2015) }\end{array}$ & https://www.conservationeasement.us/ \\
\hline $\begin{array}{l}\text { USGS National Gap Analysis } \\
\text { Program }\end{array}$ & TR2 & Protected Areas Database locations (2013) & Polygon $(1: 24,000$ to $1: 1,980,000)$ & $\begin{array}{l}\text { Geodatabase, managed by USGS GAP, that illustrates and } \\
\text { describes public land ownership, management, and other } \\
\text { conservation lands, including voluntarily provided, privately- } \\
\text { owned protected areas (USGS, 2013) }\end{array}$ & http://gapanalysis.usgs.gov/padus/data/ \\
\hline Forest Service & TR2 & Roadless areas (2001) & Polygon $(1: 24,000)$ & $\begin{array}{l}\text { Inventoried roadless areas used in the "2001 Final Environmen- } \\
\text { tal Impact Statement for the Roadless Area Conservation } \\
\text { Rule," and special designated areas (Forest Service, 2001) }\end{array}$ & $\begin{array}{l}\text { http://www.fs.usda.gov/main/ } \\
\text { roadless/2001 roadlessrule/maps }\end{array}$ \\
\hline Forest Service & TR3 & Recreational opportunities (2015) & Point, line, polygon $(1: 24,000)$ & $\begin{array}{l}\text { Recreation facilities, trails, National Monuments, National } \\
\text { Recreational Areas, National Wildlife Refuges, Wilderness } \\
\text { Areas, Wild and Scenic Rivers with recreational opportuni- } \\
\text { ties (Forest Service, 2015) }\end{array}$ & http://www.fs.fed.us/recreation/ \\
\hline U.S. Fish and Wildlife Service & TR3 & Recreational opportunities (2015) & Point, line $(1: 24,000)$ & Recreation facilities and trails (FWS, 2015) & $\begin{array}{l}\text { https://catalog.data.gov/dataset/trail-line-and- } \\
\text { point-features-u-s-fish-and-wildlife-service }\end{array}$ \\
\hline Appalachian Trail Conservancy & TR3 & Recreational opportunities (2015) & Point, line (GPS) & Shelters and parking lots (Appalachian Trail Conservancy, 2015) & $\begin{array}{l}\text { http://www.appalachiantrail.org/home/explore- } \\
\text { the-trail/gis-data }\end{array}$ \\
\hline Appalachian Trail Conservancy & TR3 & Recreational opportunities (2015) & Line (GPS) & $\begin{array}{l}\text { Appalachian Trail location (Appalachian Trail Conservancy, } \\
\text { 2015) }\end{array}$ & $\begin{array}{l}\text { http://www.appalachiantrail.org/home/explore- } \\
\text { the-trail/gis-data }\end{array}$ \\
\hline Continental Divide Trail Coalition & TR3 & Recreational opportunities (2015) & Line (GPS) & $\begin{array}{l}\text { Colorado, Montana, New Mexico, and Wyoming, trail locations } \\
\text { (Continental Divide Trail Coalition, 2015) }\end{array}$ & http://continentaldividetrail.org/cdt-data/ \\
\hline Esri & TR3 & Recreational opportunities (2013) & Polygon $(1: 24,000)$ & $\begin{array}{l}\text { Federal, State, and local park boundaries } \\
\text { (Esri, 2013) }\end{array}$ & $\begin{array}{l}\text { http://services.argis.com/ } \\
\text { P3ePLMYs2RVChklx/arcgis/rest/services/ } \\
\text { usa_Parks/Feature Server }\end{array}$ \\
\hline Bureau of Land Management & TR3 & Recreational opportunities (2015) & Polygon $(1: 24,000)$ & $\begin{array}{l}\text { Wilderness Study Areas, Wilderness Areas, } \\
\text { National Wildlife Refuges, National } \\
\text { Recreational Areas, National Monuments, National Conser- } \\
\text { vation Areas (BLM, 2015) }\end{array}$ & https://navigator.blm.gov \\
\hline $\begin{array}{l}\text { USGS National Gap Analysis } \\
\text { Program }\end{array}$ & TR3 & Recreational opportunities (2013) & Polygon $(1: 24,000)$ & $\begin{array}{l}\text { Protected areas providing outdoor recreation opportunities } \\
\text { (USGS, 2013) }\end{array}$ & http://gapanalysis.usgs.gov/ \\
\hline
\end{tabular}

Data from the International Union for Conservation of Nature (IUCN, 2013) may not be redistributed, but it may be acquired from the source (http://www.iucnredlist.org/technical-documents/spatial-data). Data presented with this report are derivatives of the IUCN source information, which was downloaded/updated from http://www.iucnredlist.org/www.iucnredlist.org in June 2014. 
Table 1.2. Aquatic Resource Values Index-Summary of source datasets used to inform aquatic species and habitat indices.

[AQ1, Aquatic Resource Values Metric 1; AQ2, Aquatic Resource Values Metric 2; AQ3, Aquatic Resource Values Metric 3; AQ4, Aquatic Resource Values Metric 4; BLM, Bureau of Land Management; EPA, U.S. Environmental Protection Agency; FS, U.S. Department of Agriculture Forest Service; FWS, U.S. Fish \& Wildlife Service; HUC, hydrologic unit codes used in the NHD; HUC8, hydrologic unit code for 8-digit sub-basins; HUC12, hydrologic unit code for 12-digit subwatershed; m, meter; NFHAP, National Fish Habitat Partnership; NHD, National Hydrologic Dataset; NHDPlus, National Hydrologic Dataset, PLUS version; USGS, U.S. Geological Survey]

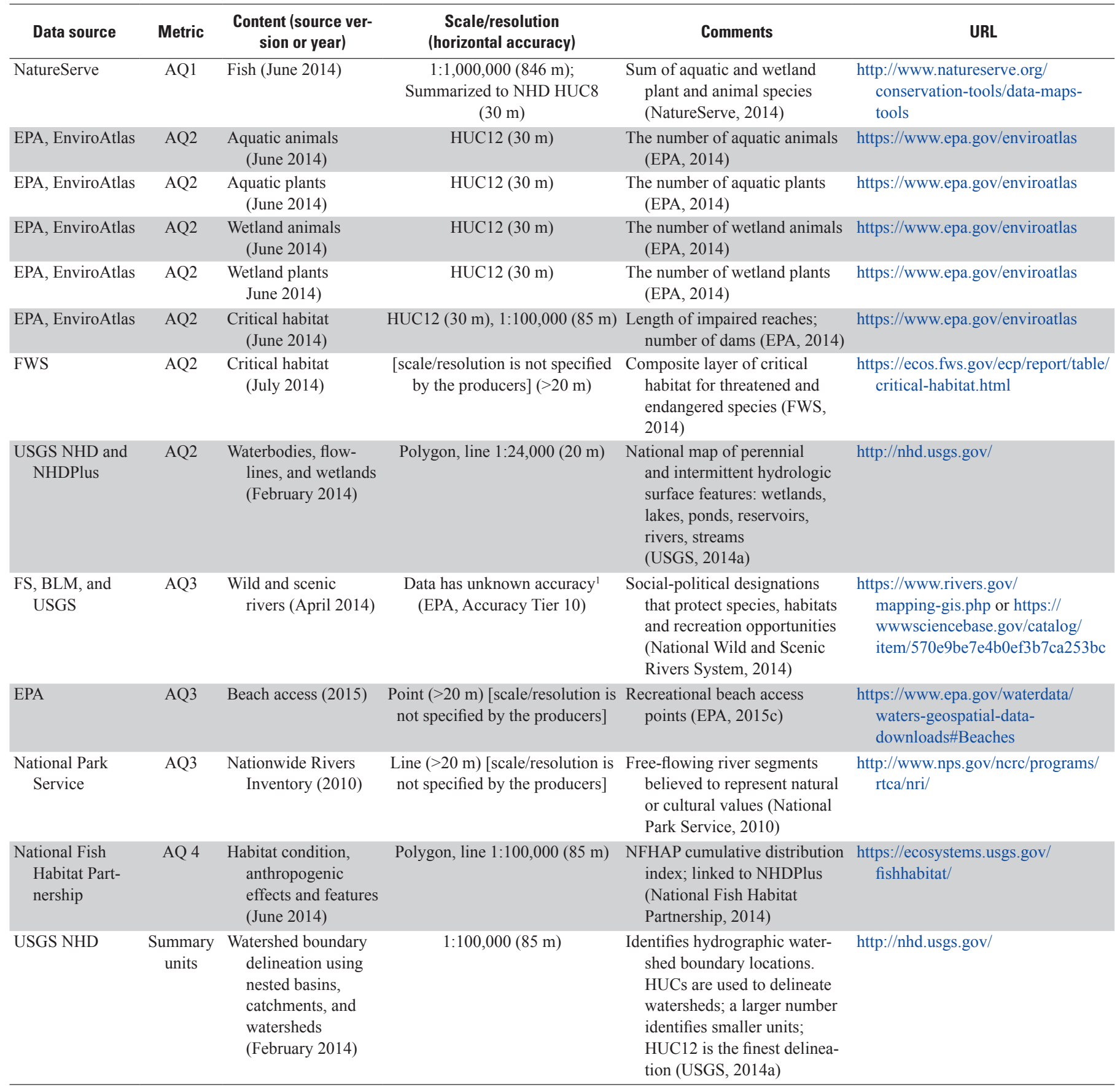

\footnotetext{
${ }^{1}$ For more information on horizontal accuracy and data standards, please see EPA's National Geospatial Data Policy at https://www.epa.gov/geospatial.
} 
Table 1.3. Cultural Resource Values Index-Summary of source datasets used to inform the development of the Cultural Resource Values Index.

[CR1, Cultural Resource Values Metric 1; CR2, Cultural Resource Values Metric 2; m, meter; NPS, National Park Service]

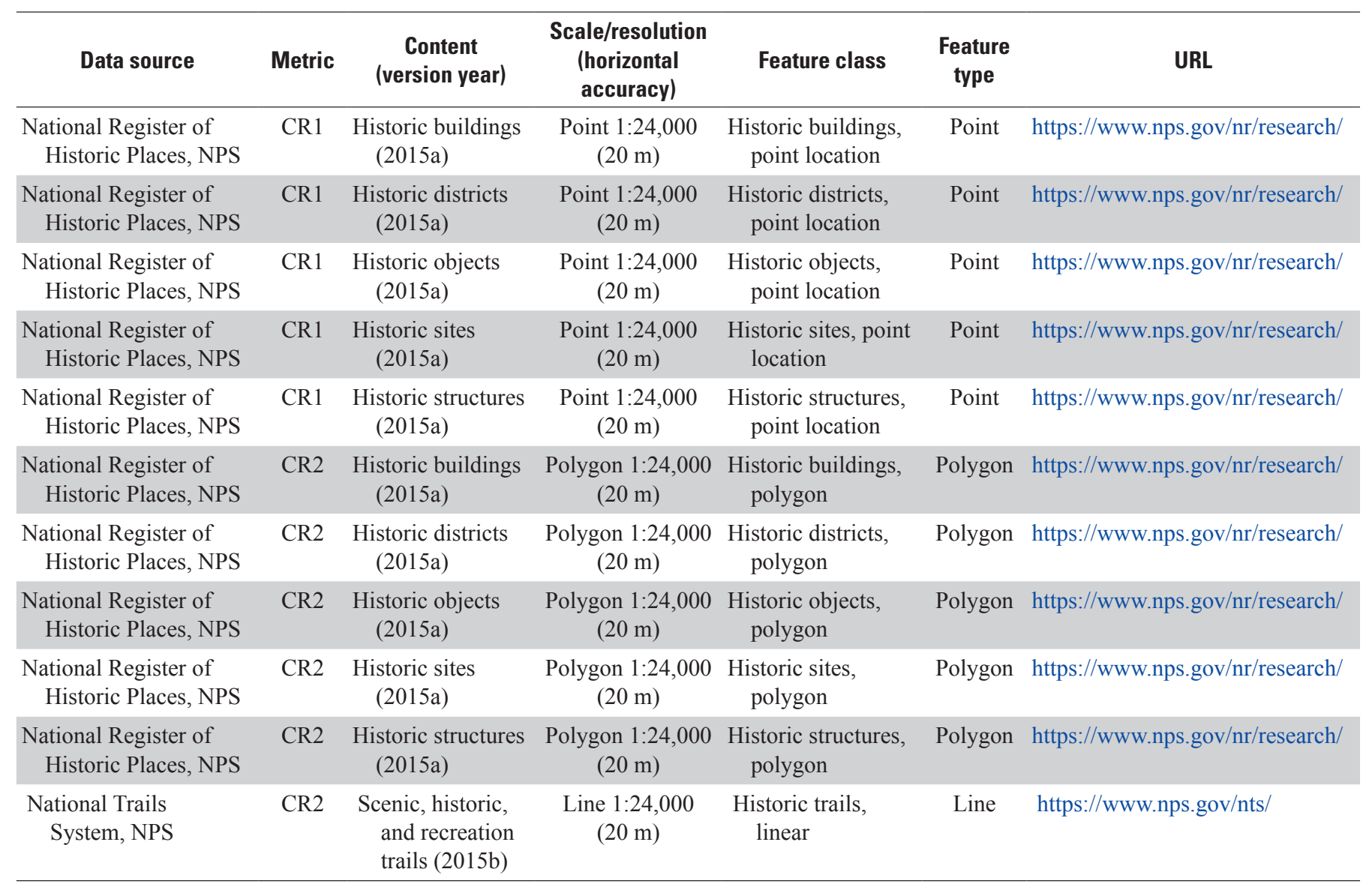


Table 1.4. Land-Use Conditions-Summary of source datasets used for the integrated land-use condition metrics.

[Additional source data exist for landscape characteristics, but these were excluded due to quality, accuracy, or duplication of content. gSSURGO, Gridded Soil Survey Geographic Database; LC1, Landscape Condition Metric 1; LC2, Landscape Condition Metric 2; m, meter; NRCS, Natural Resources Conservation Service]

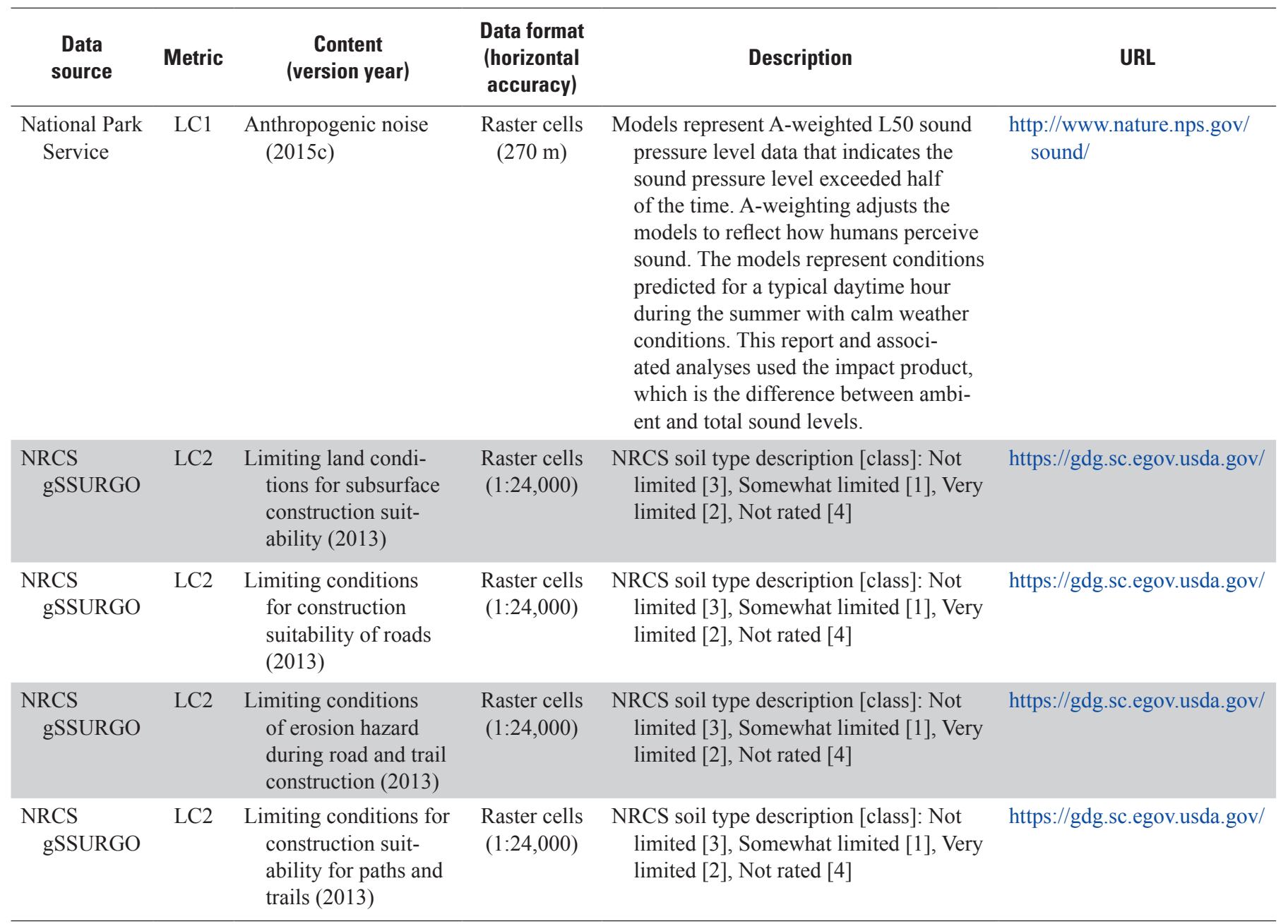


[\%, percent; EPA, U.S. Environmental Protection Agency; FEMA, Federal Emergency Management Agency; FIRM, Flood Insurance Rate Map; gSSURGO, Gridded Soil Survey Geographic Database; HZ1, Natural Hazards Metric 1; HZ2, Natural Hazards Metric 2; HZ3, Natural Hazards Metric 3; HZ4, Natural Hazards Metric 4; HZ5, Natural Hazards Metric 5; km, kilometer; m, meter; MISR, Multi-angle Imaging Spectroradiometer; MODIS, Moderate Resolution Imaging Spectroradiometer; NASA, National Aeronautics and Space Administration; NRCS, Natural Resources Conservation Service; PM 25 , particulate matter smaller than or equal to 2.5 micrometers in diameter; SeaWiFS, Sea-viewing Wide Field-of-view Sensor; USGS, U.S. Geological Survey; yrs, years]

\begin{tabular}{|c|c|c|c|c|c|}
\hline Data source & Metric & $\begin{array}{l}\text { Content (source } \\
\text { version, year) }\end{array}$ & $\begin{array}{c}\text { Scale/resolution } \\
\text { (horizontal accuracy) }\end{array}$ & Comments & URL \\
\hline $\begin{array}{l}\text { USGS, National Map: U.S. karst } \\
\text { polygons }\end{array}$ & $\mathrm{HZ1}$ & $\begin{array}{l}\text { Karst distribution for inferred } \\
\text { sinkhole potential (2004) }\end{array}$ & $1: 7,500,000(6,344 \mathrm{~m})$ & $\begin{array}{l}\text { National karst data coverage to use for graphic and demonstration purposes. This da- } \\
\text { taset is a vector near-facsimile of the National Atlas map in "Engineering Aspects } \\
\text { of Karst" by William E. Davies and others, } 1984 \text { (Tobin and Weary, 2004) }\end{array}$ & https://pubs.usgs.gov/of/2004/1352/ \\
\hline USGS landslide potential & $\mathrm{HZ} 1$ & Landslide potential (1997) & $1: 3,750,000(3,172 \mathrm{~m})$ & $\begin{array}{l}\text { National landslide potential data coverage to use for graphic and demonstration } \\
\text { purposes. It provides a general indication of areas that may be susceptible to } \\
\text { landsliding. It is not suitable for local planning or site selection. (Godt, 1997) }\end{array}$ & $\begin{array}{l}\text { https://pubs.er.usgs.gov/publication/ } \\
\text { ofr97289/ }\end{array}$ \\
\hline $\begin{array}{l}\text { USGS, National Map: significant } \\
\text { U.S. earthquakes, } 1568-2004\end{array}$ & $\mathrm{HZ} 1$ & Earthquake potential (2004) & $1: 2,000,000(1,692 \mathrm{~m})$ & $\begin{array}{l}\text { This map layer is intended for specialists and nonspecialists who have a need for } \\
\text { general, nontechnical information about significant United States earthquakes. } \\
\text { (Hopper and others, 2005) }\end{array}$ & $\begin{array}{l}\text { https://catalog.data.gov/dataset/ } \\
\text { significant-united-states- } \\
\text { earthquakes-1568-2004-direct- } \\
\text { download }\end{array}$ \\
\hline $\begin{array}{l}\text { FEMA national flood hazard } \\
\text { layer }\end{array}$ & $\mathrm{HZ} 2$ & $\begin{array}{l}\text { Flood potential from historic } \\
\text { occurrences (2015) }\end{array}$ & $1: 12,000(3 \mathrm{~m})$ & $\begin{array}{l}\text { Incorporates all FIRM databases published by FEMA; the FIRM databases archive } \\
\text { flood risk information. The risk classifications are } 1 \% \text { annual-chance event } \\
(1 \text { per } 100 \mathrm{yrs}), 0.2 \% \text { annual-chance event ( } 1 \text { per } 2,000 \text { yrs), and areas of } \\
\text { minimal flood risk. (FEMA, 2015a) }\end{array}$ & $\begin{array}{l}\text { https://www.fema.gov/national- } \\
\text { flood-hazard-layer-nfhl }\end{array}$ \\
\hline NRCS gSSURGO & HZ2 & $\begin{array}{l}\text { Flood frequency (2006, revised } \\
\text { in 2012) }\end{array}$ & $1: 100,000(846 \mathrm{~m})$ & $\begin{array}{l}\text { Dominant soil conditions of map units with attribution for engineering and building } \\
\text { conditions. Flood frequency is a component of aggregated attributes for each } \\
\text { map unit. (NRCS, 2013) }\end{array}$ & $\begin{array}{l}\text { https://www.nrcs.usda.gov/wps/ } \\
\text { portal/nrcs/detail/soils/survey/ } \\
\text { geo/ }\end{array}$ \\
\hline NRCS gSSURGO & HZ2 & $\begin{array}{l}\text { Ponding potential (2006, } \\
\text { revised in 2012) }\end{array}$ & $1: 100,000(846 \mathrm{~m})$ & $\begin{array}{l}\text { Dominant soil conditions of map units with attribution for engineering and building } \\
\text { conditions. Ponding potential is a component of the aggregated attributes for } \\
\text { each map unit. (NRCS, 2013) }\end{array}$ & $\begin{array}{l}\text { https://www.nrcs.usda.gov/wps/ } \\
\text { portal/nrcs/detail/soils/survey/ } \\
\text { geo/ }\end{array}$ \\
\hline NRCS gSSURGO & HZ2 & $\begin{array}{l}\text { Wetland potential (2006, } \\
\text { revised in 2012) }\end{array}$ & $1: 100,000(846 \mathrm{~m})$ & $\begin{array}{l}\text { Dominant soil conditions of map units with attribution for engineering and building } \\
\text { conditions. Wetland potential is a component of aggregated attributes for each } \\
\text { map unit. (NRCS, 2013) }\end{array}$ & $\begin{array}{l}\text { https://www.nrcs.usda.gov/wps/ } \\
\text { portal/nrcs/detail/soils/survey/ } \\
\text { geo/ }\end{array}$ \\
\hline EPA, EnviroAtlas & HZ3 & $\begin{array}{l}\text { Chemical and environmental } \\
\text { risks (June 2014) }\end{array}$ & $1: 24,000(20 \mathrm{~m})$ & $\begin{array}{l}\text { All transportation hubs that transport hazardous chemicals according to EPA facili- } \\
\text { tie's data. Approximately } 11,904 \text { facilities exist in this dataset. (EPA, 2014) }\end{array}$ & $\begin{array}{l}\text { https://www.epa.gov/enviro/facility- } \\
\text { registry-service-frs }\end{array}$ \\
\hline NASA, Earthdata & HZ4 & $\begin{array}{l}\text { Air pollution between } 1998 \text { and } \\
\quad 2010(2012)\end{array}$ & $10-\mathrm{km}$ raster cells & $\begin{array}{l}\text { Global Annual } \text { PM }_{2.5} \text { raster dataset combines multiple source datasets created } \\
\text { from MODIS, MISR and SeaWiFS satellite estimates of Aerosol Optical } \\
\text { Depth converted to estimates of fine particulate matter (solid particles and } \\
\text { liquid droplets). Source data were acquired for these intervals: 1998-2000, } \\
\text { 1999-2001, 2000-2002, 2001-2003, 2002-2004, 2004-2006, 2005-2007, } \\
\text { 2006-2008, 2007-2009, 2008-2010, 2009-2011, 2010-2012, and 2001-2010. } \\
\text { (van Donkelaar and others, 2015) }\end{array}$ & $\begin{array}{l}\text { https://earthdata.nasa.gov/earth- } \\
\text { observation-data/near-real-time/ } \\
\text { hazards-and-disasters/air-quality }\end{array}$ \\
\hline EPA, EnviroAtlas & HZ5 & Impaired waters (2015) & $1: 100,000(85 \mathrm{~m})$ & $\begin{array}{l}\text { Section 303(d) listings under the Clean Water Act that are linked the the National } \\
\text { Hydrologic Database. (EPA, 2015b) }\end{array}$ & https://www.epa.gov/enviroatlas \\
\hline
\end{tabular}


Table 1.6. Summary of equations and descriptions of aggregated indices and metrics compiled to support transportation planning. Source data and some intermediate metrics used to create the final metrics and indices are not specified here.

[acc, access point; ACEC, Areas of Critical Environmental Concern; AQ, Aquatic Resource Values Index; ArcGIS, geospatial data analysis software from Esri; Bch, beach; BLM, Bureau of Land Management; Cnt, count; ConsArea, conservation area; CONUS, continental United States; CrHab, critical habitat; CumDistInd, Cumulative Distance Index; dB, decibel; DEM, digital elevation model; Dist, distance to feature of interest; enddwdbcd, gSSURGO attribute for subsurface construction suitability; englrsded, gSSURGO attribute for construction suitability for roads; EPA, U.S. Environmental Protection Agency; Esri, Environmental Systems Research Institute; FEMA, Federal Emergency Management Agency; fl, flowlines; FLH, Office of Federal Lands Highway; forpehrtdc, potential for erosion of dominant soil type during road and trail construction; FWS, U.S. Fish \& Wildlife Service; GDAL, Geospatial Data Abstract Library; gSSURGO, Gridded Soil Survey Geographic Database; gw, groundwater; HCI, Habitat Condition Index; HUC12, hydrologic unit code for 12-digit subwatersheds; max, maximum; NASA, National Aeronautics and Space Administration; NCED, National Conservation Easement Database; NPS, National Park Service; NRCS, Natural Resources Conservation Service; PADUS, Protected Areas Database of the United States; Prop, proportion; T\&E, threatened and endangered; TL, total length of linear segment(s); TR, Terrestrial Resource Values Index; urbrecptdc, potential suitability of dominant soil type for constructing paths and trails; urbrecptwta, weighted average for potential suitability for constructing paths and trails; wb, waterbody; wet, wetland(s); WSRblm, Bureau of Land Management-designated Wild and Scenic River; WSRfs, U.S. Department of Agriculture Forest Service-designated Wild and Scenic River]

\begin{tabular}{|c|c|c|c|}
\hline Index & Calculation & Description & Explanation \\
\hline Terrestrial Resource Value Index & $\begin{array}{l}\mathrm{TR}=0.375 \times \mathrm{TR} 1+0.5 \times \max [\mathrm{TR} 2 \mathrm{a}, \\
\mathrm{TR} 2 \mathrm{~b}]+0.125 \times \mathrm{TR} 3\end{array}$ & $\begin{array}{l}\text { Weighted equation recommended because it increases } \\
\text { the emphasis on habitat designations and species } \\
\text { diversity, and reduces emphasis on recreation areas. }\end{array}$ & $\begin{array}{l}\text { Different weighting of input variables is important for bal- } \\
\text { ancing the influence model inputs with different attribu- } \\
\text { tion and resolution; it should be logical but also promote } \\
\text { useful delineation of the landscape. }\end{array}$ \\
\hline $\begin{array}{l}\text { Terrestrial Resource Metric 1: Species } \\
\text { Diversity }\end{array}$ & Cell-by-cell count & $\begin{array}{l}\text { Summed occurrences represented by union of species } \\
\text { distribution models. }\end{array}$ & $\begin{array}{l}\text { The total number of species represents species richness (an } \\
\text { index of diversity). }\end{array}$ \\
\hline $\begin{array}{l}\text { Terrestrial Resource Metric 2a: Critical } \\
\text { Habitat }\end{array}$ & $\begin{array}{l}\text { Watershed (HUC12) based sum: } \\
\text { [TR_T\&E animals] + [TR_T\&E } \\
\text { plants] }+[\text { Dist_FWS CrHab }]\end{array}$ & $\begin{array}{l}\text { Critical habitat value for subwatersheds (HUC12) based } \\
\text { on the number of T\&E plants and animals, and the } \\
\text { mean distance to designated critical habitats; inverse } \\
\text { so shorter distances incur greater potential value. }\end{array}$ & $\begin{array}{l}\text { Habitats were assigned wildlife value based on the number } \\
\text { of species, and listed T\&E species associated with those } \\
\text { habitats, as well as existing FWS Habitat Designations. }\end{array}$ \\
\hline $\begin{array}{l}\text { Terrestrial Resource Metric 2b: } \\
\text { Conservation Areas }\end{array}$ & $\begin{array}{l}\text { Watershed (HUC12) based sum: [Cnt_ } \\
\text { ACEC] }+ \text { [Cnt_NCED,PADUS] }+ \\
\text { [Cnt_Roadless] }+ \text { [ConsArea }]\end{array}$ & $\begin{array}{l}\text { This index is a combination of the number of conserva- } \\
\text { tion units and the area occupied by all conservation } \\
\text { areas within each subwatershed (HUC12). }\end{array}$ & $\begin{array}{l}\text { A larger metric value indicates greater potential for effects } \\
\text { of a transportation route or network on sensitive or } \\
\text { protected resources. }\end{array}$ \\
\hline $\begin{array}{l}\text { Terrestrial Resource Metric 3: Social } \\
\text { Designations }\end{array}$ & $\begin{array}{l}\text { Minimum of [Dist_gw], [Dist_park], } \\
\text { [Dist_acc], [Dist_trail] }\end{array}$ & $\begin{array}{l}\text { Calculated the minimum distance to a park (local, State, } \\
\text { Federal), greenway, trail, trailhead, or other access } \\
\text { point. }\end{array}$ & $\begin{array}{l}\text { Proximity to any of these locations implies potential for } \\
\text { impacts on visitor experiences and associated resources. }\end{array}$ \\
\hline Aquatic Resource Value Index & $\begin{array}{r}\mathrm{AQ}=(0.544 \times \max [\mathrm{AQ} 1, \mathrm{AQ} 4])+(0.364 \\
\quad \mathrm{x} \max [\mathrm{AQ} 2 \mathrm{a}, \mathrm{AQ} 2 \mathrm{~b}])+(0.092 \times \mathrm{AQ} 3)\end{array}$ & $\begin{array}{l}\text { Weighted equation recommended because it increases } \\
\text { the emphasis on species diversity and habitat designa- } \\
\text { tions, and reduces emphasis on recreation areas. }\end{array}$ & $\begin{array}{l}\text { Different weighting of input variables is important for bal- } \\
\text { ancing the influence model inputs with different attribu- } \\
\text { tion and resolution; it should be logical but also promote } \\
\text { useful delineation of the landscape. }\end{array}$ \\
\hline $\begin{array}{l}\text { Aquatic Resource Metric 1: Species } \\
\text { Diversity }\end{array}$ & Cell-by-cell count & $\begin{array}{l}\text { Summed occurrences represented by union of species } \\
\text { distribution models to describe species richness. }\end{array}$ & $\begin{array}{l}\text { The total number of species represents species richness (an } \\
\text { index of diversity). }\end{array}$ \\
\hline $\begin{array}{l}\text { Aquatic Resource Metric 2a: Critical } \\
\text { Habitat }\end{array}$ & $\begin{array}{l}\text { Watershed (HUC12) based sum: [AQ_Cnt } \\
\text { T\&EAnimals] + [AQ-Cnt-T\&E Plants] } \\
\text { + [Wet-Cnt T\&EAnimals] + [Wet-Cnt } \\
\text { T\&E Plants] + [FWS CrHab]. Euclid- } \\
\text { ian distance to AQ and Wet features }\end{array}$ & $\begin{array}{l}\text { Assigned habitat values based on the number of aquatic } \\
\text { and wetland obligate and T\&E species expected to } \\
\text { occur in these habitats. Recognized potential effects of } \\
\text { proximity using linear distance to aquatic and wetland } \\
\text { features to classify surrounding lands; inverse so } \\
\text { shorter distances incurs greater potential value. }\end{array}$ & $\begin{array}{l}\text { Statutory regulations indicate that all surface water and wet- } \\
\text { land types are protected and conserved. An abundance } \\
\text { of T\&E species or designated critical habitats may incur } \\
\text { greater review and potential effects on sensitive species. } \\
\text { Habitats scored based on abundance of T\&E species, } \\
\text { and distance to aquatic features represents gradient of } \\
\text { potential effects due to proximity. }\end{array}$ \\
\hline
\end{tabular}

$\begin{array}{cc}\text { Aquatic Resource Metric 2b: } & \text { Watershed (HUC12) based sum: } \\ \text { Conservation/Sensitivity } & {[\text { Dist_wet }]+[\text { Dist_wb }]+[\text { Dist_fl }]+} \\ & {[\text { Prop_wet }]+[\text { Prop_wb }]+[\text { TL_fl }]}\end{array}$

Subwatershed (HUC12) based sum of distance to wetland, waterbody, or flowlines; proportion of wetland and open water; and total length of flowlines (rivers and streams).

A larger metric value indicates greater potential for effects of a transportation route or network on sensitive or protected resources. 
Table 1.6. Summary of equations and descriptions of aggregated indices and metrics compiled to support transportation planning. Source data and some intermediate metrics used to create the final metrics and indices are not specified here.-Continued

[acc, access point; ACEC, Areas of Critical Environmental Concern; AQ, Aquatic Resource Values Index; ArcGIS, geospatial data analysis software from Esri; Bch, beach; BLM, Bureau of Land Management; Cnt, count; ConsArea, conservation area; CONUS, continental United States; CrHab, critical habitat; CumDistInd, Cumulative Distance Index; dB, decibel; DEM, digital elevation model; Dist, distance to feature of interest; enddwdbcd, gSSURGO attribute for subsurface construction suitability; englrsdcd, gSSURGO attribute for construction suitability for roads; EPA, U.S. Environmental Protection Agency; Esri, Environmental Systems Research Institute; FEMA, Federal Emergency Management Agency; fl, flowlines; FLH, Office of Federal Lands Highway; forpehrtdc, potential for erosion of dominant soil type during road and trail construction; FWS, U.S. Fish \& Wildlife Service; GDAL, Geospatial Data Abstract Library; gSSURGO, Gridded Soil Survey Geographic Database; gw, groundwater; HCI, Habitat Condition Index; HUC12, hydrologic unit code for 12-digit subwatersheds; max, maximum; NASA, National Aeronautics and Space Administration; NCED, National Conservation Easement Database; NPS, National Park Service; NRCS, Natural Resources Conservation Service; PADUS, Protected Areas Database of the United States; Prop, proportion; T\&E, threatened and endangered; TL, total length of linear segment(s); TR, Terrestrial Resource Values Index; urbrecptdc, potential suitability of dominant soil type for constructing paths and trails; urbrecptwta, weighted average for potential suitability for constructing paths and trails; wb, waterbody; wet, wetland(s); WSRblm, Bureau of Land Management-designated Wild and Scenic River; WSRfs, U.S. Department of Agriculture Forest Service-designated Wild and Scenic River]

\begin{tabular}{|c|c|c|c|}
\hline Index & Calculation & Description & Explanation \\
\hline $\begin{array}{l}\text { Aquatic Resource Metric 3: Social } \\
\text { Designations }\end{array}$ & $\begin{array}{l}\text { Minimum of [Dist_WSRfs], } \\
\text { [Dist_WSRblm], [Dist_Bch] }\end{array}$ & $\begin{array}{l}\text { Selected the minimum distance value from three } \\
\text { designations: Wild and Scenic Rivers in National } \\
\text { Forests, Wild and Scenic Rivers on BLM lands, and } \\
\text { U.S. beach access points. }\end{array}$ & $\begin{array}{l}\text { Proximity to any of these features implies potential impact } \\
\text { on resource (water) quality as well as user/visitor } \\
\text { experiences. }\end{array}$ \\
\hline $\begin{array}{l}\text { Aquatic Resource Metric 4: Landscape } \\
\text { Water Quality }\end{array}$ & HCI rank based on [CumDistInd_FLH] & $\begin{array}{l}\text { Habitat condition index that scored water quality within } \\
\text { assessed watersheds based on cumulative disturbances } \\
\text { affecting stream reaches. Lower scores indicate better } \\
\text { condition. }\end{array}$ & $\begin{array}{l}\text { Current (2010) ranking of disturbance effects on water qual- } \\
\text { ity using HCI as applied to the National Hydrography } \\
\text { Dataset Plus, version } 1 \text { within CONUS. }\end{array}$ \\
\hline Cultural Resource Value Index & $\begin{array}{l}\text { Minimum distance from all cells to } \\
\text { Historic Sites, Districts, Structures, } \\
\text { Objects, and Trails }\end{array}$ & $\begin{array}{l}\text { All contributing Historic Features were combined, and a } \\
\text { single raster surface representing proximity (distance) } \\
\text { was used to represent potential influence. }\end{array}$ & $\begin{array}{l}\text { Motorized transportation can contribute noise and air pollu- } \\
\text { tion, which may affect visitor experiences and preserva- } \\
\text { tion of historic features and artifacts. Distances were } \\
\text { classified; larger value indicates smaller distance. }\end{array}$ \\
\hline $\begin{array}{l}\text { Cultural Resource Metric 1: Historic } \\
\text { Points }\end{array}$ & $\begin{array}{l}\text { Minimum distance from all cells to point } \\
\text { locations of Historic Sites, Structures, } \\
\text { and Objects }\end{array}$ & $\begin{array}{l}\text { Minimum Euclidian distance from all cells to Regis- } \\
\text { tered Historic Sites, Districts, Structures, and Objects } \\
\text { described by a point location. }\end{array}$ & $\begin{array}{l}\text { The smaller the distance, the closer a cell location is to an } \\
\text { historic site. Distance is given in meters. }\end{array}$ \\
\hline $\begin{array}{l}\text { Cultural Resource Metric 2: Historic } \\
\text { Polygons }\end{array}$ & $\begin{array}{l}\text { Minimum distance from all cells to poly- } \\
\text { gon locations of Historic Sites, Dis- } \\
\text { tricts, Structures, Objects, and Trails }\end{array}$ & $\begin{array}{l}\text { Minimum distance from all cells to Historic Sites, } \\
\text { Districts, Structures, Objects, or Trails described by a } \\
\text { polygon. }\end{array}$ & $\begin{array}{l}\text { The smaller the distance, the closer a cell location is to an } \\
\text { historic site. Distance is given in meters. }\end{array}$ \\
\hline Natural Hazards Metric 1: Geophysical & $\begin{array}{l}\text { Maximum hazard potential of reclassified } \\
\text { geophysical potential attributes: karsts, } \\
\text { landslides, earthquake ranking }\end{array}$ & $\begin{array}{l}\text { Coding for inputs with different number of classes } \\
\text { (levels) were adjusted so that maximum and minimum } \\
\text { levels received the same emphasis. }\end{array}$ & $\begin{array}{l}\text { Karsts (associated with sinkhole potential), landslides, and } \\
\text { earthquakes represent potential hazards for travelers, as } \\
\text { well as construction and maintenance considerations for } \\
\text { transportation departments. Models may not be locally } \\
\text { precise, but are useful for recognizing regional patterns } \\
\text { of potential hazard risk. }\end{array}$ \\
\hline Natural Hazards Metric 2: Flooding & $\begin{array}{l}\text { Maximum potential from reclassified } \\
\text { soil data: flooding frequency, ponding } \\
\text { frequency, and ponding percent; and } \\
\text { FEMA flood hazard data }\end{array}$ & $\begin{array}{l}\text { Soil (gSSURGO) and FEMA flooding history/hazard } \\
\text { data were combined by selecting the maximum flood- } \\
\text { ing potential estimated from either source. }\end{array}$ & $\begin{array}{l}\text { Flooding history and soil potential were combined to deter- } \\
\text { mine potential flooding hazard. }\end{array}$ \\
\hline $\begin{array}{l}\text { Natural Hazards Metric 3: } \\
\quad \text { Chemical-Environmental }\end{array}$ & $\begin{array}{l}\text { Distance from all cells to hazardous waste } \\
\text { storage and transportation facilities. } \\
\text { Watershed (HUC12) density of hazard- } \\
\text { ous waste sites }\end{array}$ & $\begin{array}{l}\text { Minimum distance to any documented hazardous materi- } \\
\text { als transportation facilities. Median distance within } \\
\text { each watershed was recorded to represent average } \\
\text { conditions within that area. }\end{array}$ & Proximity to hazardous waste transportation facilities \\
\hline
\end{tabular}

data: flooding frequency, ponding azard dat

ous waste sites conditions within that area. 
Table 1.6. Summary of equations and descriptions of aggregated indices and metrics compiled to support transportation planning. Source data and some intermediate metrics used to create the final metrics and indices are not specified here.-Continued

[acc, access point; ACEC, Areas of Critical Environmental Concern; AQ, Aquatic Resource Values Index; ArcGIS, geospatial data analysis software from Esri; Bch, beach; BLM, Bureau of Land Management; Cnt, count; ConsArea, conservation area; CONUS, continental United States; CrHab, critical habitat; CumDistInd, Cumulative Distance Index; dB, decibel; DEM, digital elevation model; Dist, distance to feature of interest; enddwdbcd, gSSURGO attribute for subsurface construction suitability; englrsded, gSSURGO attribute for construction suitability for roads; EPA, U.S. Environmental Protection Agency; Esri, Environmental Systems Research Institute; FEMA, Federal Emergency Management Agency; fl, flowlines; FLH, Office of Federal Lands Highway; forpehrtdc, potential for erosion of dominant soil type during road and trail construction; FWS, U.S. Fish \& Wildlife Service; GDAL, Geospatial Data Abstract Library; gSSURGO, Gridded Soil Survey Geographic Database; gw, groundwater; HCI, Habitat Condition Index; HUC12, hydrologic unit code for 12-digit subwatersheds; max, maximum; NASA, National Aeronautics and Space Administration; NCED, National Conservation Easement Database; NPS, National Park Service; NRCS, Natural Resources Conservation Service; PADUS, Protected Areas Database of the United States; Prop, proportion; T\&E, threatened and endangered; TL, total length of linear segment(s); TR, Terrestrial Resource Values Index; urbrecptdc, potential suitability of dominant soil type for constructing paths and trails; urbrecptwta, weighted average for potential suitability for constructing paths and trails; wb, waterbody; wet, wetland(s); WSRblm, Bureau of Land Management-designated Wild and Scenic River; WSRfs, U.S. Department of Agriculture Forest Service-designated Wild and Scenic River]

\begin{tabular}{|c|c|c|c|}
\hline Index & Calculation & Description & Explanation \\
\hline Natural Hazards Metric 4: Air Quality & $\begin{array}{l}\text { Compiled and reclassified average par- } \\
\text { ticulate matter pollution }\end{array}$ & $\begin{array}{l}\text { Compiled from NASA Earthdata, which is based on } \\
\text { satellite derived estimates of particulate pollution. }\end{array}$ & $\begin{array}{l}\text { Estimates of particulates less than } 2.5 \text { micrometers in } \\
\text { diameter }\end{array}$ \\
\hline $\begin{array}{l}\text { Natural Hazards Metric 5: Water } \\
\quad \text { Quality }\end{array}$ & $\begin{array}{l}\text { Calculated distance from all cells to EPA- } \\
\text { registered Section 303(d) waters }\end{array}$ & $\begin{array}{l}\text { Multiple types of Section } 303(\mathrm{~d}) \text { features (point, linear, } \\
\text { polygon) combined and minimum distance to any one } \\
\text { (or more) assigned }\end{array}$ & $\begin{array}{l}\text { Closer proximity, smaller distance, represents greater } \\
\text { potential for influence of transportation infrastructure or } \\
\text { effects on users and wildlife. }\end{array}$ \\
\hline $\begin{array}{l}\text { Land-Use Conditions Metric 1: } \\
\text { Development Impact }\end{array}$ & $\begin{array}{l}\text { Classification of the NPS sound pressure } \\
\text { level data model for anthropogenic } \\
\text { noise impact. Orignal data use dB, } \\
\text { which are based on a logarithmic scale. }\end{array}$ & $\begin{array}{l}\text { Impact data represents the difference between existing } \\
\text { and natural sound levels to estimate anthropogenic } \\
\text { noise. A } 3 \mathrm{~dB} \text { increase in background sound levels de- } \\
\text { creases your listening area by } 50 \text { percent. This dataset } \\
\text { is a reclassification of the impact product. }\end{array}$ & $\begin{array}{l}\text { A-weighted L50 sound pressure level data that represents } \\
\text { the sound pressure level exceeded half of the time. } \\
\text { A-weighting adjusts the models to reflect how humans } \\
\text { perceive sound. The models represent conditions pre- } \\
\text { dicted for a typical daytime hour during the summer with } \\
\text { calm weather conditions. Sounds are generally lower at } \\
\text { night and during the winter. }\end{array}$ \\
\hline $\begin{array}{l}\text { Land-Use Conditions Metric 2: } \\
\quad \text { Construction Suitability }\end{array}$ & $\begin{array}{l}\text { Median, reclassified value of: [end- } \\
\text { dwbdcd], [englrsdcd], [forpehrtdc], } \\
\text { [urbrecptdc], [urbrecptwta] }\end{array}$ & $\begin{array}{l}\text { NRCS soil classification for construction suitability } \\
\text { based on a weighted average of soil conditions or the } \\
\text { dominant soil conditions in the unit }\end{array}$ & $\begin{array}{l}\text { NRCS interpretation of soil suitability and effects on con- } \\
\text { struction and maintenance }\end{array}$ \\
\hline $\begin{array}{l}\text { Land-Use Conditions Metric 3: } \\
\text { Protected and Rare Habitats }\end{array}$ & $\begin{array}{l}\text { Total amount of protected and (or) rare } \\
\text { habitats summerized within watersheds } \\
\text { (HUC 12) }\end{array}$ & $\begin{array}{l}\text { Designated natural areas, conservation areas, and rare } \\
\text { and protected habitats/ecosystems by States and (or) } \\
\text { Federal agencies (from multiple sources) }\end{array}$ & Area of designated lands within the watershed. \\
\hline Terrain Metric: Aspect & $\begin{array}{l}\text { Calculated from DEM using ArcTools } \\
\text { (Esri, 2011a) }\end{array}$ & $\begin{array}{l}\text { CONUS aspect created from a hydrologically corrected, } \\
\text { 30-m DEM }\end{array}$ & Units are degrees between $0-360$. \\
\hline Terrain Metric: Elevation & $\begin{array}{l}\text { Calculated from DEM using ArcTools } \\
\text { (Esri, 2011a) }\end{array}$ & $\begin{array}{l}\text { CONUS elevation created from the hydrologically } \\
\text { corrected 30-m DEM }\end{array}$ & Units are meters above mean sea level. \\
\hline Terrain Metric: Slope & $\begin{array}{l}\text { Calculated from DEM using ArcTools } \\
\text { (Esri, 2011a) }\end{array}$ & $\begin{array}{l}\text { CONUS slope created from a hydrologically corrected, } \\
\text { 30-m DEM }\end{array}$ & Units are degrees between $0-90$. \\
\hline Terrain Metric: Ruggedness & $\begin{array}{l}\text { Calculated from DEM using Geospa- } \\
\text { tial Data Abstract Library software } \\
\text { (GDAL, 2014) }\end{array}$ & $\begin{array}{l}\text { CONUS terrain ruggedness created from the aspect of } \\
\text { the hydrologically corrected } 30-\mathrm{m} \mathrm{DEM}\end{array}$ & $\begin{array}{l}\text { Unitless and provides no limits on a maximum scale. The } \\
\text { larger the positive value, the more rugged the terrain. }\end{array}$ \\
\hline
\end{tabular}



Publishing support provided by the Science Publishing Network, Denver Publishing Service Center

For more information concerning the research in this report, contact the Center Director, USGS Fort Collins Science Center

2150 Centre Ave., Bldg. C

Fort Collins, CO 80526-8118

(970) 226-9398

Or visit the Fort Collins Science Center website at https://www.fort.usgs.gov/ 


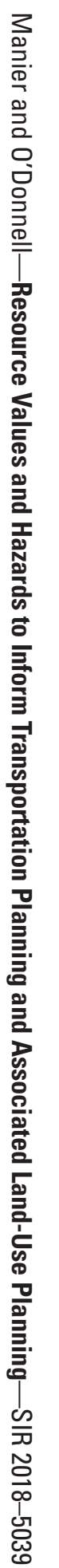

